Florida International University

FIU Digital Commons

FIU Electronic Theses and Dissertations

University Graduate School

$4-13-2020$

\title{
The Effects of Individual Differences on Employment Incentives
}

Andrew J. Laginess

Florida International University, alagi001@fiu.edu

Follow this and additional works at: https://digitalcommons.fiu.edu/etd

Part of the Industrial and Organizational Psychology Commons

\section{Recommended Citation}

Laginess, Andrew J., "The Effects of Individual Differences on Employment Incentives" (2020). FIU Electronic Theses and Dissertations. 4531.

https://digitalcommons.fiu.edu/etd/4531

This work is brought to you for free and open access by the University Graduate School at FIU Digital Commons. It has been accepted for inclusion in FIU Electronic Theses and Dissertations by an authorized administrator of FIU Digital Commons. For more information, please contact dcc@fiu.edu. 


\section{FLORIDA INTERNATIONAL UNIVERSITY}

Miami, Florida

THE EFFECTS OF INDIVIDUAL DIFFERENCES ON EMPLOYMENT INCENTIVE PREFERENCES AND EFFECTIVENESS

A dissertation submitted in partial fulfillment of

the requirements for the degree of

DOCTOR OF PHILOSOPHY

in

PSYCHOLOGY

by

Andrew J. Laginess 
To: Dean Michael R. Heithaus

College of Arts, Sciences, and Education

This dissertation, written by Andrew J. Laginess, and entitled The Effects of Individual Differences on Employment Incentive Preferences and Effectiveness, having been approved in respect to style and intellectual content, is referred to you for judgment.

We have read this dissertation and recommend that it be approved.

Valentina Bruk-Lee

$\begin{array}{r}\hline \text { Stefany Coxe } \\ \hline \text { Juan Sanchez } \\ \hline \text { Chockalingam Viswesvaran, Major Professor }\end{array}$

Date of Defense: April 13, 2020

The dissertation of Andrew J. Laginess is approved.

Dean Michael R. Heithaus

College of Arts, Sciences and Education

Andrés G. Gil

Vice President for Research and Economic Development and Dean of the University Graduate School

Florida International University, 2020 
C Copyright 2020 by Andrew J. Laginess

All rights reserved. 


\section{DEDICATION}

To my wife Elaine, who has loved and supported me every step of this long

journey. You are my inspiration, my best friend, the one whom my soul loves. 


\section{ACKNOWLEDGMENTS}

I am truly grateful for the guidance of my committee members. Many thanks to Dr. Valentina Bruk-Lee, on whom I can always count to help me improve the clarity and quality of my papers, and Dr. Juan Sanchez, whose research is always an inspiration to me. Special thanks to Dr. Stefany Coxe, who has taught me practically everything I know about statistics. Finally, I am extremely thankful for my mentor and committee chair, Dr. Vish, whose insight, encouragement, and patience brought me through the program successfully. 


\section{ABSTRACT OF THE DISSERTATION \\ THE EFFECTS OF INDIVIDUAL DIFFERENCES ON EMPLOYMENT INCENTIVE PREFERENCES AND EFFECTIVENESS}

by

Andrew J. Laginess

Florida International University, 2020

Miami, Florida

Professor Chockalingam Viswesvaran, Major Professor

This dissertation sought to examine the interaction between employment incentives and various individual differences. The main objectives were to create a taxonomy of incentives, explore how personal characteristics influence individuals' attraction to different types of incentives, and shed light on how individual differences affect preferences for incentive systems that are tied to performance versus those that are independent of performance. Four studies were conducted to achieve those objectives, utilizing expert ratings and data from over 800 undergraduate students. A preliminary categorization system with 14 types of incentives was developed, which served as a framework for the subsequent exploration of incentive-individual differences relationships in this paper. Additionally, a reliable measure of incentive administration preferences was developed and validated in a hypothetical work context. Ultimately, this dissertation paves the way for future research on work incentives by providing a coherent, logical organization of incentives and a means to assess individuals' inclination towards or against performance-based incentive administration. 


\section{TABLE OF CONTENTS}

\section{CHAPTER}

PAGE

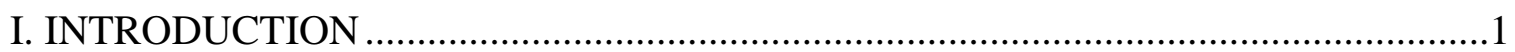

Study I. Generating a Comprehensive List of Incentives and Incentive Taxonomy ...........7

Study II. Individual Differences and Valence of Incentives ........................................10

Study III. Individual Differences in Incentive Administration Preferences ....................11

Study IV. PPBI Moderating the Incentive-Motivation Relationship ..............................14

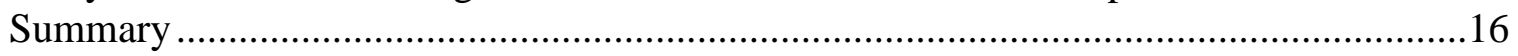

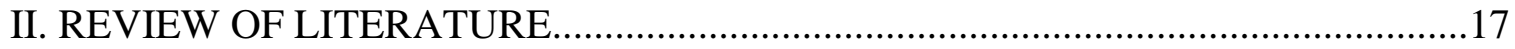

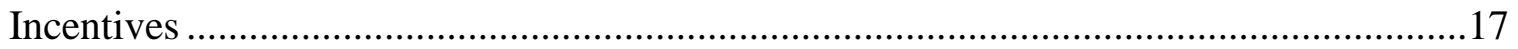

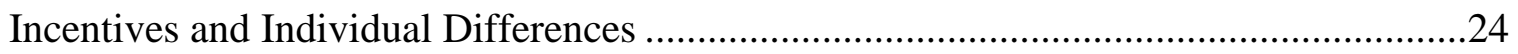

Preference for Performance-Based Incentives..........................................................28

PBI Alignment and Work Outcomes: Recruitment, Retention, and Performance .............32

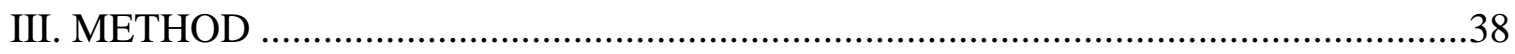

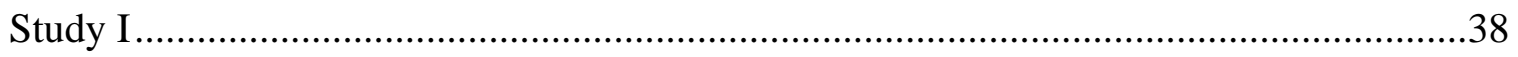

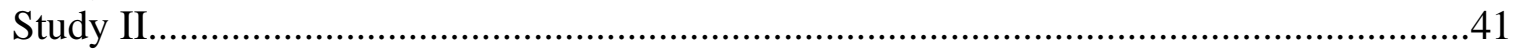

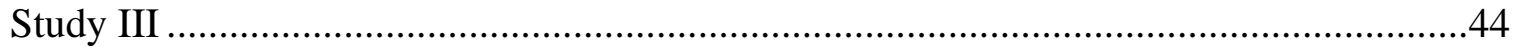

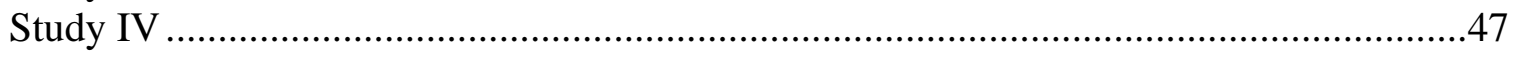

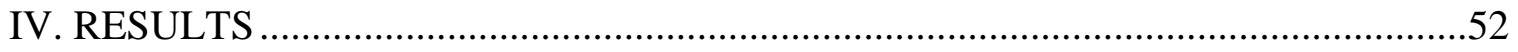

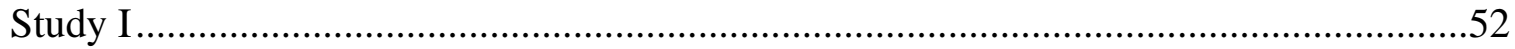

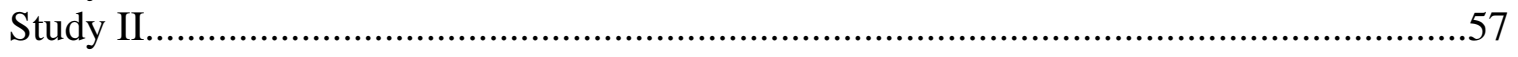

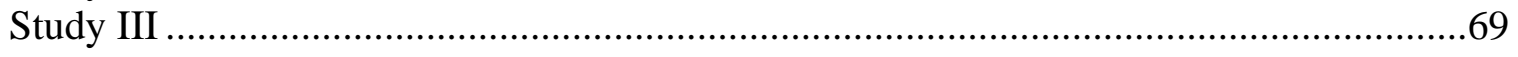

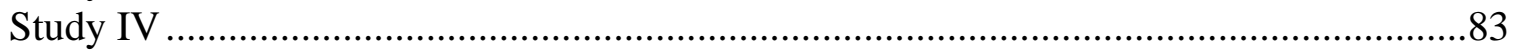

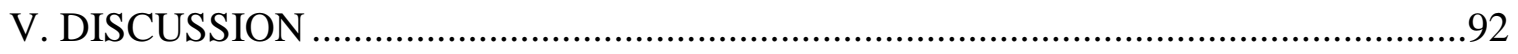

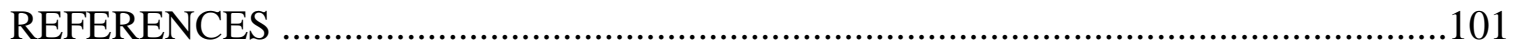

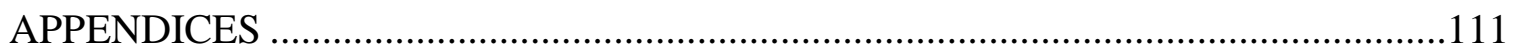

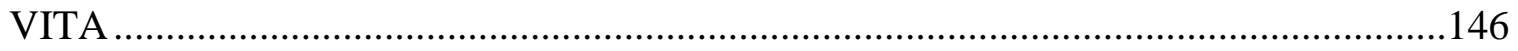




\section{LIST OF TABLES}

TABLE

PAGE

1. Hypothesized Interaction Effect of PBI Offered and PPBI on Organizational Attractiveness

2. Hypothesized Interaction Effect of PBI Offered and PPBI on Performance

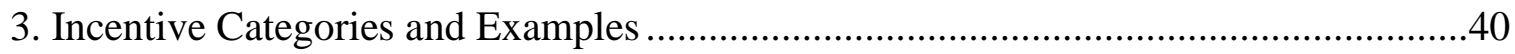

4. Study I - Summary of Subject Matter Expert Ratings ...........................................54

5. Study I - Alternative Categories for Select Incentives with Higher or Equal SVC ......56

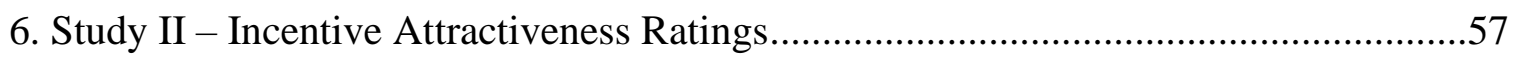

7. Study II - Incentive Category Attractiveness Ratings and Rankings .........................60

8. Study II - Correlations of Personality Factors/Facets with Incentive Categories .........64

9. Study II - Correlations Between Demographics and Incentive Categories ..................65

10. Study II - Incentive Attractiveness Comparison by Demographics (Binary) .............65

11. Study II - Incentive Attractiveness Comparison by Demographics (Multigroup) ......68

12. Study II - Summary of Demographics and Personality Regressions .......................69

13. Study III and Study IV - PPBIS Item and Scale Properties .................................74

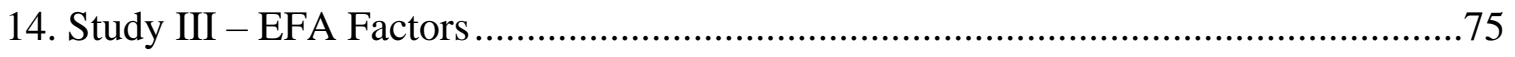

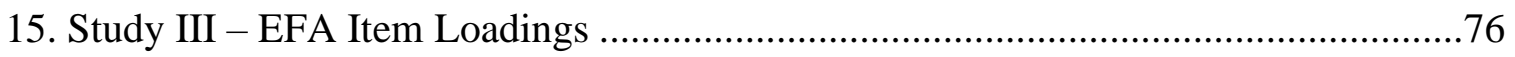

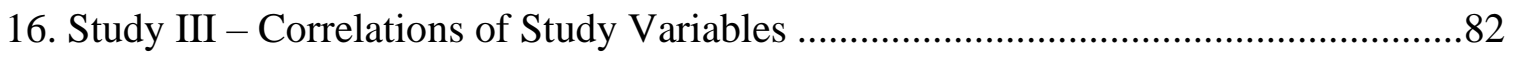

17. Study IV - Descriptive Statistics and Correlations of Study Variables (Whole

Sample)

18. Study IV - Correlations between Study Variables (Disaggregated by Study Condition) 
19A. Study IV - Hierarchical Regression of Organizational Attractiveness on PPBIS,

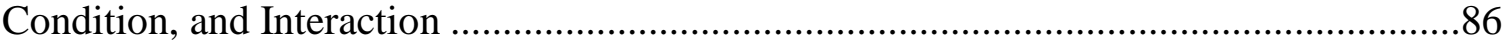

19B. Study IV - Hierarchical Regression of Performance on PPBIS, Condition, and

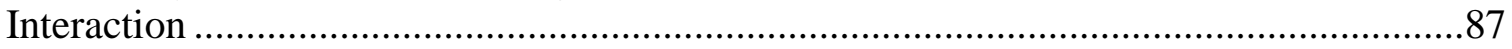

20. Study IV - Effect of PBI Offered by PPBI on OA and Task Performance ..................91 


\section{LIST OF FIGURES}

FIGURE PAGE

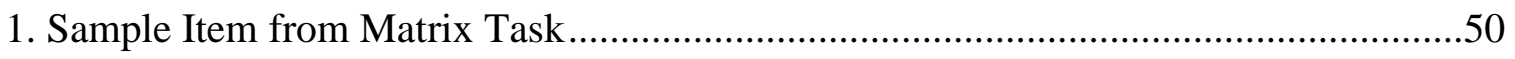

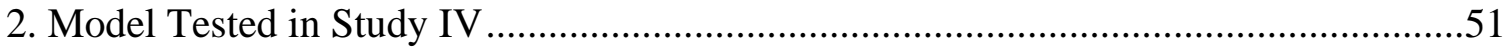

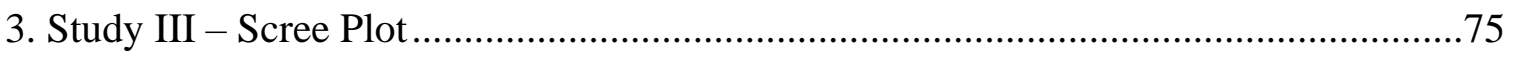

4. Study III - Unidimensional PPBI Model..........................................................77

5. Study III - Correlated API and UPI Factors Model ...........................................78

6. Study III - Superordinate PPBI Factor Model....................................................... 79

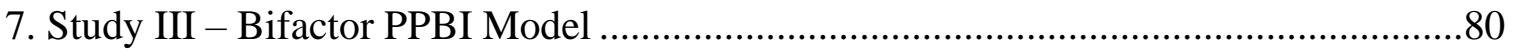

8. Study IV - Standardized Estimates for Base Model in Multigroup Path Analysis .......88

9. Study IV - Standardized Estimates for Constrained Model ....................................89 


\section{ABBREVIATIONS AND ACRONYMS}

BLS Bureau of Labor Statistics

FFM Five Factor Model

LOC Locus of Control

Nach Need for Achievement

NPBI Non-Performance-Based Incentive

OA Organizational Attractiveness

PBI Performance-Based Incentive

PPBI Preference for Performance-Based Incentives

PSA Proportion of Substantive Agreement

SHRM Society for Human Resource Management

SME Subject Matter Expert

SVC Substantive Validity Coefficient 


\section{CHAPTER I. INTRODUCTION}

Employment incentives come in many different forms, such as employee stock options, retirement plans, and health insurance. On average, benefits and incentives accounted for over 30\% of the costs for employee compensation in 2017 (Bureau of Labor Statistics, 2017). The incentives or benefits an employer offers are used for three main motivational purposes (Jex \& Britt, 2014): to help persuade prospective employees to accept employment at an organization (recruitment), to motivate employees to work harder and avoid counterproductive behavior (performance management), and to convince employees to remain at an organization (retention).

The terms benefits, incentives, and perquisites (or perks) are used frequently by employers and within the literature, but the distinction between them is often unclear and differs between sources. Benefits may be defined as any form of employee compensation outside of regular wages or salary (Bureau of Labor Statistics, 2016). Typical examples used in the field include health insurance and retirement plans. Incentives are not welldefined in the literature but can be more broadly described as motivational devices used to encourage an individual to perform a desired behavior (Incentive, 2017). Finally, perks are also not defined well in the literature, but may be described as special privileges given to employees on top of their salaries and benefits (e.g., gym membership).

Academics and business professionals alike tend to use these terms somewhat interchangeably at times. Given the definitions presented above (which are not often adhered to in the literature), it would appear that "incentive" encompasses all benefits and perks - essentially any and every tool or aspect of an organization that is used to motivate individuals. The terms "incentive" will be used hereafter to describe any commodity, 
activity, characteristic, or policy supplied, embodied, or enacted by organization that can be used to influence employees' or prospective employees' attraction to the organization (to begin or remain working) or motivation to perform.

Incentives are an effective means of drawing in top talent and convincing them to stay despite other offers they may receive (Gerhart \& Milkovich, 1992). As employers are becoming more aware of the impact a quality workforce has in creating a competitive edge, the demand for research on incentives has increased (Gupta \& Shaw, 2014). Unfortunately, few researchers have examined the effects of incentives on employee motivation, and the scope of incentives considered in such research (e.g., Bonner \& Sprinkle, 2002) is narrow, typically focusing on traditional, customary incentives. Indeed, most incentive research deals with basic compensation of employees (i.e., regular salary or hourly wages; Jenkins, Mitra, Gupta, \& Shaw, 1998; Shaw \& Gupta, 2015).

Compensation is indeed a vital part of the employer-employee relationship and an effective motivational tool (Gerhart \& Rynes, 2003; Jenkins et al., 1998; Lawler, 1990). Base wages play a substantial role in both recruitment and retention, determining the quality of recruits, new employees, and retained employees, as well as candidates' job acceptance (Balkin \& Groeneman, 1985; Saks, Wiesner, \& Summers, 1996; Shaw \& Gupta, 2007). Additionally, monetary compensation can be used to influence virtually any workplace behavior (e.g., safety behaviors; Mattson, Torbiörn, \& Hellgren, 2014), not simply performance.

Nonmonetary incentives can be equally as effective as monetary incentives in attracting and retaining talent (Casper \& Buffardi, 2004), though their financial worth is often underestimated by employees (Wilson, Northcraft, \& Neale, 1985). Nonetheless, 
many employees recognize that nonmonetary incentives represent a significant portion of their remuneration from their employer and may value some of these incentives even more than monetary incentives (De Vos \& Meganck, 2008; Lester \& Kickul, 2001; Milkovich, Newman, \& Gerhart, 2017).

In line with expectancy theory (Vroom, 1964), incentives of all types can be powerful motivators because they are a form of contingent reward. Recruits expect to receive the benefits promised by an organization if they accept the job offer, just as employees expect to receive the incentives that have been promised to them if they remain working at the organization or achieve the level of performance required for certain incentives. Expectancy theory contains three key elements: expectancy, instrumentality, and valence.

The first element, expectancy, refers to the strength of the link between effort and performance: an employee must believe that the effort he or she exerts will lead to attainment of the performance goal. Self-efficacy-in particular, task-specific selfefficacy - plays an important role in this step, as it reflects the underlying belief about the employee's capabilities to reach the goal. The difficulty of the goal also influences expectancy, such that employees are less likely to believe they can achieve their goal if it is too challenging. Finally, employees must feel as though they have control over the outcome or that their performance is a direct result of their action (or inaction) rather than other factors.

Instrumentality, the second element, may be described as the perceived likelihood of receiving a reward once the performance goal has been met. This factor may be examined from two perspectives: (1) the prescribed schedule of reinforcement and (2) the 
level of trust an employee has in his or her organization following through on the awarding the incentive. The first perspective relates to the employees' understanding of how the attainment of performance goals correlates to the incentive being granted, in terms of the ratio or interval between instances of meeting goals and administrations of the incentive. From the second perspective, the degree to which an employee can be confident their employer will in fact reward an incentive as promised is the issue.

Finally, the third element of expectancy theory involves the valence of the outcome. Valence represents the expected satisfaction with or value of the reward (or in this case, an incentive) to the individual. Thus, the valence aspect of the theory allows for differences in the usefulness of various incentives as motivational tools. Note that it is the perceived worth of the reward rather than the objective (e.g., monetary) worth that is important to employees, which allows for potential variation in the motivational value of different incentives across employees.

Several lines of research have in fact found such differences between certain groups in their preferences for particular types of incentives (e.g., Gough \& Hick, 2009; Nelson, 1999). As such, several researchers have claimed that incentive packages or pay schedules should be customized to fit each employee according to his or her needs (e.g., Furnham, 2003; Pappas \& Flaherty, 2006; Tetrick, Weathington, Da Silva, \& Hutcheson, 2010). Such an approach, it is argued, will increase the effectiveness of the incentive program in motivating employee or potential employee behavior.

Despite the vast body of research on incentives overall, very few studies have empirically examined how individual differences may influence preferences for different incentives. Among these studies, the predominant focus has been on the influence of 
demographics such as sex (Hong, Yang, Wang, Chiou, \& Huang, 1995), marital status (Tetrick et al., 2010), or generation (Hong et al., 1995) on incentive preferences, whereas very few have examined how psychological variables (e.g., personality) have influenced the effectiveness or attractiveness of incentives (Nienaber, Bussin, \& Henn, 2011). As a result of the paucity of such research, several questions remain on how individual differences influence the effectiveness of incentives.

First, what are the different types of incentives offered by organizations? Unfortunately, there is no comprehensive listing of various incentives used in organizational settings to serve as a foundation for categorizing incentives. Lists of limited scope have been created to facilitate surveys conducted by professional organizations (e.g., the Society of Human Resource Management [SHRM]) and governmental agencies (e.g., the United States Bureau of Labor Statistics [BLS]). None of these lists can be considered a "comprehensive" listing as might be supported on a rational basis. As such, a comprehensive list and categorization of incentives used in organizational settings was generated in this dissertation by invoking the lexical hypothesis, which has previously been used in trait personality theories in psychology (Costa \& McCrae, 1995) and theories of job performance construct domain specification (Viswesvaran, Ones, \& Schmidt, 1996; Viswesvaran, Schmidt, Ones, 2005).

Second, how do various individual differences relate to preferences for incentives? Although prior research has linked demographic variables to incentive preferences (Davis, Giles, \& Field, 1985), differential psychology clearly supports the claim that demographic groups (e.g., men or women) are not homogeneous (e.g., Costa, Terracciano, \& McCrae, 2001). Women and men may differ on average, but substantial 
variability occurs within each of these groups. The same can be said of different age generations (Twenge \& Campbell, 2008; Wong, Gardiner, Lang, \& Coulon, 2008), racial categories (Foldes, Duehr, \& Ones, 2008), or any other demographic grouping. Thus, the second objective of the current dissertation was to examine how individual differences in personality, in addition to demographics, relate to the valence of different incentives.

Third, do individuals differ in their preference for performance-based incentives, and if so, how do such preferences relate to other individual differences? To the extent that incentives are tied to performance, an individual's compensation has the potential to vary. Individuals will differ in their preferences for such risks; this preference represents an individual difference that may be specific to a particular incentive or may generalize across all incentives. In addition to its alignment with risk-taking preferences, a desire for performance-based incentives is likely to relate to other individual differences such as locus of control and self-efficacy. Thus, additional goals of the present dissertation were to (1) investigate the possibility that there are stable individual differences in preferences for incentive administration that are linked directly to performance and (2) explore how dispensation preference relates to other established individual differences variables.

Finally, does an individual's preference for performance-based incentives moderate the effectiveness of performance-based and non-performance-based incentives in increasing an individual's motivation? That is, will performance-based incentives being offered by an organization have a stronger effect on an individual's attraction to that organization or willingness to put forth more effort in their job when that individual has a high preference for performance-based incentives? Organizations may choose to tie employee compensation to some measure of their performance, or they may pay their 
employees without any regard to the performance of each. Therefore, it is worth investigating how the match (or mismatch) between the incentives an organization offers and the preferences of an employee influence the employee's motivation to work for a company. Ultimately, the behaviors that will be influenced by incentives relate to (1) their willingness to begin working for an organization, (2) the effort they put forth in their job, and (3) their willingness to remain working for an organization. More broadly, these behaviors can be labelled attraction, effort, and retention.

To address the four questions above, the current dissertation includes a series of four corresponding studies. The first study compiles and organizes a list of incentives that may be used by employers. The second study investigates if the valence of incentives in general vary across individuals. An additional objective of this study was to investigate how various individual differences may affect the attractiveness of incentives based on the specific type of incentive. The third study involves the development and construct validation of a scale that measures an individual's preference for performancebased incentives, thereby exploring the third question listed above. Given that organizations may choose whether the incentives they offer are tied to employees' performance, the final study examines the how one's preference for performance-based incentives interacts with whether an organization offers incentives that are tied to performance or not in relation to organizational outcomes.

\section{Study I: Generating a Comprehensive List of Incentives and Incentive Taxonomy}

An effective and thorough investigation of incentives in studies 2-4 may only be accomplished if a list of common incentives is first compiled and organized. A comprehensive list of incentives has yet to be enumerated in academic literature, but 
researchers have examined a wide variety of incentive types individually, such as signing bonuses (Choi, 2011), work-life balance programs (Lori \& Aspinwall, 2009; Miller, 1984), merit pay (Schaubroeck, Shaw, Duffy, \& Mitra, 2008), and tuition reimbursement programs (Pyle, 2011). These studies provide some basis for determining incentives that are common enough to be considered worthy of study. However, organizations use many other things to attract, motivate, and retain employees that are rarely or never examined empirically, such as employee-of-the-month programs or use of a company car.

As noted previously, different incentives are rarely studied in tandem, mainly because of the methodological and statistical challenges in doing so. If it is assumed that each incentive is unique, to examine the independent and interaction effects of two incentives experimentally requires four conditions: (1) no incentive offered, (2) only first incentive offered, (3) only second incentive offered, and (4) both incentives offered. The complexity grows exponentially each time an additional incentive is desired to be investigated with the initial ones: examining three incentives requires 8 conditions, examining four incentives requires 16 conditions, examining five incentives requires 32 conditions, and so on. There are dozens of well known, widely used incentives, and studying them together empirically would require prohibitively large sample sizes for most researchers.

A simple way to solve this issue is by grouping incentives that are qualitatively similar into incentive types, essentially reducing the total number of unique categories. Unfortunately, a taxonomy of incentives that is both comprehensive and recognizes meaningful differences in incentives has yet to be produced. Some categorizations contain a few basic categories into which all incentives can be placed relatively easily 
and logically (e.g., Jex \& Britt, 2014), but the categories are too broad, with incentives that are quite different being lumped together. Other taxonomies differentiate several different types of incentives but are more limited in their inclusiveness of incentives.

Given the shortcomings of the existing incentive taxonomies, a necessary initial step in making comparisons of different incentives is to organize them into simple, logical, and comprehensive clusters. The resulting framework strives to be straightforward and thorough, such that any given incentive should clearly and easily be able to be sorted into one of the identified categories. Additionally, the members of each category should be similar enough to each other that their motivational effects do not vary substantially for people with similar characteristics. For example, highly conscientious individuals (or women or parents of young children) should find any two incentives in the same cluster to be equally attractive/motivating.

Parallels for the challenge to develop a comprehensive yet fine-grained list exist in other research areas, such as personality (Goldberg, 1992) and job performance (Viswesvaran, Schmidt, \& Ones, 2005). The lexical hypothesis has been used historically to facilitate the development of an empirically-based taxonomy of personality (Allport \& Odbert, 1936). A lexical approach assumes that if an important distinction between individuals exists, a word will be created to describe such an individual difference. Theoretically, all adjectives in the dictionary can then be factor analyzed to produce an exhaustive analysis of individual differences.

Similarly, for a comprehensive specification of the construct domain of job performance, Viswesvaran et al. $(1996,2005)$ invoked the lexical hypothesis that if there is a meaningful measure of job performance in which employees vary, that measure 
would have been studied in the management literature. Viswesvaran and colleagues (2005) reasoned that by compiling a list of all measures of job performance used in the published management literature, a comprehensive specification of the job performance construct can be obtained.

Correspondingly, the current research will assume that if individuals can be motivated by something, organizations will incorporate it as a means of influencing its members or potential members (when legally, socially, and morally acceptable). Such incentives would then be included in surveys, especially national surveys conducted by professional associations and governmental agencies. Thus, a list of incentives as thorough as possible can be generated by compiling incentives listed in surveys, textbooks, journal articles, and other media.

Once an incentive list is generated, subject matter experts (SMEs) can be used to group them into rational categories (with similar incentives in the same category). Subject matter experts were directed to sort incentives into groups based on their qualitative similarity. Agreement between SMEs served as the basis for constructing the rationally- and empirically-based comprehensive incentive taxonomy.

\section{Study II: Individual Differences and Valence of Incentives}

Once an incentive taxonomy was generated, the next goal in the current investigation was to determine how various individual characteristics influence the effectiveness of different incentive types in motivating employees or prospective employees. Any significant relationships observed would provide strong empirical support for the notion that incentives have differential effects on various groups of individuals, bolstering the advice of many practitioners (e.g., Benefitfocus, 2016; Human 
Resources Inc., n.d.) for organizations to provide personalized benefits packages to best attract, motivate, and retain employees. Moreover, these individual difference-incentive relationships can be used as a preliminary recommendation of which incentives should be offered to individuals based on their psychological or demographic characteristics.

As noted previously, most of the research on incentives has focused on demographic rather than psychological variables. Of the research that has examined the effects of demographics on incentive attractiveness, the relationships investigated are generally rather intuitive (e.g., parents are more attracted than non-parents to incentives that facilitate being a parent, such as an on-site daycare or flextime). Similarly, some personality-incentive relationships can be hypothesized on the basis of the motivations and desires underlying the personality traits as they have been defined. For example, highly extraverted individuals— by definition — enjoy socializing; thus, incentives such as regular office parties or corporate retreats will be desirable to these individuals. I review this literature in more detail in Chapter II.

\section{Study III: Individual Differences in Incentive Administration Preferences}

Despite the general lack of consistency across researchers in clustering incentive types, a clear and important distinction that can be made between different types of incentives is the conditions under which they are awarded (Campbell, 1984; London \& Oldham, 1976). Whereas many incentives are granted simply by working for an organization (non-performance-based incentives, or NPBIs), some incentives are linked with individual performance (performance-based incentives, or PBIs). A considerable amount of research has examined PBIs (e.g., pay-for-performance schemes), which offer increases in (typically monetary) rewards that depend on the quality or quantity of an 
individual's work (Campbell, 1984). In theory, any incentive could be linked to an employee's performance in some way.

The key purpose of these types of incentive schemes is to increase performance, typically by introducing goals and incentivizing employees to meet them. Performancebased incentives are introduced as a desirable outcome with guaranteed attainment if an individual puts forth the necessary effort to reach the desired performance level. Essentially, PBIs maximize the second element of expectancy theory (instrumentality) and capitalize on the third element (valence). The first element of expectancy theory, the expectation that the desired performance level can be achieved if effort is increased, represents an important caveat: the performance goal must be realistic and related to the amount of effort an employee puts forth.

Goal-setting theory (Locke, 1968; Locke \& Latham, 2002, 2006) provides a set of principles that can be followed in order to build effective goals: (1) clarity, (2) challenge, (3) commitment, (4) feedback, and (5) task complexity. Incorporating each of these elements provides a strong basis for developing goals that are highly motivating to employees. Locke and Latham (2006) also describe the mechanisms by which goals can influence behavior. Of interest, one of these mechanisms is increased effort, which is related to the first element of expectancy theory - the expectation that increased effort will lead to meeting performance goals.

As described earlier, incentive types may vary in their valence (i.e., attractiveness) depending on the individual. Thus, it is expected that individuals with certain characteristics will be drawn to PBIs. In particular, individual differences in selfefficacy (Bandura, 1982), locus of control (Rotter, 1966), risk-taking, and motivation to 
achieve can be theoretically linked to a preference for performance-based incentives (PPBI). Self-efficacy relates to an individual's confidence in their capabilities (Bandura, 1982), and locus of control describes individuals' beliefs that their outcomes are mainly influenced by their own action versus external forces (Rotter, 1966). Both self-efficacy and locus of control can be either general or task-specific (Bandura, 1997; Rotter, 1975), and it is likely that the level of specificity of the performance goal will determine whether the general or task-specific forms of these constructs offer better prediction (Hogan \& Holland, 2003).

Individuals high in self-efficacy will be likely to be high in PPBI because of selfefficacy on expectancy (i.e., an individual's understanding that an increase in effort will lead to the achievement of a goal). Thus, individuals who believe they are likely to have high performance should prefer PBIs. Locus of control (LOC) plays a similar role, whereby those high in LOC will feel that they have control over obtaining the outcome (i.e., the incentive) and as a result be more attracted to PBIs.

Because PBIs are contingent rewards and not guaranteed, risk-taking is also an important factor in determining PPBI. Individuals who are averse to risks are less likely to find PBIs desirable, as there is a chance that they may not be obtained. Performancebased incentives are inherently achievement-oriented in that they are only awarded when some standard or desired performance level has been met. As such, motivation to achieve is theoretically linked with PPBI.

Another part of the research agenda for the current dissertation is to establish a measure of PPBI and investigate the relationships proposed above. First, it is necessary to test if there is a preference for PBI that generalizes across all incentives to determine if 
a psychological PPBI construct exists. If so, a measure created for that construct should show individual differences across respondents. These individual differences should be systematically related to other established psychological constructs to validate the nomological net of this new construct.

\section{Study IV: PPBI Moderating the Incentive-Motivation Relationship}

Once the measure of PPBI is validated in Study III, organizations could use this PPBI measure to help structure its incentive programs in two ways. First, if each employee receives the same benefits, the organization could examine which types of incentives, on average, employees would prefer linked to their performance in some way and which they would prefer to be given unconditionally. Second, if the organization is able to offer incentive packages tailored to the individual, this scale could help them determine to how much each employee would like to have their organizational rewards linked with their performance. Either of these approaches can help organizations optimize the utility of their incentives and maximize the motivation of their employees.

In line with these two approaches, the final study examined the actual impact of matching an individual's incentive preferences with the organization's incentive administration. Ultimately, incentives are designed to influence behaviors related to job performance, retention, and attraction, among others (Milkovich et al., 2017).

Performance is a unique criterion in the sense that it may be influenced by motivating an employee to increase their effort, whereas attraction and retention are influenced by appealing to more affective factors (e.g., liking a company) or individual needs (e.g., requiring a certain level of salary or benefits to pay for one's expenses). In other words, performance incentives follow the motivating effects described in expectancy theory, 
whereas incentives designed to increase organizational attractiveness and retention can be best understood in terms of how well the needs of an individual are met by an organization, an aspect of the fit between a person and an organization.

Person-organization fit (P-O fit; Caplan, 1987) describes the importance of the match between the resources provided by and required by the individual and the organization (Kristof, 1996). The fourth study in the present dissertation investigates a specific element of P-O fit: the fit between an individual's PPBI and an organization's reward systems. Although P-O fit is mainly used to describe the processes of attraction, selection, and retention, it is also likely to affect performance through more general motivating (or demotivating) effects of an employee.

In essence, the fourth study examines how PPBI moderates the relationship between organizational incentive systems and individual motivations (e.g., organizational attractiveness, retention, job performance). The fourth study also cross-validates the nomological net for PPBI established in Study III by linking PPBI with personality variables again.

This line of research has a potential for a large impact on organizational policy, especially for building incentives schemes to attract top talent. It can also help organizations create customized incentive plans for employees or prospective employees in order to maximize offer acceptance, performance, and retention. Finally, these studies can also shed light on the individual factors that may enhance or undermine the effectiveness of incentives that are made contingent on performance. 


\section{Summary}

Incentives serve an important function in several aspects of employment, including the recruitment and retention of talented individuals and the effective motivation of the workforce. Although it is commonly held that there are systematic individual differences in preferences for incentives, the research investigating this notion is relatively scant and lacking in structure. In order to enable more efficient research of incentives and address the gaps in literature, the following research was proposed: (1) organize incentives into a framework that is comprehensive and refined enough to allow for the recognition of meaningful differences in incentive types, (2) examine how the attractiveness of these incentive types varies as a function of individual differences, (3) develop and validate a scale that assesses preferences for performance-based incentives (PPBI), and (4) test a model that investigates the linkages between personality, PPBI, and motivation. 


\section{CHAPTER II. REVIEW OF LITERATURE}

The overarching purpose of the series of studies in this dissertation is to explore the linkages between incentives and various individual differences. A review of the relevant literature will identify the issues faced currently in this area of study and provide a rationale for the set of studies proposed in this dissertation. The literature review will follow the major content investigated in each of the four studies, beginning with lists of incentives and incentive taxonomies, transitioning into individual differences in incentive preferences, and finally focusing on personality relationships with performance-based incentives.

\section{Incentives}

Some of the main human resource issues faced by organizations revolve around the effective motivation of individuals. Whether the objective is to convince individuals to seek employment with an organization, put forth more effort in their jobs, or remain at an organization, these motivational challenges are addressed through incentive and reward systems (Milkovich et al., 1999). However, there is often a disconnect between what incentives employees desire and what employers think their employees desire (Kowalewski \& Phillips, 2012).

Because of their ubiquity, incentives and their effects should be widely researched to ensure optimal use. However, they have received little attention by researchers and practitioners compared with their importance (Gupta \& Shaw, 2014). The vast majority of the research in this area has proceeded piece by piece, with each study typically examining the effects of only one incentive at a time and only very rarely more than a few incentives within a single study. 
This approach has helped organizations determine which incentives are effective (as well as when and how they are effective). However, little is known about how incentives compare with each another and interact within an incentive system. The main barrier in conducting such investigations is the sheer number of incentives to be examined. There are dozens of unique incentives investigated in the literature, though many of them often have a conceptual similarity with others. However, without a widely accepted classification system for incentives, progress in this area will continue be impeded by the fact that each incentive must then be examined individually.

Personality researchers have drawn upon the lexical hypothesis to tackle this classification issue. The lexical hypothesis assumes that if a meaningful characteristic on which individuals differ exists, a descriptive word (i.e., an adjective) to describe such a characteristic will be created within the language (Allport \& Odbert, 1936). Accordingly, factor analyzing an exhaustive list of adjectives (i.e., words that describe a characteristic) allows for the empirical organization of the entire construct domain of personality. Several of the major personality models currently in use were developed in this fashion. For example, one of the most widely accepted of these empirically-derived models, the Five Factor Model (FFM) or Big Five (Digman, 1990), will in fact be used in this dissertation for examining how personality interacts with organizational incentives.

The method described above has also been successfully applied to the domain of job performance to explore and organize its dimensionality. Viswesvaran and colleagues (2005) organized a list of job performance dimensions that had been used in the literature (Viswesvaran et al., 1996) into a coherent job dimension framework by placing 
conceptually similar dimensions into distinct categories. This process produced a set of job performance factors that facilitated subsequent analyses.

Forming a taxonomy of incentives. The lexical hypothesis approach can be used to create a taxonomy for any given content domain, provided a comprehensive list of the subject matter may be obtained and factor analyzed. In the case of incentives, this list would be compiled from various sources, spanning academic (e.g., journal articles) and practitioner (e.g., governmental and professional) bodies of literature. Despite the absence of such a list, several independent groups have developed categories for incentives. None of these categorizations encompass the entire scope of incentives as defined above, thereby falling short of the key element in the taxonomy development process: a comprehensive list of the content domain. However, these categories and the incentive lists upon which they are based aid in the development of the taxonomy created in this dissertation, and thus warrant a brief review here.

The earliest documented categorization of incentives was attempted by Bendig and Stillman (1958). Participants in their study ranked incentives in order of their attractiveness. Factor analysis was performed on the ratings, extracting three factors: (1) need achievement vs. fear of failure, (2) interest in the job itself vs. the job as an opportunity for acquiring status, and (3) job autonomy vs. supervisor dependent. Interestingly, these factor labels reflect the underlying psychological needs of the raters more than the actual similarity of the item content. This was appropriate, given that the ratings were not of content similarity, but of preference. However, since the focus was on the individuals rather than the incentives themselves, this classification reveals less about the nature of the incentives than it does about which employment needs tend to 
covary. Moreover, there were only eight incentives included in the factor analysis, though these included several not often considered in similar research (e.g., "friendly fellow workers" and "freedom to assume responsibility").

Furnham (2003) also attempted an empirical grouping of incentives, but similar to the work of Bendig and Stillman (1958), categorization was based on ratings of each incentive's attractiveness rather than their qualitative or theoretical similarity. Furnham (2003) labelled the four resulting factors (1) time/benefits, (2) status, (3) money, and (4) long-term offers. Realistically, the factors that were produced are largely uninterpretable, since incentives are grouped not by their qualitative similarity, but by the relative equality of their attractiveness across the sample. For example, the first factor (time/benefits) had high loadings from incentives as varied as time off, healthcare, a subsidized car, store vouchers, free travel, company stock, a premium parking space, increased pension benefits, early retirement, and a lifetime supply of a product. Clearly, there is no real common theme to the incentives that load on this factor; they just had a similar level of desirability compared to the other incentives. Note that the incentives loading similarly on the factors identified by Bendig and Stillman (1958) were equally as varied as those found by Furnham (2003).

The main distinction made between different incentive types described in contemporary literature is tangible versus intangible (Jex \& Britt, 2014). Tangible rewards are those that result in financial or material gain (e.g., salary or monetary bonuses), whereas intangible rewards are those that do not provide financial or material gain (e.g., praise, recognition, or increased autonomy). Jex and Britt (2014) use this framework when referring to incentives that organizations use to influence a variety of 
employee attitudes and behaviors, including attraction to the organization, productive and counterproductive work behaviors, and turnover intentions. The advantage of this classification is in its simplicity: once understood, it is often clear whether a given incentive is tangible or intangible. However, these categories are problematic in several ways.

First, the terms tangible and intangible may be misleading as to the type of incentive being referred. Typically, these terms are used to distinguish between the physical and the non-physical — things that can be seen, touched, or sensed directly versus things that cannot and are purely psychological. However, some intangible incentives are physical in nature (e.g., the size of one's office as a symbol of status within a company), whereas some tangible rewards have much more psychological value than monetary value (e.g., paid time off may be considered a tangible benefit since it results in financial gain, but it is the intangible, psychological value of being able to rest that is the important aspect of this incentive).

Second, many incentives in practice are a mixture of tangible and intangible. A yearly bonus may provide an employee with both a tangible reward (i.e., the money) and intangible reward since the bonus may be seen by an employee as a form of recognition for his or her hard work. Similarly, an incentive of growth opportunities (e.g., succession planning) involves both tangible and intangible benefits: each promotion carries the potential for increases in salary (tangible) but also changes in title, office location, parking spot, or special privileges (intangible).

Finally, it is far too simplistic given the vast array of possible employment incentives. There may be very clear qualitative and quantitative differences between any 
two tangible or intangible incentives. For example, both paid time off and merit bonuses are considered tangible incentives, but they may differ in many ways, such as how they are earned (e.g., accrued over a given period of time versus dependent on performance) and their importance or value to employees or prospective employees (e.g., use of a company car versus commuter checks). Because of these differences, incentives within the same category may have significantly different effects on recruitment, performance, or retention outcomes. Thus, only distinguishing between tangible and intangible incentives creates categories that are too general and whose members may differ substantially, vastly reducing the usefulness of these classifications in research or application.

Several non-academic bodies such as the Bureau of Labor Statistics (BLS), the Society for Human Resource Management (SHRM), and employment websites have organized incentives into distinct categories. In its yearly reports, the BLS (e.g., BLS, 2017) classifies incentives into "paid leave," "supplemental pay," "insurance," "retirement and savings," and "legally required." Elsewhere, the BLS groups incentives into the following more comprehensive and interpretable categories: (1) retirement, (2) healthcare, (3) life insurance, (4) paid leave, (5) disability, and (6) other benefits. Although this taxonomy is in some way more refined than the two categories offered by Jex and Britt (2014), it omits several important and widely recognized incentives, such as all types of recognition and professional growth incentives (these are not mentioned in the benefits described as "other benefits").

In their examination of incentives, the professional association SHRM groups 13 incentive types into four larger categories: (1) health, leave, and retirement benefits, (2) 
work-life and convenience benefits, (3) financial and career benefits, and (4) travel and relocation benefits (SHRM, 2017). Though it has fewer categories than the BLS grouping, each of these groups is broad and encompasses several different types of incentives, thus SHRM's taxonomy actually includes more incentives. However, it still neglects most intangible benefits mentioned by Jex and Britt (2014).

A slightly more comprehensive framework for incentives is used at the job searching/recruitment website Glassdoor (www.glassdoor.com), which provides information on incentives offered by various organizations. The website organizes the incentives (55 total) into six categories: (1) insurance, health, and wellness, (2) financial and retirement, (3) family and parenting, (4) vacation and time off, (5) perks and discounts, and (6) professional support. This list offers slightly improved inclusiveness over the BLS and SHRM taxonomies, but again fails to recognize many non-traditional incentives, such as aspects of the organizational culture or environment that may influence employee or potential employee motivation.

The shortcomings of the previous incentive taxonomies will be addressed in this dissertation by invoking the lexical hypothesis. A comprehensive list of incentives was compiled from the various sources outlined above. In the first study of this dissertation, subject matter experts (SMEs) were used to refine and provide empirical support for these categories. The final taxonomy produced in Study I was used in the remaining studies in this dissertation and can be adopted by others to further the progress in this body of research. 


\section{Incentives and Individual Differences}

Individual differences in incentive preferences have frequently been found within the literature (Milkovich et al., 1999). The vast majority of these investigations involve demographic rather than psychological variables. Unfortunately, most studies investigate an isolated few individual differences in relation to a restricted set of incentives. Moreover, the few studies that look at multiple individual differences and multiple incentives are plagued by methodological issues. Regardless, this line of research has uncovered several consistent differences in preferences for incentives across certain variables, which are listed in the subsequent sections.

Age. Much of the discussion in how age groups relate to incentive preferences is centered around differences across generations (e.g., Baby Boomers versus Generation X versus Millennials). While general differences between generational groups may or may not exist (Benson \& Brown, 2011), more proximal variables such as age and psychological constructs are likely to offer better prediction of incentive preferences given the heterogeneity of generational groups (Dencker, Joshi, \& Martocchio, 2008). Accordingly, although there are widespread recommendations for businesses to tailor their incentive packages to an individual's generation (e.g., Biro, 2014; Gurchiek, 2016; Hewlett, 2009), empirical evidence to support such claims is relatively weak (Moore \& Bussin, 2012; Schweyer, 2015). Researchers that have found cross-generational variation in incentive preferences often attribute these differences to the fact that members of different generations tend to be at different stages in their lives (e.g., entering retirement versus building a career). The main finding with respect to age that can been seen consistently throughout the literature is a positive relationship between age and 
importance placed on pension or retirement benefits (Gough \& Hick, 2009; Mahoney, 1964; Nealey, 1963). This relationship is unsurprising given that retirement benefits become more salient as employees draw nearer to the point where they will need to use these savings. There is also some evidence that incentive programs in general have a stronger effect on the job performance of younger employees compared to older employees (Hong et al., 1995).

Gender. Several studies have found that men and women differ in their incentive preferences. Men appear to place more value on incentives related to money and career progression, whereas women tend to prefer benefits related to their lives outside of work. For example, men value job security, promotion opportunities/pay raises, further education/training, and typical employment benefits (e.g., sick pay, vacations, health insurance) more than women do, whereas women value sick leave, maternity leave, flextime, and childcare benefits (Hong et al., 1995; Jurgensen, 1947; Nealey, 1963; Thompson \& Aspinwall, 2009) more than men do. Women also show more interest in their work environment, such as having a friendly supervisor or coworkers and their working conditions (Jurgensen, 1947).

Marital status and number of dependents. Incentive preferences have also been shown to vary based on marital status and number of dependents. Compared to married employees, single employees place more importance on education and career development and are less interested in childcare and retirement benefits (Hong et al., 1995; Nealey \& Goodale, 1967). Research has also indicated that employees who have dependents—regardless of how many—may tend to prefer increased health insurance 
coverage (e.g., hospital insurance) and may be less interested in retirement benefits (Nealey, 1963).

Education. There is some evidence that education level has an impact on preferences for certain types of incentives. Several studies have shown a negative relationship between education and material or monetary benefits, such that less educated employees tend to prefer incentives like store vouchers, company stock, or higher retirement benefits (Furnham, 2003; Hong et al., 1995). Conversely, more educated employees tend to prefer incentives related to psychological growth and well-being, such as social programs and self-actualization experiences (Hong et al., 1995).

Income and job level. Studies that have investigated the relationship between income or job level and incentive preferences have found mixed results. For example, Nealey (1963) found that employees who have lower incomes place more emphasis on pay raises, whereas Furnham (2003) found virtually no relationship between income and pay incentive preferences. In fact, lower-income employees tend to prefer incentives related to how their job is done (e.g., flextime) and status indicators (e.g., job title or office size) rather than monetary benefits (Furnham, 2003). Hong et al. (1995) found a similar pattern with job level, where lower-level employees are concerned with flextime and job security while higher-level employees and executives are largely concerned with monetary benefits (e.g., base pay or retirement plan). Mid-level employees appear to be interested mostly in incentives related to individual development (e.g., training or paid tuition) and growth (Hong et al., 1995).

It is important to note that various demographics interact with one another in influencing incentive preferences. For example, men ages 50 and over regard pension 
and retirement benefits as most important by a wide margin, whereas women 50 and older regard a pay raise as the most important incentive, with pension and sick leave benefits ranked just behind in importance (Nealey, 1963). Additionally, certain demographics (e.g., employee age) have been linked to a more general desire for incentives, such that benefits—regardless of type — have a stronger impact on the performance of younger employees compared to older employees.

Personality. A handful of researchers have also examined how personality variables influence the attractiveness of incentives. The model of personality most commonly invoked in this line of research is the FFM, which includes the traits conscientiousness, extraversion, agreeableness, neuroticism, and openness to experience (Goldberg, 1992). Individuals who are high in extraversion or low in conscientiousness may find incentives more attractive in general (Depue \& Collins, 1999; Fong \& Tosi, 2007; Komarraju, Karau, \& Schmeck, 2009). Other research has demonstrated that specific incentives may be more or less attractive depending on an individual's personality (Furnham, 2003; Hsieh, 2011; Nagle, Riener, \& Wolf, 2016; Nienaber et al., 2011). Additionally, Furnham (2003) found evidence that personality variables predict incrementally over demographic variables.

Each of the Big Five traits can be broken down into subfactors often called facets, though the exact number and organization of facets outlined below the Big Five varies between measures. Although the research investigating personality-incentive relationships has not examined them the facet level of personality, the current study seeks to explore this level of granularity. It is possible that narrower personality traits will produce stronger relationships with incentives (Paunonen \& Ashton, 2001). 
It is expected that the current research will find similar relationships between various individual differences and incentive preferences. However, due to the large number of incentives and individual differences being examined in Study II, hypotheses will not be generated for incentive-individual differences relationships in this study. Instead, this investigation will simply explore these incentive-individual differences relationships by examining the effects of these personal characteristics on the average attractiveness of incentives within a category. Additionally, the strongest relationships with specific incentives are reported to demonstrate which of these are most and least attractive to various types of individuals.

\section{Preference for Performance-Based Incentives}

The link between employee motivation and performance is well-established in the literature (Antoni, Baeten, Perkins, Shaw, \& Vartiainens, 2017). Incentives are offered with the intent of motivating an individual, thereby improving their performance (Bonner \& Sprinkle, 2002). As noted above, employers often assume that incentives will be effective in motivating all individuals equally, but researchers have found that the actual effectiveness of a given incentive depends on several individual differences.

One important distinction between incentives that has seen a great deal of research is whether its administration is linked with individual performance or not. The latter, non-performance-based incentives (NPBIs), may be more useful as recruitment or retention tools, whereas the former, performance-based incentive (PBIs), would be designed specifically to improve performance. It is important to note that almost any incentive could be administered either regardless of performance (NPBI) or tied with performance to some degree (PBI). 
Most traditional incentives are not performance-based: they are granted to individuals immediately or regularly for behaviors that are not linked with their level of performance. NPBIs tend to be better suited for influencing specific behaviors that are more decision-based, such as decisions to begin working at a company or remain there in spite of potentially better opportunities elsewhere. All NPBIs are awarded binarily (i.e., they are either given or not given); for example, health insurance benefits are typically used as NPBIs in that given simply for working for a company and do not vary with performance (i.e., better or worse health benefits are not awarded to an employee based on his or her job performance).

By contrast, PBIs are designed such that their increase is beneficial and desirable to employees, thereby motivating them to put forth more effort in order to obtain them. These incentives are typically monetary, though other incentives may also be contingent on performance, such as recognition/praise or travel incentives. Given that money is one of the most powerful motivators that an organization can supply and that its effects do not substantially weaken as it is increased (Milkovich et al., 1999), it is only logical that it be used commonly as a PBI. Monetary incentives are indeed effective, but researchers have demonstrated that their power is limited, especially when they are not aligned with individual motivations (Fehr \& Falk, 2002; Gneezy, Meier, \& Rey-Biel, 2011). However, ample evidence exists to refute the notion that incentives can undermine intrinsic motivation (Hamner \& Foster, 1975).

Research has shown that the effectiveness and attractiveness of PBIs can vary depending on certain individual characteristics. Although the Big Five traits are often useful in predicting a variety of criteria, there are several other personality traits 
commonly used in the literature that are believed to be either not clearly delineated within the Big Five framework (or outside of it altogether) that are nonetheless useful in predicting certain behavior or criteria (Paunonen \& Jackson, 2000). As such, the current research investigates risk-taking, self-efficacy, locus of control, and motivation to achieve in addition to the Big Five factors and facets.

The fit of these other traits within the FFM has been studied, with some having moderate to strong relationships with several of the Big Five and some having only weak relationships with one or some of the Big Five. Financial risk-taking has small, negative relationships with neuroticism, agreeableness, and conscientiousness (Nicholson, Soane, Fenton-O’Creevy, \& Willman, 2005). Career self-efficacy is related to conscientiousness (moderate to strong positive correlations), neuroticism (weak to moderate negative correlations), and extraversion (moderate correlations with leadership and interpersonal aspects; Hartman \& Betz, 2007). Moderate correlations have been found between locus of control and emotional stability (Judge, Erez, Bono, \& Thoresen, 2002), and researchers contend that locus of control is in fact a component of emotional stability (Bono \& Judge, 2003; Ng, Sorensen, \& Eby, 2006). Intrinsic achievement motivation is strongly related to conscientiousness, moderately related to openness, and weakly related to extraversion (Hart, Stasson, Mahoney, \& Story, 2007).

PBIs are often administered in such a way that increases the risk to employees (mainly financial risk), thus individuals who are less risk-averse are more likely to accept or prefer PBIs (Kuhn \& Yockey, 2003; Pappas \& Flaherty, 2006; Tetrick et al., 2010). Assuming that the risk involved in PBIs is whether an individual can achieve the goal required for the incentive, those who are high in self-efficacy will have their risk-aversion 
mitigated by their belief that they will succeed (Kuhn \& Yockey, 2003). A third related factor is locus of control. Employees who have a more internal locus of control believe that attainment of the incentive is dependent on their efforts rather than chance. Conversely, those who have a more external locus of control believe that their performance is relatively unrelated to whether they will obtain the incentive. As such, individuals who have a more external locus of control may feel that PBIs are riskier (and therefore less attractive) than do individuals with an internal locus of control.

Because PBIs must be earned, their attainment can be seen as an indicator of achievement. To individuals who have a high need for achievement (or are achievementoriented), PBIs offer a challenge and an opportunity for accomplishment that is desirable to them. As a result, it is likely that achievement-oriented individuals are more attracted to PBIs than are individuals with a lower need for achievement.

Given that incentive attractiveness often varies across individuals depending on their personality (e.g., Furnham, 2003), it is likely that the individual difference in attraction to PBIs can be represented as a single trait: preference for performance-based incentives (PPBI). As described above, an individual who has a high PPBI would likely have low risk-aversion, high self-efficacy, a generally internal locus of control, and high need for achievement. Given the relationships between PPBI and various traits outlined above, the following hypotheses were put forth for Study III:

Hypothesis 1. PPBI is positively related to self-efficacy. Hypothesis 2. PPBI is positively related to financial risk-taking. Hypothesis 3. PPBI is positively related to internal locus of control. Hypothesis 4. PPBI is positively related to need for achievement. 


\section{PBI Alignment and Work Outcomes: Recruitment, Retention, and Performance}

Incentives are typically used to motivate individuals regarding recruitment, retention, and performance (Jex \& Britt, 2014; Milkovich et al., 1999), though they may also be used to influence other employee behaviors, such as counterproductive work behaviors (Jex \& Britt, 2014) and safety-related behaviors (Mattson et al., 2014). There are several theories that explain why and how incentives can be used to motivate individuals, such as equity theory, agency theory, and expectancy theory. Equity theory (Adams, 1963) posits that employees strive to achieve a fair balance between the work they put in and the rewards they receive. In this theory, employees may work more or less hard to maintain an equitable relationship between themselves and their employer. Similarly, agency theory views incentives as tools an employer uses to align the interests of employees with their own-in other words, incentives are used to convince employees to perform labor (Laffont \& Martimort, 2002). Both of equity and agency theories essentially see employees as relatively passive, mostly reacting to the circumstances around them.

In contrast, expectancy (Vroom, 1964) and goal-setting theories view employees as active and having more complex motivation. Expectancy theory explains that individuals make certain choices (e.g., work hard at their job) in order to achieve a certain outcome. The first two components of the theory (i.e., expectancy and instrumentality), set up the mechanism by which incentives can motivate employees to work harder: increased effort is expected to improve performance, and performance achievements will be related to the attainment of certain outcomes (i.e., incentives). Because this theory assumes these two relationships, it readily applies to PBIs. 
As noted in Chapter I, the third element of expectancy theory (i.e., valence) is of particular relevance to the current series of studies. It is this aspect of the theory that allows outcomes (i.e., incentives) to vary in their attractiveness to individuals, which has indeed been found to occur by many researchers. This component of the theory also applies to NPBIs; variation in preferences for incentives may also occur when the behavior to be influenced is one's decisions rather than one's effort.

Because these motivational processes (e.g., to increase effort or make a particular decision) may be different, each incentive may motivate individuals towards certain behaviors but not necessarily others. For example, an organization's mission statement may help attract employees (i.e., make a decision to work there) but may not provide motivation for retention (i.e., a decision to remain working there), especially if other needs are not being fulfilled (Brown \& Yoshioka, 2003). This has borne out in the literature, as researchers have found the effectiveness of incentives varies not only between individuals but also within individuals depending on the behavior to be motivated.

Some of the incentives that have been linked with organizational attractiveness (in a recruitment context) include flextime (Casper \& Buffardi, 2004; Thompson \& Aspinwall, 2009), salary (Tetrick et al., 2010), dependent care assistance (Casper \& Buffardi, 2004; Miller, 1984; Thompson \& Aspinwall, 2009), amount of vacation time (Tetrick et al., 2010), signing bonuses (Choi, 2011), free meals (Garcia, Posthuma, \& Quiñones, 2010), mission statement (Brown \& Yoshioka, 2003), positive organizational image (Cable \& Turban, 2003), pension/retirement plans (Loretto, White \& Duncan, 2000; Tetrick et al., 2010), tuition reimbursement (Pyle, 2011), skills training (Fahey, 
Walker, \& Sleigh, 2002), telecommuting (Thompson \& Aspinwall, 2009), and health insurance plan (Tetrick et al., 2010). Several of these recruitment incentives are also effective at retaining employees: pension/retirement plans (Gough \& Hick, 2009; Loretto et al., 2000), dependent care assistance (Miller, 1984), tuition reimbursement (Pyle, 2011; Spetz \& Adams, 2006), training (Fahey et al., 2002), and flextime (Spetz \& Adams, 2006). Additionally, succession planning systems (McDonald, 2008), perquisites (Renaud, Morin, \& Bechard, 2017), merit pay (Schaubroeck et al., 2008), and positive work environments (Spetz \& Adams, 2006) are also effective at retaining employees.

In relation to performance, incentives can be administered either based directly or indirectly on performance (i.e., PBIs) or not based on performance (i.e., NPBIs). Several researchers have demonstrated that linking incentives directly to performance leads to greater effort and performance (e.g., Bonner \& Sprinkle, 2002), most notably regular wages (Cerasoli, Nicklin, \& Ford, 2014; Farr, 1976; Hong et al., 1995; LaMere, Dickinson, Henry, Henry, \& Poling, 1996; Mir et al., 2011) and monetary bonuses (Landry et al., 2017). However, incentives that are linked indirectly to performance (e.g., pay based on group performance or stock dividends) can also lead to increases in individual effort (Cerasoli et al., 2014; Farr, 1976; Hong et al., 1995). Even when administered independently of performance, pensions (Hong et al., 1995; Loretto et al., 2000), paid meals (Hammermann \& Mohnen, 2014; Jessup \& Stahelski, 1999), personal items (e.g., phone, personal computer, car; Hammermann \& Mohnen, 2014), paid leave/workers' compensation (Hong et al., 1995), dependent care assistance (Miller, 1984) and gift certificates (Jessup \& Stahelski, 1999) can have a positive influence on employee performance. 
Because individuals vary in their preferences for specific incentives, it is expected that the effectiveness of PBIs in improving performance will likewise vary between individuals. More specifically, PBIs will be more effective in improving performance for individuals who are attracted to them (i.e., have a high PPBI) and less effective for those who are not attracted to them (i.e., have a low PPBI). As a result, individual performance will vary depending not only on whether PBIs or NPBIs are offered but also on whether an individual has a high or low PPBI.

Organizations may choose to offer PBIs or NPBIs (or most commonly a mixture of both; Park, 2018) in their attempts to recruit individuals, retain incumbents, and motivate employees to perform; similarly, PPBI will vary between individuals. As such, individuals will likely seek employment with organizations whose incentive offerings best fit their preferences — high PPBI individuals with employers that offer PBIs and low PPBI individuals with organizations that do not. The alignment between incentive offering and individual preference can have a strong impact on various work outcomes.

Person-organization fit (P-O fit; Caplan, 1987) describes the importance of the match between the resources provided by and required by the individual and the organization (Kristof, 1996). Prospective employees may use the incentives an organization offers to help determine P-O fit in two distinct ways. First and foremost, incentives help employees meet several needs in their life in ways that can be much less expensive than if these were being met by the individual (e.g., health benefits cost much less for an employer to purchase than an individual employee, as the employer essentially buys them in "bulk" for all of its employees). Individuals may vary widely in their 
specific needs, and those whose particular needs are satisfied by an organization will be more attracted to it (Kristof, 1996).

Second, incentives may help candidates ascertain how much the values of an organization align with their own, given that incentives are often viewed as indicative of the organization's culture and values (Kuhn, 2009) and play a role in employer branding (Lievens \& Slaughter, 2016). For example, having an on-site daycare or flextime policy may indicate that an organization values a healthy balance between work and family; having free massages or a break room may show that an organization values relaxation and comfort. A company that offers PBIs may be indicating that it values productivity, achievement, or results. Because preferences may indicate an individual's underlying values, individuals with high PPBI will be attracted to organizations that offer PBIs. Conversely, individuals with low PPBI would be less attracted to organizations that offer PBIs and more attracted to employers that provide NPBIs.

Ultimately, the overall effectiveness of an incentive depends on whether the incentive administration aligns with the preferences of the individual. This relationship has an impact on both the attractiveness of the organization to the individual (i.e., the desire to begin or remain working at an organization) and the individual's performance within the organization. Therefore, the following hypotheses were put forth for the final study:

Hypothesis 5. Incentive offer type moderates the relationship between PPBI and organizational attractiveness, such that participants with low PPBI will be less attracted to an organization offering PBI and more attracted to an organization offering NPBI, whereas participants with high PPBI will be more attracted to an 
organization offering PBI and less attracted to an organization offering NPBI (see Table 1).

Hypothesis 6. Incentive offer type moderates the relationship between PPBI and performance, such that participants with low PPBI will have the lowest performance when being offered NPBIs and slightly higher performance when offered PBIs, whereas participants with high PPBI will have the highest performance when offered PBIs and slightly lower performance when offered NPBIs (see Table 2).

Table 1

Hypothesized Interaction Effect of Incentive Offered and PPBI on Organizational Attractiveness

PPBI Incentive offered

\begin{tabular}{llll} 
PPBI & High & High attractiveness & Low attractiveness \\
& Low & Low attractiveness & High attractiveness \\
\hline
\end{tabular}

Table 2

Hypothesized Interaction Effect of PBI Offered and PPBI on Performance Incentive offered PPBI NPBI

\begin{tabular}{lccc} 
PPBI & $\begin{array}{c}\text { High } \\
\text { Low }\end{array}$ & $\begin{array}{c}\text { Highest performance } \\
\text { Moderately low performance }\end{array}$ & $\begin{array}{c}\text { Moderately high performance } \\
\text { Lowest performance }\end{array}$ \\
\hline
\end{tabular}




\section{CHAPTER III. METHODS}

\section{Study I}

Participants. Subject matter experts (SMEs, $N=14$ ) were recruited to participate in Study I. Faculty and former and current graduate students at a large public university in southeastern U.S. were used as SMEs. The average age of SMEs was $35(S D=8.6)$; their average time in the workforce was 16.60 years $(S D=9.91)$ and the average number of organizations SMEs had worked at in their lives was $6(S D=3.07)$. The sample was $60 \%$ female, $40 \%$ Hispanic, $47 \%$ Caucasian, $7 \%$ Asian, and $7 \%$ other ethnic background. A plurality of the SMEs were alumni of an industrial-organizational psychology program (57\%), with the remaining SMEs being current $\mathrm{PhD}$ students (29\%) and current university faculty (14\%).

Measures. A total of 89 different incentives were listed for the item sort (see Appendix A). The incentives were presented in a random order to each participant. Participants were asked to sort each incentive into the following category options: Monetary, Retirement, Time Off, Job Characteristics, Company-Provided Resources, Gifts and Discounts, Personal Services, Daily Life Conveniences, Health and WellBeing, Family Life Facilitation, Professional Growth, Organizational Culture, Physical Working Conditions, and Status and Recognition (see Table 3 for the description of each category and examples of encompassed incentives). Subject matter experts were also asked to indicate how representative they felt each incentive is of the category they selected (i.e., how well that incentive matches the category description provided to them). An additional category could also be selected if the SME felt that the incentive fit into more than one category, along with another field for them to rate the representativeness 
of the incentive of this second category. Space was be provided to allow SMEs to list any comments they may have for each incentive (e.g., if they feel the incentive fits into more than two categories or none of the categories). Finally, SMEs were asked to name any incentives they can think of that were omitted from the list and indicate which (if any) categories the incentive may fall under. 
Table 3

Incentive Categories and Examples

\begin{tabular}{|c|c|c|}
\hline Incentive Category & Description & Example Incentives \\
\hline Monetary & $\begin{array}{l}\text { Cash or cash-convertible (e.g., stocks or bonds) } \\
\text { incentives provided by an employer }\end{array}$ & Salary, cash bonus, employee stock \\
\hline Retirement & Incentives related to facilitation of retirement & Pension plan, 401(k) plan \\
\hline Time Off & Incentives related to time away from work & $\begin{array}{l}\text { Paid sick days, paid holidays, } \\
\text { extended leave }\end{array}$ \\
\hline Job Characteristics & $\begin{array}{l}\text { Incentives related to the manner in which employees } \\
\text { complete their work }\end{array}$ & $\begin{array}{l}\text { Flextime, telecommuting, high } \\
\text { autonomy }\end{array}$ \\
\hline Company-Provided Resources & $\begin{array}{l}\text { Items provided by an employer that may be used for } \\
\text { personal use outside of work }\end{array}$ & Company car, phone, housing \\
\hline Gifts and Discounts & $\begin{array}{l}\text { Free or discounted goods and services paid for or } \\
\text { provided by an employer }\end{array}$ & $\begin{array}{l}\text { Employee discounts, tickets, } \\
\text { personalized items }\end{array}$ \\
\hline Personal Services & $\begin{array}{l}\text { Free or discounted services provided by an employer to } \\
\text { assist employees with personal decisions and issues }\end{array}$ & $\begin{array}{l}\text { Financial advising, legal counsel, life } \\
\text { coaching }\end{array}$ \\
\hline Daily Life Convenience & $\begin{array}{l}\text { Regular needs and necessities are made more easily } \\
\text { accessible to employees }\end{array}$ & $\begin{array}{l}\text { On-site dining options, laundry } \\
\text { service }\end{array}$ \\
\hline Health and Well-being & $\begin{array}{l}\text { Incentives related to physical and mental health and } \\
\text { well-being }\end{array}$ & $\begin{array}{l}\text { Health insurance, gym membership, } \\
\text { standing desks }\end{array}$ \\
\hline Family Life Facilitation & Incentives that help employees with their family lives & $\begin{array}{l}\text { On-site daycare, parental leave, } \\
\text { fertility assistance }\end{array}$ \\
\hline Professional Growth & $\begin{array}{l}\text { Incentives related to the professional development of } \\
\text { employees }\end{array}$ & $\begin{array}{l}\text { Tuition reimbursement, conference } \\
\text { funding, mentoring }\end{array}$ \\
\hline $\begin{array}{l}\text { Organizational } \\
\text { Culture }\end{array}$ & $\begin{array}{l}\text { Incentives that relate to the image of an organization or } \\
\text { promote positive interactions between employees }\end{array}$ & $\begin{array}{l}\text { Company retreats, positive company } \\
\text { image, friendly coworkers }\end{array}$ \\
\hline Physical Work Conditions & $\begin{array}{l}\text { Incentives that facilitate a positive and comfortable } \\
\text { work atmosphere }\end{array}$ & $\begin{array}{l}\text { Free food/snacks/beverages, casual } \\
\text { dress, pet-friendly workplace }\end{array}$ \\
\hline Status and Recognition & $\begin{array}{l}\text { Incentives that offer special recognition or employees } \\
\text { or indicate status or achievement }\end{array}$ & $\begin{array}{l}\text { Employee-of-the-month program, } \\
\text { spacious office, praise }\end{array}$ \\
\hline
\end{tabular}


Procedure. Subject matter experts were recruited via email and asked to complete an item sorting exercise. In the item sort, participants were presented with a series of items (i.e., incentives, along with their descriptions) and asked to assign them into the one of the fourteen categories listed in Table 3; an optional second category could also be indicated. These categories were determined by examining the existing incentive literature for common themes.

Analysis. Two indices of substantive validity were used to analyze the ratings: the proportion of substantive agreement (PSA) and the substantive validity coefficient (SVC; Anderson \& Gerbing, 1991). The PSA ranges between 0 and 1; it is simply the proportion of SMEs who assign a given item to the hypothesized category (the hypothesized categories are displayed in Appendix A). The SVC reflects the extent to which SMEs classify an item to its hypothesized category more than to any other category (Anderson \& Gerbing, 1991). It is calculated as $\frac{n_{c}-n_{o}}{N}$, where $n_{c}$ is the number of SMEs that assign an item to the hypothesized category, $n_{o}$ is the number of SMEs that assign an item to a category other than the hypothesized one, and $N$ is the overall sample size. The values for this index range from -1.0 to 1.0 , with larger values indicating greater substantial validity. Anderson and Gerbing (1991) suggest that a substantive validity coefficient greater than .5 indicates acceptable agreement. Both the proportion of substantive agreement and the substantive agreement coefficient were calculated for each individual item and then averaged for each category.

\section{Study II}

Participants. Psychology and business undergraduate students $(N=300)$ at a large university in Southeast U.S. were recruited to participate in Study II. A university 
research participation website was used to recruit participants from undergraduate psychology classes. Students who volunteered for the study received course credit. Participants were predominantly female (79\%), Hispanic (77\%; with $9 \%$ Caucasian/White, 12\% Black/African American, 2\% Asian, and 1\% other ethnic background), and currently unmarried (86\%) and without children (87\%). The average age of participants was $23.92(S D=6.06)$. All were enrolled in a 4-year bachelor's degree program, and almost half (47\%) had already obtained a 2-year degree. Most of the students were currently working (32\% full-time, $51 \%$ part-time; working an average of 28.74 hours per week), with the remaining percentage (17\%) having worked previously but being only a full-time student currently. The participants had worked an average of 5.92 years $(S D=5.32)$ at an average of 3.6 different organizations $(S D=$ 2.38).

\section{Measures.}

Personality. The Big Five personality traits were measured using the 100-item Big Five Aspects Scales (BFAS; DeYoung, Quilty, \& Peterson, 2007). The BFAS measures personality at the facet level with two facets per factor. The dimensions measured include Neuroticism (with facets Volatility and Withdrawal), Agreeableness (with facets Compassion and Politeness), Conscientiousness (with facets Industriousness and Orderliness), Extraversion (with facets Enthusiasm and Assertiveness), and Openness/Intellect (with facets Intellect and Openness). DeYoung et al. (2007) demonstrated that both the factor and facet scales have adequate reliability and assert that the 10 facets may be linked with genetic factors. 
Incentive preferences. Participants were asked to rate how desirable each incentive is generally $(1=$ Not desirable at all, $2=$ Slightly desirable, $3=$ Moderately desirable, $4=$ Highly desirable , and $5=$ Extremely desirable ). An additional question asked if the participant has ever received such a benefit during employment.

Demographics. A variety of demographics were also measured, including age, gender, education level (current and desired), race, household income, marital status (current and desired), number of children (current and desired), pet ownership, and length and type of employment. Additionally, single items were used to assess each participant's tendency to experience physical and mental health issues.

Procedure. Participants completed the study measures via a testing website (i.e., Qualtrics). Upon completion of the study, participants were debriefed on the nature of the study and awarded course credit.

Analysis. The relationships between different incentive types and various individual differences were examined via correlation, $t$-tests, and one-way ANOVA depending on the type of individual difference being examined. Given that the purpose of this study was to explore the relationships between individual differences and incentive preferences, the analysis focused primarily on those relationships. For the crux of the analysis, correlations, $t$-tests, and ANOVAs are used to demonstrate the relationships between individual differences (demographics or personality variables) and incentive categories. The influence of the individual difference variables on incentive attractiveness were also included as a supplemental analysis; for interpretability, only the 5 most attractive incentives are shown for each individual difference variable. 
Supplementary analyses also show the relationships between the set of personality variables, as well as the demographic variables and incentive categories.

A second set of analyses were conducted to determine the best predictors of attractiveness to each incentive category. Since a large amount of literature supports the notion that demographic variables influence incentive attractiveness, it was of particular interest to determine if personality traits would predict the attractiveness of different incentive types above and beyond demographic variables. As such, two regressions were performed for each incentive category: one with demographic variables as predictors only and one with demographics plus personality traits as predictors.

\section{Study III}

Participants. Undergraduate students $(N=300)$ majoring in psychology at a large Southeastern university participated in Study III. Participants were recruited via a university research participation website. Students who participated in the study received course credit. Similar to the sample in Study II, the sample was $85 \%$ female, $75 \%$ Hispanic (7\% White/Caucasian, 15\% Black/African American, 2\% Asian, 1\% other ethnic background), $95 \%$ unmarried, and $92 \%$ without children. The average age in this sample was $22.06(S D=3.67)$. Many of the students $(52 \%)$ had completed a 2 -year degree already. The majority of the sample was currently employed (23\% full-time, $51 \%$ part-time, working an average of 23.52 hours per week). Participants had been working for an average of 4.47 years $(S D=3.46)$ at 3.06 different organizations on average $(S D=$ 2.08). 


\section{Measures.}

Preference for Performance-Based Incentives. The Preference for PerformanceBased Incentives Scale (PPBIS) contains 14 items designed to assess an individual's preference that each type of incentive be tied to performance (see Appendix B). Each item lists an incentive category (with example incentives) to which respondents must choose the extent they would like the administration of the incentive to be determined by their individual performance based on the following prompt: "I would prefer of my [incentive category] to be linked to my performance." Preferences are recorded on a 5-point Likert scale $(1=$ None, $2=$ Some, $3=$ Half, $4=$ Most, $5=A l l)$.

Need for Achievement. Need for Achievement (Nach, sometimes seen as Achievement-Striving, Achievement Motivation, or Achievement Orientation) is often considered a facet of Conscientiousness in some personality models (e.g., Goldberg, 1992). However, the BFAS used in this study does not clearly delineate this construct in its factor structure. Moreover, some research has shown that the construct actually spans several of the Big Five (Hart, Stasson, Mahoney, \& Story, 2007). As such, the 10-item Revised Achievement Motivation Scale (AMS-R; Lang \& Fries, 2006) was used to measure Nach. Because the original items were in German, the wording of the translated items listed by Lang and Fries (2006) were modified slightly to reflect more natural language. Evidence has been provided previously that this measure has adequate reliability for both Nach factors, Hope of Success and Fear of Failure (Lang \& Fries, 2006). The two factors represent individuals' desire to demonstrate their capability and, conversely, a fear of situations where success is uncertain. 
Risk-taking. Risk-taking propensity was measured with the Domain-Specific Risk-Taking (Adult) Scale (DOSPERT; Blais \& Weber, 2006). The DOSPERT contains 30 items and examines risk-taking behavior patterns in ethical, financial, health/safety, recreational, and social domains. This scale has been used previously by many researchers and has demonstrated adequate reliability overall (Blais \& Weber, 2006).

Self-efficacy. The Generalized Self-Efficacy Scale (GSES; Schwarzer \& Jerusalem, 1995) was used to measure self-efficacy. This 10-item, unidimensional scale is used extensively in research and has demonstrated adequate internal consistency. It has also been shown validity in predicting constructs such as favorable emotions, optimism, and work satisfaction (Schwarzer \& Jerusalem, 1995).

Locus of control. Locus of control was measured using Rotter's (1966) 29-item scale. This scale has been validated in many situations and used extensively in research (Halpert \& Hill, 2011).

Big Five personality traits. The Big Five was measured by the same scale used in Study II, the BFAS (DeYoung et al., 2007).

Demographics. Participants' age, gender, education level (current and desired), race, household income, marital status (current and desired), number of children (current and desired), pet ownership, and length and type of employment were measured. Additionally, single items were used to assess each participant's tendency to experience physical and mental health issues.

Procedure. The study measures were administered to participants via a testing website. Participants were debriefed on the nature of the study upon their completion of the questionnaire and awarded course credit. 
Analysis. Both the reliability and construct validity of the PPBIS were examined. The reliability of the PPBIS was examined using traditional methods (e.g., Cronbach's Alpha, corrected item-total correlations). Exploratory and confirmatory factor analyses (EFA, CFA) were used to investigate the dimensionality of the PPBIS. Finally, the construct validity of the PPBIS was examined via correlations and regressions between the PPBIS and various traits, including the Big Five, Nach, Risk-Taking, Self-Efficacy, and Locus of Control.

\section{Study IV}

Participants. Undergraduate psychology students at a large Southeastern university were recruited participate in Study IV. Study IV relied on a longitudinal design, thus requiring participants to provide responses at two different time points. Of the 287 students that participated in the first part, 155 completed the full study. A university research recruitment website was used to procure participants from undergraduate psychology classes; those who volunteered for the experiment received course credit.

The sample was again mostly female (87\%), Hispanic (77\%; with an additional 9\% Caucasian/White, 10\% Black/African America, 3\% Asian, and 1\% other racial backgrounds), unmarried $87 \%$, and with no children (81\%). Participants were again fairly young on average though there were also several middle-aged individuals in the sample $(M=23.62$ years old, $S D=6.01)$. A large number of students had already completed a 2-year degree (53\%), and the majority were currently working, either parttime (54\%) or full-time (25\%), for an average of 25.54 hours per week ( $S D=14.57)$. 
The average lifetime tenure of the sample was 5.63 years $(S D=5.41)$ at an average of 3.43 different organizations $(S D=2.41)$.

Measures. The PPBIS (in Appendix B) that was developed and validated in Study III was used to measure PPBI. The same measures of the Big Five (BFAS), selfefficacy (GSES), risk-taking (DOSPERT), need for achievement (AMS-R) and locus of control (Rotter's [1966] scale) used in Study III were used for this study.

Organizational attractiveness. The 15-item Organizational Attractiveness (OA) scale (Highhouse, Lievens, \& Sinar, 2003) was used to measure the OA of the companies presented in the scenarios. This scale includes three subdimensions related to (1) the general attractiveness of the organization, (2) intentions to pursue a job there, and (3) the prestige of the organization.

Demographics. Several demographics variables were measured, including age, gender, education level (current and desired), race, household income, marital status (current and desired), number of children (current and desired), pet ownership, and length and type of employment. Additionally, single items were used to assess each participant's tendency to experience physical and mental health issues.

Procedure. A testing website (Qualtrics) was used to conduct the study. Upon signing up for the study, participants were asked to complete the first part of the study, which included the PPBIS, BFAS, GSES, DOSPERT, the Locus of Control scale, and demographics variables. Two to three weeks after finishing the first part, participants were sent an email with a link to the second half of the study. In this part, participants were placed in one of two scenarios, both of which began with a description of an organization and a mock letter from the organization that offers the individual a position 
at the organization. In one scenario, an incentive was linked with the individual's performance (i.e., the individual could earn an extra reward by being the top performer). In the other scenario, none of the incentives were tied to the individual's performance. Essentially, half the participants were offered PBIs (OPBI condition), whereas the other half were offered NPBIs (NPBI condition). After reading the description of the organization, participants rated their attraction to the organization using the OA scale.

In the next phase of the scenario, participants had accepted the employment offer and were asked to begin their employment with a training exercise. For this exercise, participants were presented with a series of $7 \times 7$ matrices of random 0 s and 1s (see Figure 1). Participants were asked to type the number of $1 \mathrm{~s}$ in the matrix in the space provided next to each, completing as many matrices as possible within 3 minutes. In the scenario where the organization offers NPBIs, participants were informed that their incentive (i.e., course credit) would be granted regardless of their performance on the task. By contrast, participants in OPBI condition were told that the participant who completed the most matrices would receive a $\$ 10$ Visa gift card. Upon completion of this task, participants were debriefed on the nature of the study and awarded course credit. One gift card was distributed to the top scorer in the OPBI condition. 
Figure 1

Sample Item from Matrix Task

\begin{tabular}{|l|l|l|l|l|l|l|}
\hline 0 & 1 & 0 & 0 & 1 & 1 & 0 \\
\hline 1 & 1 & 0 & 1 & 0 & 1 & 0 \\
\hline 1 & 0 & 1 & 0 & 0 & 0 & 1 \\
\hline 0 & 0 & 1 & 0 & 0 & 0 & 1 \\
\hline 1 & 0 & 0 & 1 & 0 & 1 & 0 \\
\hline 0 & 0 & 0 & 0 & 1 & 0 & 0 \\
\hline 0 & 1 & 1 & 1 & 0 & 1 & 1 \\
\hline
\end{tabular}

Analysis. The scale properties of the PPBIS were reexamined using Study 4 participants as a second sample. To investigate the interaction between study condition and PPBI on OA and performance, a pair of hierarchical regressions (one for OA and one for performance) were used. Additionally, multigroup path analysis (using SEM) was also used in order to assess the full model depicted in Figure 2, testing the equivalence of the model—specifically, the effect of PPBI on OA and performance-across the two study conditions (i.e., "Incentive Type Offered"). 
Figure 2

Model Tested in Study IV

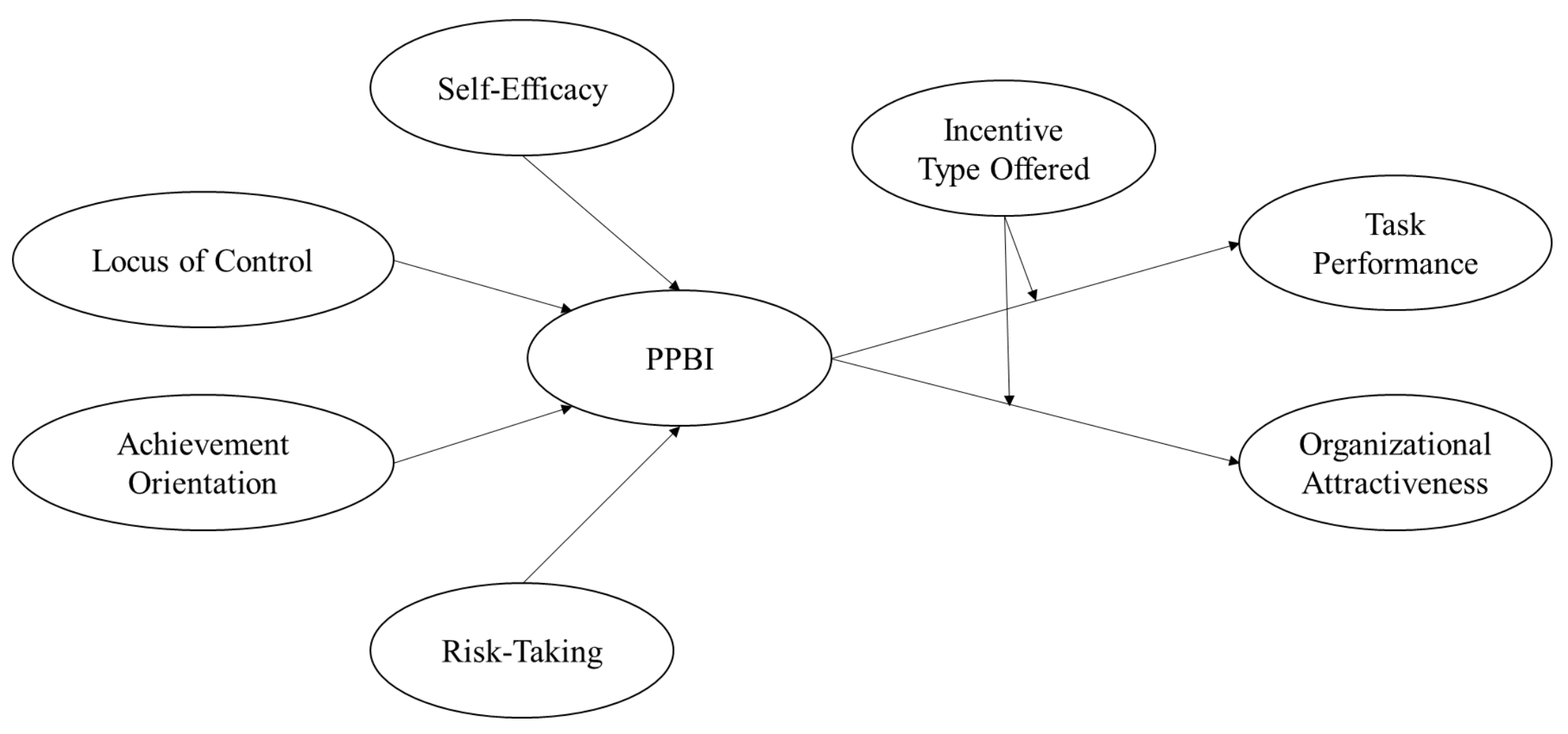




\section{CHAPTER IV. RESULTS}

\section{Study I}

The SME ratings in Study I largely confirmed the proposed incentive categorization scheme, though the level of consensus among SMEs varied greatly across incentives. Additionally, there was some variation in both the clarity and distinctiveness of the different categories, as shown by the average consensus across incentives within a category and the corresponding number of alternate categories SMEs indicated the incentives may fall under (the full table of responses can be seen in Appendix C). Table 4 shows the finalized groupings of incentives, which was primarily determined by

the category for which each incentive had the highest SVC (calculated $\frac{n_{c}-n_{o}}{N}, n_{c}=$ number of SMEs that assign an item to a particular category, $n_{o}=$ number of SMEs that assign an item to a different category, and $N=$ overall sample size. Note that participants could indicate a possible second category; $n_{c}$ includes SMEs that assigned the ratings in either the first or second response option. Additional categories that were indicated in the text response options for each item were not included in $n_{c}$.

Some incentives were placed into categories other than that with the highest SVC; these decisions were made on the basis of the incentives fitting better with the description in other categories (see Table 5). There were seven such incentives total: fertility assistance; free travel; free food, snacks, or beverages; a pet-friendly workplace; assistance programs; charitable gift-matching; and tuition/student loan reimbursement. Of these, three incentives still had at least half of the SMEs place them in the final category and an additional three incentives had at least a quarter of the SMEs place them in the final category. Moreover, six of these incentives had a maximum SVC of .00 for 
any category, indicating that there was no majority agreement that the incentive belonged in a different category than the one selected for the final grouping. The rarity of some of these incentives (e.g., fertility assistance or free travel) may have contributed to the general disagreement as to which category the incentives belonged, since unfamiliarity with the incentive may result in an improper understanding of how the incentive truly functions.

In the qualitative responses there were several comments that indicated the SMEs found that certain incentives did not fit cleanly within a single incentive category. The lack of orthogonality is also demonstrated by the fact that the option to choose a "secondary" incentive category was used an average of 3.72 times across incentives. In fact, some incentives had the majority of participants list an alternative category (e.g., “on-site clinic/pharmacy” had Daily Life Convenience alone listed as a secondary category by 6 SMEs, with still other categories receiving votes as a secondary category from other SMEs).

Regardless of incentives potentially fitting into multiple categories, the existence of 14 distinct incentive groups was established. The overall average agreement across all incentives for the final taxonomy was 74\% (or an average SVC of .47). The text responses revealed no additional incentives that could not be sorted into one of these 14 categories. 
Table 4

Study I - Summary of Subject Matter Expert Ratings

\begin{tabular}{|c|c|c|c|c|c|c|c|}
\hline Category/Incentives & $n$ Agreed & PSA & SVC & Category/Incentives & $n$ Agreed & PSA & SVC \\
\hline Monetary & $\underline{12.57}$ & .90 & .80 & Job Characteristics & 9.67 & .69 & .38 \\
\hline Salary & $\overline{14}$ & $\overline{1.00}$ & $\overline{1.00}$ & Flextime & 9 & $\overline{.64}$ & .29 \\
\hline Monetary bonus & 14 & 1.00 & 1.00 & Telecommuting/remote work & 8 & .57 & .14 \\
\hline Employee stock & 14 & 1.00 & 1.00 & High autonomy & 11 & .79 & .57 \\
\hline Profit-sharing & 14 & 1.00 & 1.00 & Interesting/meaningful work & 11 & .79 & .57 \\
\hline Gainsharing & 14 & 1.00 & 1.00 & Job swapping & 10 & .71 & .43 \\
\hline Commuter checks & 10 & .71 & .43 & Job security & 9 & .64 & .29 \\
\hline Relocation costs & 8 & .57 & .14 & Company-Provided Resources & $\underline{10.50}$ & .75 & .50 \\
\hline Family Life Facilitation & $\underline{9.00}$ & .64 & .29 & Company phone & 12 & .86 & .71 \\
\hline On-site daycare & 12 & .86 & .71 & Company car & 12 & .86 & .71 \\
\hline Lactation/mother's room & 7 & .50 & .00 & Company computer or tablet & 10 & .71 & .43 \\
\hline Fertility assistance $^{1}$ & 7 & .50 & .00 & Housing & 8 & .57 & .14 \\
\hline Adoption assistance & 10 & .71 & .43 & Gifts and Discounts & $\underline{10.33}$ & .74 & .48 \\
\hline Dependent care & 10 & .71 & .43 & Personalized items & 8 & $\overline{.57}$ & .14 \\
\hline Family medical leave & 8 & .57 & .14 & Employee discounts & 12 & .86 & .71 \\
\hline Health and Well-being & $\underline{10.82}$ & .77 & .55 & Phone discounts & 11 & .79 & .57 \\
\hline Health insurance & 13 & .93 & .86 & Tickets/coupons & 13 & .93 & .86 \\
\hline Dental insurance & 13 & .93 & .86 & Gift cards & 13 & .93 & .86 \\
\hline Vision insurance & 12 & .86 & .71 & Free travel ${ }^{2}$ & 5 & .36 & -.29 \\
\hline Life insurance & 7 & .50 & .00 & $\underline{\text { Physical Working Conditions }}$ & $\underline{7.50}$ & .54 & .07 \\
\hline Disability/accident insurance & 9 & .64 & .29 & Free food, snacks, beverages ${ }^{3}$ & $\overline{1}$ & $\overline{.07}$ & $-\overline{-.86}$ \\
\hline Staff psychologist & 12 & .86 & .71 & Game rooms, nap rooms & 11 & .79 & .57 \\
\hline Gym membership & 10 & .71 & .43 & Pet-friendly workplace ${ }^{4}$ & 4 & .29 & -.43 \\
\hline On-site gym & 12 & .86 & .71 & Casual dress & 7 & .50 & .00 \\
\hline On-site clinic/pharmacy & 11 & .79 & .57 & Comfortable work conditions & 14 & 1.00 & 1.00 \\
\hline Diet/exercise plans/classes & 11 & .79 & .57 & Standing desks & 8 & .57 & .14 \\
\hline Massages & 9 & .64 & .29 & Office size/location & 9 & .64 & .29 \\
\hline
\end{tabular}


Table 4 (continued)

\begin{tabular}{|c|c|c|c|c|c|c|c|}
\hline Category/Incentives & $n$ Agreed & PSA & SVC & Category/Incentives & $n$ Agreed & PSA & SVC \\
\hline Personal Services & $\underline{9.00}$ & .59 & .19 & Time Off & 11.40 & .82 & .63 \\
\hline Financial advising & $\overline{10}$ &.$\overline{.71}$ & .43 & Sick days & 12 & .86 & .71 \\
\hline Legal counsel & 10 & .71 & .43 & Paid holidays & 13 & .93 & .86 \\
\hline Loan assistance & 10 & .71 & .43 & Paid jury duty & 8 & .57 & .14 \\
\hline Life coaching & 9 & .64 & .29 & Extra paid time off & 13 & .93 & .86 \\
\hline Assistance programs (EAPs) ${ }^{5}$ & 7 & .50 & .00 & Paid volunteer time off & 11 & .79 & .57 \\
\hline Travel concierge & 8 & .57 & .14 & Paid sabbatical & 10 & .71 & .43 \\
\hline Retirement & $\underline{10.33}$ & .74 & .47 & Unpaid extended leave & 12 & .86 & .71 \\
\hline Pension plan & 12 & .86 & .71 & Parental leave & 12 & .86 & .71 \\
\hline Defined contribution plan & 12 & .86 & .71 & Bereavement leave & 12 & .86 & .71 \\
\hline Retiree insurance & 7 & .50 & .00 & Military leave & 11 & .79 & .57 \\
\hline Daily Life Conveniences & 11.50 & .83 & .64 & Professional Growth & $\underline{12.00}$ & .86 & .71 \\
\hline On-site dining options & $\overline{11}$ & $\overline{.79}$ & $\overline{.57}$ & Tuition/loan reimbursement ${ }^{7}$ & 7 & $\overline{.50}$ & $\overline{.00}$ \\
\hline On-site hair/nail salon & 13 & .93 & .86 & Conference funding & 13 & .93 & .86 \\
\hline Laundry service & 11 & .79 & .57 & Growth opportunities & 14 & 1.00 & 1.00 \\
\hline On-site car services & 11 & .79 & .57 & Mentoring & 12 & .86 & .71 \\
\hline Organizational Culture & $\underline{11.00}$ & .79 & .57 & Training opportunities & 14 & 1.00 & 1.00 \\
\hline Employee outings/retreats & $\overline{14}$ & $\overline{1.00}$ & $\overline{1.00}$ & $\underline{\text { Status and Recognition }}$ & $\underline{9.43}$ & .67 & .35 \\
\hline Team bonding events & 14 & 1.00 & 1.00 & Employee of month & 14 & 1.00 & 1.00 \\
\hline Positive organizational image & 11 & .79 & .57 & Premium parking spot & 8 & .57 & .14 \\
\hline Diversity program & 11 & .79 & .57 & Private bathroom & 7 & .50 & .00 \\
\hline Charitable gift matching $^{6}$ & 6 & .43 & -.14 & Praise & 9 & .64 & .29 \\
\hline Friendly coworkers/boss & 13 & .93 & .86 & Work anniversary awards & 11 & .79 & .57 \\
\hline Birthday celebration & 8 & .57 & .14 & Work anniversary gifts & 8 & .57 & .14 \\
\hline
\end{tabular}

Note: $n$ Agreed = number of SMEs that placed the item as belonging to the category indicated; PSA = Proportion of Substantive

Agreement, calculated as $n$ Agreed / $N$ Total; SVC $=$ Substantive Validity Coefficient, calculated as ( $n$ Agreed $-n$ Disagreed) / $N$ Total, where $n$ Disagreed is the number of SMEs that place the item as belonging to any category other than the one indicated; category averages are underlined. ${ }^{1,2,3,4,5,6,7}$ See Table 5 for the highest SVC categories for these incentives. 
Table 5

Study I-Alternative Categories for Select Incentives with Higher or Equal SVC

\begin{tabular}{|c|c|c|c|c|c|}
\hline Category/Incentives & $\begin{array}{c}\text { Final } \\
\text { category }\end{array}$ & $\begin{array}{l}\text { Final } \\
\text { SVC }\end{array}$ & $\begin{array}{l}\text { Alternative } \\
\text { category }\end{array}$ & $\begin{array}{l}\text { Alternative } \\
\text { SVC }\end{array}$ & Rationale for decision \\
\hline 1. Fertility assistance & FLF & .00 & HW & .00 & $\begin{array}{l}\text { Fertility assistance facilitates an employee's } \\
\text { family (i.e., having children) rather than } \\
\text { physical or mental health }\end{array}$ \\
\hline 2. Free travel & GD & -.29 & Mon. & -.14 & $\begin{array}{l}\text { Free travel incentives are for a specific } \\
\text { purpose and not fungible }\end{array}$ \\
\hline 3. Free food, snacks, beverages & PWC & -.86 & GD & -.14 & $\begin{array}{l}\text { Free food provided in a workplace is more } \\
\text { relevant to the physical work environment }\end{array}$ \\
\hline 4. Pet-friendly workplace & PWC & -.43 & $\mathrm{OC}$ & .00 & $\begin{array}{l}\text { Allowing pets in the workplace is more } \\
\text { relevant to the physical work environment }\end{array}$ \\
\hline 5. Assistance programs (EAPs) & PS & .00 & HW & .00 & $\begin{array}{l}\text { EAPs are not strictly limited to dealing with } \\
\text { employee health and wellness issues }\end{array}$ \\
\hline 6. Charitable gift matching & $\mathrm{OC}$ & -.14 & GD & .00 & $\begin{array}{l}\text { Employees do not receive the money from } \\
\text { employers' charitable gift matching }\end{array}$ \\
\hline 7. Tuition/loan reimbursement & PG & .00 & Mon. & .57 & $\begin{array}{l}\text { Tuition/loan reimbursements are for a specific } \\
\text { purpose and not fungible }\end{array}$ \\
\hline
\end{tabular}

Note: SVC = Substantive Validity Coefficient, calculated as ( $n$ Agreed $-n$ Disagreed) / $N$ Total, where $n$ Agreed represents the number of SMEs that placed the item as belonging to the indicated category and $n$ Disagreed represents the number of SMEs that place the item as belonging to any category other than the indicated category. Mon = Monetary, GD $=$ Gifts and Discounts, PS $=$ Personal Services, HW = Health and Well-being, FLF = Family Life Facilitation, PG = Professional Growth, OC = Organizational Culture, PWC = Physical Working Conditions. 


\section{Study II}

The exploratory analyses conducted in Study II demonstrated that incentives vary in their general attractiveness (see Table 6). However, most incentives were rated at least moderately desirable (i.e., a "3" on the 5-point scale) by participants; even the least desirable incentive (standing desks) was rated between slightly desirable (i.e., "2") and moderately desirable on average. In fact, over $33 \%$ of incentives were rated as at least highly desirable (i.e., "4") on average. The most desirable incentive on average was paid holidays, whereas a standing desk was the least attractive on average.

Table 6

Study II - Incentive Attractiveness Ratings

\begin{tabular}{lccccccc}
\hline & Category & $n$ & $M$ & $S D$ & Skew. & Kurt. & $\%$ Ex. \\
\hline Paid holidays & TO & 300 & 4.81 & 0.54 & -3.86 & 19.30 & 47 \\
Friendly coworkers/boss & OC & 300 & 4.69 & 0.65 & -2.38 & 6.33 & 77 \\
Salary & Mon & 300 & 4.69 & 0.69 & -2.70 & 8.65 & 59 \\
Interesting/meaningful work & JC & 299 & 4.68 & 0.63 & -2.12 & 4.31 & 57 \\
Tuition/loan reimbursement & PG & 300 & 4.64 & 0.69 & -2.19 & 5.48 & 21 \\
Comfortable work conditions & PWC & 299 & 4.63 & 0.68 & -2.03 & 4.51 & 69 \\
Job security & JC & 300 & 4.61 & 0.73 & -2.36 & 6.62 & 48 \\
Sick days & TO & 299 & 4.60 & 0.69 & -1.81 & 3.45 & 59 \\
Growth opportunities & PG & 300 & 4.58 & 0.73 & -1.93 & 3.98 & 63 \\
Health insurance & HW & 299 & 4.57 & 0.89 & -2.29 & 4.94 & 51 \\
Extra paid time off & TO & 300 & 4.54 & 0.72 & -1.57 & 1.91 & 22 \\
Family medical leave & FLF & 300 & 4.48 & 0.80 & -1.72 & 3.19 & 29 \\
Free travel & GD & 298 & 4.43 & 0.99 & -2.01 & 3.68 & 8 \\
Employee discounts & GD & 300 & 4.40 & 0.83 & -1.51 & 2.39 & 74 \\
Monetary bonus & Mon & 299 & 4.38 & 1.00 & -1.73 & 2.40 & 30 \\
Defined contribution plan & Ret & 299 & 4.38 & 1.02 & -1.73 & 2.41 & 51 \\
Positive organizational image & OC & 300 & 4.37 & 0.88 & -1.41 & 1.60 & 58 \\
Training opportunities & PG & 299 & 4.36 & 0.88 & -1.27 & 0.96 & 60 \\
Dental insurance & HW & 299 & 4.35 & 0.96 & -1.51 & 1.68 & 41 \\
Life insurance & HW & 300 & 4.26 & 1.05 & -1.50 & 1.60 & 38 \\
Flextime & JC & 299 & 4.19 & 1.14 & -1.37 & 0.94 & 29 \\
Free food, snacks, beverages & PWC & 300 & 4.18 & 1.01 & -1.02 & 0.17 & 56 \\
Mentoring & PG & 299 & 4.14 & 1.06 & -1.23 & 0.96 & 40 \\
Disability/accident insurance & HW & 299 & 4.12 & 1.11 & -1.24 & 0.78 & 31 \\
Vision insurance & HW & 300 & 4.12 & 1.12 & -1.23 & 0.72 & 37 \\
Pension plan & Ret & 300 & 4.10 & 1.14 & -1.19 & 0.58 & 26 \\
\hline & & & & & & &
\end{tabular}


Table 6 (continued)

\begin{tabular}{|c|c|c|c|c|c|c|c|}
\hline & Category & $n$ & $M$ & $S D$ & Skew. & Kurt. & $\%$ Ex. \\
\hline Paid sabbatical & TO & 300 & 4.01 & 1.25 & -1.09 & 0.09 & 10 \\
\hline Paid jury duty & TO & 300 & 4.01 & 1.19 & -1.06 & 0.22 & 21 \\
\hline Praise & SR & 298 & 4.00 & 1.11 & -0.91 & 0.08 & 53 \\
\hline Paid volunteer time off & TO & 299 & 4.00 & 1.24 & -1.03 & -0.01 & 10 \\
\hline Retiree insurance & Ret & 299 & 3.99 & 1.22 & -1.10 & 0.22 & 23 \\
\hline Tickets/coupons & GD & 300 & 3.99 & 1.13 & -0.89 & -0.06 & 35 \\
\hline Work anniversary awards & SR & 299 & 3.97 & 1.17 & -0.89 & -0.22 & 32 \\
\hline Parental leave & TO & 299 & 3.96 & 1.36 & -1.08 & -0.13 & 21 \\
\hline High autonomy & $\mathrm{JC}$ & 299 & 3.91 & 1.13 & -0.85 & -0.02 & 32 \\
\hline On-site gym & HW & 300 & 3.86 & 1.20 & -0.84 & -0.20 & 18 \\
\hline Gym membership & HW & 299 & 3.85 & 1.37 & -0.89 & -0.49 & 14 \\
\hline Employee outings/retreats & $\mathrm{OC}$ & 300 & 3.83 & 1.23 & -0.76 & -0.49 & 53 \\
\hline Office size/location & PWC & 300 & 3.82 & 1.18 & -0.86 & 0.03 & 29 \\
\hline On-site dining options & DLC & 299 & 3.82 & 1.18 & -0.81 & -0.12 & 39 \\
\hline Work anniversary gifts & SR & 299 & 3.80 & 1.31 & -0.73 & -0.66 & 33 \\
\hline Company computer or tablet & CPR & 299 & 3.80 & 1.26 & -0.83 & -0.33 & 38 \\
\hline Gift cards & GD & 300 & 3.79 & 1.25 & -0.77 & -0.41 & 33 \\
\hline Relocation costs & Mon & 300 & 3.78 & 1.26 & -0.83 & -0.30 & 11 \\
\hline Phone discounts & GD & 300 & 3.77 & 1.22 & -0.76 & -0.30 & 13 \\
\hline Financial advising & PS & 299 & 3.77 & 1.29 & -0.76 & -0.52 & 10 \\
\hline Team bonding events & $\mathrm{OC}$ & 300 & 3.76 & 1.24 & -0.65 & -0.66 & 49 \\
\hline Private bathroom & $\mathrm{SR}$ & 300 & 3.73 & 1.30 & -0.64 & -0.78 & 36 \\
\hline Diet/exercise plans/classes & HW & 300 & 3.72 & 1.30 & -0.69 & -0.64 & 16 \\
\hline Telecommuting/remote work & $\mathrm{JC}$ & 300 & 3.72 & 1.33 & -0.66 & -0.75 & 17 \\
\hline Commuter checks & Mon & 300 & 3.69 & 1.30 & -0.71 & -0.58 & 13 \\
\hline Birthday celebration & $\mathrm{OC}$ & 299 & 3.65 & 1.29 & -0.52 & -0.85 & 49 \\
\hline Bereavement leave & TO & 300 & 3.65 & 1.33 & -0.61 & -0.79 & 28 \\
\hline On-site clinic/pharmacy & HW & 300 & 3.64 & 1.20 & -0.56 & -0.60 & 22 \\
\hline Employee stock & Mon & 300 & 3.64 & 1.34 & -0.69 & -0.67 & 23 \\
\hline Profit-sharing & Mon & 298 & 3.63 & 1.29 & -0.61 & -0.65 & 15 \\
\hline Assistance programs & PS & 298 & 3.59 & 1.32 & -0.56 & -0.79 & 24 \\
\hline Company car & CPR & 299 & 3.55 & 1.39 & -0.52 & -0.96 & 7 \\
\hline Staff psychologist & HW & 300 & 3.55 & 1.27 & -0.45 & -0.79 & 15 \\
\hline Casual dress & PWC & 300 & 3.54 & 1.19 & -0.39 & -0.70 & 60 \\
\hline Premium parking spot & $\mathrm{SR}$ & 299 & 3.53 & 1.47 & -0.47 & -1.18 & 14 \\
\hline Dependent care & FLF & 300 & 3.51 & 1.33 & -0.50 & -0.87 & 9 \\
\hline Personalized items & GD & 300 & 3.49 & 1.34 & -0.41 & -1.01 & 32 \\
\hline Game rooms, nap rooms & PWC & 299 & 3.48 & 1.43 & -0.38 & -1.22 & 12 \\
\hline Massages & HW & 300 & 3.47 & 1.45 & -0.39 & -1.25 & 11 \\
\hline Conference funding & PG & 299 & 3.43 & 1.44 & -0.45 & -1.10 & 12 \\
\hline Loan assistance & PS & 299 & 3.43 & 1.36 & -0.44 & -0.97 & 15 \\
\hline Diversity program & $\mathrm{OC}$ & 298 & 3.42 & 1.22 & -0.39 & -0.69 & 21 \\
\hline
\end{tabular}


Table 6 (continued)

\begin{tabular}{|c|c|c|c|c|c|c|c|}
\hline Category & & $n$ & $M$ & $S D$ & Skew. & Kurt. & $\%$ Ex. \\
\hline Housing & CPR & 299 & 3.41 & 1.45 & -0.42 & -1.13 & 6 \\
\hline Legal counsel & PS & 300 & 3.40 & 1.33 & -0.41 & -0.90 & 14 \\
\hline Job swapping & $\mathrm{JC}$ & 300 & 3.38 & 1.33 & -0.36 & -0.98 & 19 \\
\hline On-site car services & DLC & 299 & 3.36 & 1.39 & -0.33 & -1.12 & 7 \\
\hline Travel concierge & PS & 300 & 3.32 & 1.40 & -0.32 & -1.15 & 8 \\
\hline Employee of month & SR & 299 & 3.30 & 1.39 & -0.25 & -1.16 & 35 \\
\hline Pet friendly workplace & PWC & 299 & 3.28 & 1.52 & -0.26 & -1.37 & 18 \\
\hline Life coaching & PS & 297 & 3.27 & 1.41 & -0.24 & -1.19 & 9 \\
\hline Gainsharing & Mon & 299 & 3.16 & 1.42 & -0.15 & -1.24 & 9 \\
\hline Charitable gift matching & $\mathrm{OC}$ & 300 & 3.14 & 1.24 & -0.06 & -0.82 & 15 \\
\hline Unpaid extended leave & TO & 300 & 3.13 & 1.51 & -0.18 & -1.40 & 26 \\
\hline On-site daycare & FLF & 299 & 3.07 & 1.50 & -0.08 & -1.40 & 7 \\
\hline Company phone & CPR & 299 & 3.02 & 1.47 & 0.02 & -1.34 & 14 \\
\hline Lactation/mother's room & FLF & 300 & 2.82 & 1.49 & 0.17 & -1.33 & 10 \\
\hline On-site hair/nail salon & DLC & 300 & 2.81 & 1.55 & 0.20 & -1.46 & 12 \\
\hline Laundry service & DLC & 300 & 2.78 & 1.52 & 0.23 & -1.38 & 7 \\
\hline Fertility assistance & FLF & 300 & 2.74 & 1.50 & 0.26 & -1.34 & 7 \\
\hline Military leave & TO & 299 & 2.59 & 1.50 & 0.40 & -1.24 & 13 \\
\hline Adoption assistance & FLF & 300 & 2.56 & 1.40 & 0.38 & -1.11 & 7 \\
\hline Standing desks & PWC & 299 & 2.54 & 1.44 & 0.39 & -1.20 & 16 \\
\hline
\end{tabular}

Note: Ex. $\%=$ percentage of sample that indicated they had received the incentive, either from their current or past employer; Skew. $=$ item skewness; Kurt. $=$ item kurtosis. Mon $=$ Monetary, Ret $=$ Retirement, $\mathrm{TO}=$ Time Off, $\mathrm{JC}=$ Job Characteristics, $\mathrm{CPR}=$ Company-Provided Resources, GD = Gifts and Discounts, PS $=$ Personal Services, DLC $=$ Daily Life Convenience, HW $=$ Health and Well-being, FLF $=$ Family Life Facilitation, $\mathrm{PG}=$ Professional Growth, $\mathrm{OC}=$ Organizational Culture, $\mathrm{PWC}=$ Physical Working Conditions, SR = Status and Recognition.

Examining the average incentive attractiveness between incentive groups reveals that there is a pattern to how appealing incentives are in general, with incentives belonging to certain categories tending to be more desirable than those belonging to other categories. Table 7 shows that Professional Growth and Retirement incentives are among the most attractive on average, whereas Family Life Facilitation and Daily Life Convenience incentives are the least desired. This pattern of results may reflect socially desirable responding to some degree, since employees may believe that expressing 
interest in professional growth incentives indicates to the employer a (possibly accurate) belief that they have high potential—or at least a desire for more responsibility. On the other hand, individuals may feel that showing interest in family-oriented or convenience incentives may signal to an employer that work is a lesser priority than their family or that they are averse to extra work. Note that these average incentive ratings are likely to be sample-specific, since the sample was fairly homogenous (e.g., all students, mostly female, relatively young).

Table 7

Study II - Incentive Category Attractiveness Ratings and Rankings

\begin{tabular}{cccccc}
\hline \multirow{2}{*}{ Incentive category } & \multirow{2}{*}{ \# of incentives } & \multicolumn{2}{c}{ Incentive attractiveness rating } & \multicolumn{2}{c}{ Incentive rank $^{1}$} \\
\cline { 3 - 6 } & & $M$ & $S D$ & $M$ & $S D$ \\
\hline PG & 5 & 4.23 & 0.64 & 24.20 & 24.43 \\
Ret & 3 & 4.16 & 0.86 & 24.33 & 7.64 \\
JC & 6 & 4.08 & 0.67 & 31.33 & 26.01 \\
GD & 6 & 3.98 & 0.77 & 35.00 & 19.40 \\
HW & 11 & 3.96 & 0.71 & 36.18 & 18.30 \\
TO & 10 & 3.93 & 0.64 & 35.70 & 28.78 \\
Mon & 7 & 3.85 & 0.77 & 43.00 & 25.55 \\
OC & 7 & 3.84 & 0.71 & 43.14 & 26.86 \\
SR & 6 & 3.72 & 0.86 & 47.67 & 17.20 \\
PWC & 7 & 3.64 & 0.70 & 50.57 & 29.45 \\
PS & 6 & 3.46 & 0.88 & 64.83 & 11.30 \\
CPR & 4 & 3.45 & 1.06 & 62.50 & 16.58 \\
FLF & 6 & 3.20 & 0.93 & 68.00 & 28.85 \\
DLC & 4 & 3.19 & 1.05 & 69.75 & 20.56 \\
\hline
\end{tabular}

Note: ${ }^{1}$ The average incentive ranking within a group when all individual incentives studied are ordered from most attractive to least attractive (as done in Table 6).

Note that there is plenty of variability in both individual incentive ratings and the combined incentive category ratings; it is likely that the variability in incentive attractiveness is related to individual differences. These relationships were confirmed by the next set of analyses, which included correlations (Table 8 and Table 9; additional correlation tables of non-investigated relationships are included in Appendices D1-D3), 
$t$-tests (Table 10), and ANOVAs (Table 11). Altogether, there is ample support that incentive preferences differ greatly depending on certain individual characteristics. Supplementary analyses are presented in Appendices E1-2.

Although the correlations between personality factors/facets and incentive categories were generally weak (there were no correlations above .30), several patterns emerged in the correlation matrix (Table 8). Significant correlations tended to be clustered, with certain personality facets or incentive categories having multiple significant correlations. In fact, there were no personality traits or incentive categories that had only one significant correlation; they either had several or none. The only personality traits that had no significant correlations were Withdrawal (facet of Neuroticism) and Openness (facet of Openness/Intellect). Conversely, Extraversion had significant correlations (the strongest observed in the matrix, in fact) with nine incentive categories (driven primarily by the Assertiveness facet, which had significant correlations with 10 categories), as did Intellect (facet of Openness/Intellect).

For incentive categories, Company-Provided Resources, Daily Life Conveniences, and Physical Working Conditions had no significant correlations with any personality traits. On the other hand, Professional Growth and Organizational Culture had significant correlations with every personality trait (except the aforementioned facets Withdrawal and Openness) and again held the strongest correlations in the matrix. Time Off and Health and Well-being have significant correlations with factors or facets in four out of the five personality trait groupings, indicating that these incentive categories are also influenced by personality. 
Correlations with the remaining continuously-measured demographic variables are displayed in Table 9. There were no significant correlations observed between the frequency of experiencing physical or mental health issues and incentive preferences by category, though there were small but significant correlations between mental health issues and a handful of the individual incentives (e.g., on-site pharmacy, staff psychologist). Because age, overall tenure, and number of organizations worked for are all strongly intercorrelated, their relationships with incentive categories are similar; two or all three of these variables have significant correlations with Retirement, Job Characteristics, Personal Services, Family Life Facilitation, and Professional Growth. Average work hours had small but significant correlations with Retirement, CompanyProvided Resources, and Physical Working Conditions.

Table 10 shows the comparison of means of the variables split into binary groups: gender, generation, marital status, parental status, and desired education level. There were gender differences in ratings of two incentive categories: Monetary and Organizational Culture, with men being more interested than women in Monetary incentives and women being more interested than men in Organizational Culture. Differences between generational groups were investigated between Generation Z (or Post-Millennials; born 1997-2012) and Millennials (or Generation Y; born 1981-1996) there were too few individuals in the sample with ages outside those two groups (e.g., Generation X) to provide any other viable comparison groups. Millennials found several incentive categories to be more attractive than did Generation Z, including Retirement ( $d$ $=0.35)$, Company-Provided Resources $(d=0.30)$, Health and Well-being $(d=0.29)$, Family Life Facilitation $(d=0.28)$, and Professional Growth $(d=0.30)$. 
A relatively small proportion of the sample was married or a parent, but there were significant differences for both variables (Table 10). Participants who were married or had children rated Family Life Facilitation incentives higher on average than did those who were unmarried or had no children ( $d=0.47$ and 0.52 , respectively). There were also significant differences between parents and non-parents in ratings of Retirement $(d=$ 0.47), Time Off ( $d=0.37)$, Job Characteristics $(d=0.40)$, and Personal Services $(d=$ 0.42), with parents rating each of these as more desirable. Finally, participants who sought to obtain a graduate degree differed from those who only wanted an undergraduate degree in their ratings of Status and Recognition incentives $(d=0.34)$.

Note that there were no corrections made for multiple comparisons in the aforementioned set of analyses, so it is possible that several of the significant relationships observed are spurious. However, if all observed significant relationships were in fact due to Type I error (i.e., "false positives"), there would be much fewer of them. For example, Table 8 contains 210 correlations, and if there were in reality no significant relationships, there should be approximately 11 (spurious) significant correlations. Instead, there are 66 significant correlations observed in Table 8, most of which occur in a distinct pattern (i.e., clustered in particular incentive or personality factors). It is therefore unlikely that the general interpretation is incorrect due to false positives. However, the significant relationships observed with certain factors where the evidence is less strong (e.g., differences in the desire for Status and Recognition incentives between those who desire a graduate degree vs those who do not) should be interpreted with caution or less confidence. 
Table 8

Study II - Correlations of Personality Factors/Facets with Incentive Categories

\begin{tabular}{|c|c|c|c|c|c|c|c|c|c|c|c|c|c|c|}
\hline & Mon & Ret & TO & $\mathrm{JC}$ & $\mathrm{CPR}$ & GD & PS & DLC & $\mathrm{HW}$ & FLF & PG & $\mathrm{OC}$ & PWC & SR \\
\hline Neuroticism & -.09 & -.08 & -.03 & -.03 & .00 & -.01 & -.06 & .05 & -.04 & -.03 & $*_{-} .12$ & $*_{-} .14$ & .01 & -.03 \\
\hline Volatility & -.09 & -.07 & -.04 & -.04 & .04 & .01 & -.02 & .10 & -.04 & -.02 & $*_{-} .12$ & $*_{-} .15$ & .04 & .00 \\
\hline Withdrawal & -.08 & -.08 & -.02 & -.02 & -.05 & -.03 & -.10 & -.03 & -.04 & -.04 & -.09 & -.10 & -.03 & -.07 \\
\hline Agreeableness & .05 & .05 & $* * .16$ & $* .13$ & -.04 & .05 & -.04 & -.05 & .11 & -.03 & $* * .19$ & $* * .15$ & .00 & -.01 \\
\hline Compassion & .09 & .10 & $* * .16$ & $* .14$ & .01 & .06 & .00 & -.03 & $* .14$ & -.02 & $* * .20$ & $* .13$ & .02 & .03 \\
\hline Politeness & -.02 & -.03 & .11 & .08 & -.08 & .02 & -.08 & -.06 & .05 & -.04 & $* .13$ & $* .13$ & -.01 & -.04 \\
\hline Conscientiousness & .06 & $* .12$ & $* .13$ & .08 & -.02 & $* .13$ & .09 & -.02 & $* * .15$ & .09 & $* * .18$ & $* * .24$ & .05 & $* * .16$ \\
\hline Industriousness & .08 & $* .13$ & .09 & .05 & .00 & .08 & $* .12$ & -.03 & $* .15$ & $* .13$ & $* * .17$ & $* * .20$ & .05 & $* .14$ \\
\hline Orderliness & .03 & .07 & $* .15$ & .09 & -.03 & $* .15$ & .04 & .00 & .11 & .03 & $* .14$ & $* * .21$ & .04 & $* .13$ \\
\hline Extraversion & $* .13$ & $* .14$ & $* * .16$ & $* * .20$ & .07 & .10 & $* .13$ & .00 & $* * .16$ & .06 & $* * .22$ & $* * .27$ & .10 & $* * .18$ \\
\hline Enthusiasm & .03 & .06 & .09 & .11 & .04 & .07 & .06 & -.04 & .09 & -.02 & $* .13$ & $* * .22$ & .06 & .11 \\
\hline Assertiveness & $* * .19$ & $* * .18$ & $* * .18$ & $* * .23$ & .07 & .10 & $* * .16$ & .04 & $* * .17$ & $* .13$ & $* * .24$ & $* * .24$ & .11 & $* * .20$ \\
\hline Openness/Intellect & .11 & .09 & .09 & $* * .19$ & .03 & -.01 & .07 & .03 & .11 & .06 & $* * .17$ & $* .13$ & .06 & .04 \\
\hline Intellect & $* * .17$ & $* .12$ & $* .13$ & $* * .22$ & .10 & .05 & $* .13$ & .07 & $* .14$ & .11 & $* * .23$ & $* .17$ & .07 & .09 \\
\hline Openness & .00 & .02 & .01 & .08 & -.05 & -.07 & -.02 & -.03 & .03 & -.02 & .03 & .03 & .02 & -.04 \\
\hline
\end{tabular}

Note: $N=300 ; *$ indicates $p<.05$, ** indicates $p<.01$. Mon $=$ Monetary, Ret $=$ Retirement, TO $=$ Time Off, JC = Job

Characteristics, $\mathrm{CPR}=$ Company-Provided Resources, GD = Gifts and Discounts, PS = Personal Services, DLC $=$ Daily Life

Convenience, $\mathrm{HW}=$ Health and Well-being, FLF $=$ Family Life Facilitation, $\mathrm{PG}=$ Professional Growth, OC $=$ Organizational

Culture, $\mathrm{PWC}=$ Physical Working Conditions, $\mathrm{SR}=$ Status and Recognition. 
Table 9

Study II - Correlations Between Demographics and Incentive Categories

\begin{tabular}{|c|c|c|c|c|c|c|c|c|c|c|c|c|c|c|c|}
\hline & $n$ & Mon & Ret & TO & $\mathrm{JC}$ & CPR & GD & PS & DLC & $\mathrm{HW}$ & FLF & PG & $\mathrm{OC}$ & PWC & SR \\
\hline Age & 294 & .03 & $* .15$ & .06 & $* .14$ & .04 & $*_{-} .13$ & .10 & -.03 & .07 & $* .12$ & .11 & -.07 & -.10 & -.10 \\
\hline Avg. Work Hrs. & 240 & .03 & $* * .22$ & .11 & .13 & $* .14$ & .00 & .10 & .11 & .08 & .07 & .11 & -.02 & $* .13$ & .05 \\
\hline Total Tenure & 299 & .07 & $* * .17$ & .11 & $* * .20$ & .06 & -.06 & $* .13$ & .04 & .10 & $* .13$ & $* * .15$ & -.02 & -.03 & -.02 \\
\hline Total Jobs Held & 299 & .11 & $* * .16$ & $* .12$ & $* * .16$ & $* .14$ & .02 & $* * .19$ & .11 & *.14 & $* * .15$ & $* * .16$ & -.01 & .06 & .04 \\
\hline Physical Health & 300 & -.02 & -.04 & -.05 & -.05 & -.05 & .00 & .01 & -.04 & .01 & -.08 & -.09 & -.05 & .02 & -.04 \\
\hline Mental Health & 299 & .07 & .07 & -.04 & .00 & .10 & .03 & .05 & .08 & .00 & .04 & .02 & .07 & .03 & .08 \\
\hline
\end{tabular}

Note: $*$ indicates $p<.05, * *$ indicates $p<.01$. Mon = Monetary, Ret $=$ Retirement, TO = Time Off, JC = Job Characteristics, CPR = Company-Provided Resources, GD = Gifts and Discounts, PS = Personal Services, DLC = Daily Life Convenience, HW =

Health and Well-being, FLF = Family Life Facilitation, PG = Professional Growth, OC = Organizational Culture, PWC = Physical

Working Conditions, SR = Status and Recognition.

Table 10

Study II - Incentive Attractiveness Comparison by Demographics (Binary)

\begin{tabular}{|c|c|c|c|c|c|c|c|c|c|c|c|c|c|c|c|}
\hline & & Mon & Ret & TO & $\mathrm{JC}$ & CPR & GD & PS & DLC & HW & FLF & PG & $\mathrm{OC}$ & PWC & SR \\
\hline Male & $M$ & 4.03 & 4.22 & 3.83 & 4.06 & 3.54 & 3.81 & 3.53 & 3.02 & 3.91 & 3.09 & 4.15 & 3.66 & 3.57 & 3.56 \\
\hline$(n=63)$ & $S D$ & 0.68 & 0.74 & 0.64 & 0.67 & 0.94 & 0.81 & 0.84 & 0.93 & 0.69 & 0.95 & 0.69 & 0.75 & 0.73 & 0.86 \\
\hline Female & $M$ & 3.81 & 4.14 & 3.96 & 4.09 & 3.43 & 4.02 & 3.45 & 3.24 & 3.96 & 3.22 & 4.26 & 3.88 & 3.65 & 3.77 \\
\hline$(n=236)$ & $S D$ & 0.79 & 0.90 & 0.64 & 0.67 & 1.10 & 0.76 & 0.89 & 1.07 & 0.71 & 0.5 & 0.63 & 0.70 & 0.70 & 0.86 \\
\hline$t(d f=297)$ & & $* 1.98$ & 0.67 & 1.34 & 0.36 & 0.76 & 1.96 & 0.63 & 1.46 & 0.49 & 1.01 & 1.20 & $* 2.26$ & 0.83 & 1.76 \\
\hline Gen. Z & $M$ & 3.81 & 4.0 & 3.88 & 4.02 & 3.3 & 4.0 & 3.3 & 3.1 & 3.8 & 3.1 & 4.1 & & 3.65 & 3.74 \\
\hline$(n=175)$ & $S D$ & 0.76 & 0.91 & 0.65 & 0.68 & 1.08 & 0.76 & 0.91 & 0.99 & 0.71 & 0.92 & 0.67 & 0.68 & 0.67 & 0.83 \\
\hline Millennials & $M$ & 3.96 & 4.33 & 4.03 & 4.17 & 3.66 & 4.01 & 3.59 & 3.28 & 4.09 & 3.3 & 4.35 & 3.86 & 3.63 & 3.73 \\
\hline$(n=105)$ & $S D$ & 0.74 & 0.74 & 0.60 & 0.62 & 0.99 & 0.76 & 0.84 & 1.11 & 0.66 & 0.90 & 0.60 & 0.74 & 0.74 & 0.90 \\
\hline$t(d f=278)$ & & 1.66 & $* * 2.85^{1}$ & 1.92 & 1.91 & $* 2.41$ & 0.13 & 1.97 & 0.89 & $* 2.35$ & $* 2.27$ & $* 2.44$ & 0.18 & 0.22 & 0.07 \\
\hline
\end{tabular}


Table 10 (continued)

\begin{tabular}{|c|c|c|c|c|c|c|c|c|c|c|c|c|c|c|c|}
\hline & & Mon & Ret & TO & $\mathrm{JC}$ & $\mathrm{CPR}$ & GD & PS & DLC & $\mathrm{HW}$ & FLF & PG & $\mathrm{OC}$ & PWC & SR \\
\hline Married & $M$ & 3.92 & 4.45 & 4.06 & 4.31 & 3.38 & 3.77 & 3.60 & 3.26 & 4.10 & 3.58 & 4.29 & 3.80 & 3.57 & 3.52 \\
\hline & $S D$ & 0.75 & 0.57 & 0.53 & 0.55 & 1.07 & 0.92 & 0.84 & 1.19 & 0.71 & 0.86 & 0.52 & 0.77 & 0.72 & 0.94 \\
\hline Not Married & $M$ & 3.85 & 4.13 & 3.92 & 4.06 & 3.46 & 4.00 & 3.45 & 3.18 & 3.94 & 3.16 & 4.22 & 3.84 & 3.64 & 3.74 \\
\hline$(n=272)$ & $S D$ & 0.77 & 0.88 & 0.65 & 0.67 & 1.06 & 0.75 & 0.89 & 1.03 & 0.70 & 0.93 & 0.66 & 0.71 & 0.70 & 0.85 \\
\hline$t(d f=298)$ & & 0.46 & $1.90^{2}$ & 1.17 & 1.90 & 0.39 & 1.50 & 0.86 & 0.37 & 1.13 & $* 2.33$ & 0.53 & 0.28 & 0.52 & 1.33 \\
\hline Parent & $M$ & 3.99 & 4.48 & 4.13 & 4.31 & 3.51 & 3.89 & 3.78 & 3.21 & 4.16 & 3.60 & 4.41 & 3.8 & 3.58 & 3.69 \\
\hline$(n=40)$ & $S D$ & 0.86 & 0.70 & 0.58 & 0.65 & 1.03 & 0.74 & 0.82 & 1.06 & 0.60 & 0.86 & 0.57 & 0.77 & 0.69 & 0.92 \\
\hline Not a Parent & $M$ & 3.83 & 4.11 & 3.90 & 4.05 & 3.44 & 3.99 & 3.42 & 3.19 & 3.92 & 3.13 & 4.20 & 3.84 & 3.65 & 3.73 \\
\hline$(n=260$ & $S D$ & 0.76 & 0.88 & 0.65 & 0.66 & 1.07 & 0.78 & 0.88 & 1.05 & 0.72 & 0.93 & 0.65 & 0.70 & 0.71 & 0.85 \\
\hline$t(d f=298)$ & & 1.19 & $* 2.52$ & $* 2.11$ & $* 2.36$ & 0.40 & 0.75 & $* 2.48$ & 0.11 & 1.96 & $* 2.99$ & 1.84 & 0.04 & 0.56 & 0.23 \\
\hline Grad Deg. & $M$ & 3.84 & 4.16 & 3.95 & 4.08 & 3.46 & 4.00 & 3.48 & 3.22 & 3.98 & 3.23 & 4.24 & 3.86 & 3.65 & 3.77 \\
\hline $\begin{array}{l}\text { Wanted } \\
(n=251)\end{array}$ & $S D$ & 0.78 & 0.90 & 0.65 & 0.68 & 1.08 & 0.77 & 0.90 & 1.06 & 0.71 & 0.93 & 0.66 & 0.71 & 0.71 & 0.85 \\
\hline Grad Deg. & $M$ & 3.95 & 4.15 & 3.84 & 4.08 & 3.40 & 3.85 & 3.36 & 3.01 & 3.85 & 3.02 & 4.18 & 3.72 & 3.56 & 3.48 \\
\hline $\begin{array}{l}\text { Not Wanted } \\
(n=49)\end{array}$ & $S D$ & 0.71 & 0.68 & 0.62 & 0.60 & 0.97 & 0.79 & 0.76 & 0.96 & 0.67 & 0.95 & 0.53 & 0.69 & 0.70 & 0.86 \\
\hline$t(d f=298)$ & & 0.98 & 0.08 & 1.03 & 0.05 & 0.34 & 1.22 & 0.91 & 1.31 & 1.16 & 1.47 & ${ }^{3} 0.61$ & 1.25 & 0.84 & $* 2.15$ \\
\hline
\end{tabular}

Note: $*$ indicates $p<.05 ; * *$ indicates $p<.01 .^{1,2,3}$ Levene's Test is significant; when equal variances not assumed: ${ }^{1} t(254.20)=$ $3.00, p<.01 ;{ }^{2} t(41.84)=2.70, p<.05 ;{ }^{3} t(80.57)=0.71, p=.48$. Mon = Monetary, Ret $=$ Retirement, TO = Time Off, JC = Job Characteristics, CPR = Company-Provided Resources, GD = Gifts and Discounts, PS = Personal Services, DLC = Daily Life Convenience, HW = Health and Well-being, FLF = Family Life Facilitation, PG = Professional Growth, OC = Organizational Culture, PWC = Physical Working Conditions, SR = Status and Recognition. 
Potential differences between ethnic groups and income levels were also examined in Study II (Table 11). The ANOVAs on ethnicity revealed that Black participants found Retirement, Personal Services, and Professional Growth incentives to be more desirable than did White participants, whereas Hispanic participants only found Professional Growth incentives to be more desirable than did White participants. No significant differences were observed between income groups.

The final set of analyses for Study II involved regressing the demographics variables and personality facets onto each of the 14 incentive categories. Hierarchical regression was used to determine if personality offered incremental prediction above demographics variables. The results of these regressions, including significant predictors and whether incremental validity was obtained from personality, are summarized in Table 12 (see Appendix F1-F14 for full results of regression). As shown in the table, personality traits were seldom predictive of incentive attractiveness when demographic differences had been accounted for and only offered incremental validity for Professional Growth, Organizational Culture, and Status and Recognition incentives groups. In contrast, one or more demographic variables were predictors in all 14 incentive categories. 
Table 11

Study II - Incentive Attractiveness Comparison by Demographics (Multigroup)

\begin{tabular}{|c|c|c|c|c|c|c|c|c|c|c|c|c|c|c|c|}
\hline Ethnicity & & Mon & Ret & TO & $\mathrm{JC}$ & CPR & GD & PS & DLC & $\mathrm{HW}$ & FLF & PG & $\mathrm{OC}$ & PWC & SR \\
\hline (1) White & $M$ & 3.68 & 3.96 & 3.74 & 4.06 & 3.27 & 3.75 & 3.14 & 3.19 & 3.81 & 3.19 & 3.88 & 3.63 & 3.56 & 3.54 \\
\hline$n=27$ & $S D$ & 0.68 & 0.70 & 0.55 & 0.61 & 0.74 & 0.74 & 0.83 & 0.90 & 0.69 & 0.86 & 0.61 & 0.61 & 0.60 & 0.69 \\
\hline (2) Hispanic & $M$ & 3.87 & 4.15 & 3.94 & 4.10 & 3.46 & 4.00 & 3.46 & 3.19 & 3.96 & 3.16 & 4.26 & 3.86 & 3.65 & 3.76 \\
\hline$n=221$ & $S D$ & 0.79 & 0.92 & 0.66 & 0.68 & 1.10 & 0.79 & 0.90 & 1.07 & 0.72 & 0.96 & 0.66 & 0.72 & 0.71 & 0.86 \\
\hline (3) Black & $M$ & 3.89 & 4.39 & 4.05 & 4.06 & 3.51 & 4.01 & 3.73 & 3.11 & 4.10 & 3.38 & 4.30 & 3.93 & 3.68 & 3.67 \\
\hline$n=42$ & $S D$ & 0.71 & 0.59 & 0.53 & 0.66 & 1.10 & 0.72 & 0.68 & 1.09 & 0.65 & 0.84 & 0.53 & 0.74 & 0.73 & 0.92 \\
\hline \multirow{3}{*}{\multicolumn{2}{|c|}{$\begin{array}{l}{ }^{1} \text { Levene Statistic } \\
{ }^{2} F / \text { Welch } \\
{ }^{3} \text { Tukey HSD/G-H } \\
\text { Differences }\end{array}$}} & 0.39 & $* 3.33$ & 2.01 & 0.33 & $* 3.65$ & 0.40 & $* 3.41$ & 1.15 & 0.40 & 0.88 & 0.77 & 0.80 & .36 & 1.89 \\
\hline & & 0.81 & $* 4.08$ & 1.93 & 0.07 & 0.85 & 1.25 & $* 5.02$ & 0.11 & 1.50 & 0.94 & $* 4.66$ & 1.58 & 0.26 & 0.95 \\
\hline & & - & $1-3$ & - & - & - & - & $1-3$ & - & - & - & $\begin{array}{l}1-2 \\
1-3\end{array}$ & - & - & - \\
\hline \multicolumn{2}{|c|}{ Income } & Mon & Ret & TO & $\mathrm{JC}$ & CPR & GD & PS & DLC & HW & FLF & $\mathrm{PG}$ & $\mathrm{OC}$ & PWC & SR \\
\hline (1) $0-49 \mathrm{k}$ & $M$ & & & 3.91 & .05 & 3.53 & $4 .($ & 3.48 & & & & & & 3.62 & 3.66 \\
\hline$n=136$ & $S D$ & 81 & 0.95 & 0.69 & 0.75 & 1.11 & 0.72 & 0.85 & 1.05 & 0.76 & 0.91 & 0.68 & 0.73 & 0.70 & 0.85 \\
\hline (2) $50-99 \mathrm{k}$ & $M$ & 84 & 4.23 & 3.99 & 4.15 & 3.52 & 4.01 & 3.48 & 3.21 & 4.02 & 3.28 & 4.3 & 3.77 & 3.67 & 3.76 \\
\hline$n=80$ & $S D$ & & & 0.59 & 0.58 & & 0.76 & 0.92 & 1.07 & 0.63 & 0.8 & 0.6 & 0.70 & 0.76 & 0.91 \\
\hline (3) $100-150 \mathrm{k}$ & $M$ & 3.76 & 4.12 & 3.95 & 4.09 & 3.10 & 3.78 & 3.54 & 2.97 & 3.92 & 3.18 & 4.19 & 3.77 & 3.66 & 3.78 \\
\hline$n=22$ & $S D$ & 0.78 & 0.97 & 0.64 & 0.57 & 1.11 & 0.88 & 0.93 & 0.94 & 0.70 & 1.16 & 0.70 & 0.78 & 0.71 & 0.90 \\
\hline (4) $>150 \mathrm{k}$ & $M$ & & & 3.77 & 3.93 & 3.05 & 3.71 & 3.34 & 3.02 & 3.81 & 3.08 & 4.09 & 3.84 & 3.61 & 3.73 \\
\hline$n=15$ & $S D$ & 0.75 & 0.80 & 0.61 & 0.80 & 1.15 & 0.76 & 0.83 & 1.22 & 0.76 & 1.05 & 0.59 & 0.80 & 0.64 & 0.87 \\
\hline \multicolumn{2}{|c|}{${ }^{1}$ Levene Statistic } & 0.27 & 0.89 & 0.52 & 2.56 & 0.40 & 0.76 & 0.70 & 0.54 & 0.64 & 2.2 & 0.86 & 0.17 & 0.34 & 0.46 \\
\hline \multicolumn{2}{|c|}{$F$} & 0.13 & 0.50 & 0.61 & 0.63 & 1.76 & 1.29 & 0.15 & 0.43 & 0.41 & 0.46 & 0.49 & 0.46 & 0.10 & 0.33 \\
\hline
\end{tabular}

Note: * indicates $p<.05 .{ }^{1}$ Levene statistic is calculated based on the median. ${ }^{2,3}$ For variables where Levene's Test is significant;

${ }^{(2)}$ Welch Test is used instead of ANOVA $F$ and ${ }^{(3)}$ Games-Howell used instead of Tukey HSD. Mon = Monetary, Ret $=$ Retirement,

$\mathrm{TO}=$ Time Off, JC = Job Characteristics, $\mathrm{CPR}=$ Company-Provided Resources, GD = Gifts and Discounts, PS $=$ Personal

Services, DLC $=$ Daily Life Convenience, $\mathrm{HW}=$ Health and Well-being, FLF $=$ Family Life Facilitation, $\mathrm{PG}=$ Professional

Growth, $\mathrm{OC}=$ Organizational Culture, PWC $=$ Physical Working Conditions, $\mathrm{SR}=$ Status and Recognition. 
Table 12

Study II - Summary of Demographics and Personality Regressions

\begin{tabular}{|c|c|c|}
\hline Incentive Category & Significant predictors (direction/comp. group) & Inc. Val. \\
\hline Monetary & $\begin{array}{l}\text { Hispanic (vs White), number of jobs held }(+), \\
\text { graduate degree not wanted (vs graduate } \\
\text { degree wanted), mental health }(+)\end{array}$ & No \\
\hline Retirement & Work hours $(+)$ & No \\
\hline Time Off & Hispanic (vs White), children (vs no children) & No \\
\hline Job Characteristics & Children (vs no children) & No \\
\hline $\begin{array}{l}\text { Company-Provided } \\
\text { Resources }\end{array}$ & Number of jobs held $(+)$, mental health $(+)$ & No \\
\hline Gifts and Discounts & $\begin{array}{l}\text { Female (vs male), number of jobs held }(+) \text {, } \\
\text { Orderliness }(+)\end{array}$ & No \\
\hline Personal Services & $\begin{array}{l}\text { Hispanic (vs White), children (vs no children), } \\
\text { number of jobs held }(+)\end{array}$ & No \\
\hline Daily Life Conveniences & $\begin{array}{l}\text { Age (-), female (vs male), number of jobs held } \\
(+) \text {, mental health }(+)\end{array}$ & No \\
\hline Health and Well-being & Children (vs no children) & No \\
\hline Family Life Facilitation & Number of jobs held (+), physical health (-) & No \\
\hline Professional Growth & Hispanic (vs White), Openness (-) & Yes \\
\hline Organizational Culture & $\begin{array}{l}\text { Age (-), female (vs male), Hispanic (vs White), } \\
\text { physical health (-), Orderliness (+), } \\
\text { Assertiveness (+) }\end{array}$ & Yes \\
\hline Physical Work Conditions & Age $(-)$, number of jobs held $(+)$ & No \\
\hline Status and Recognition & $\begin{array}{l}\text { Age }(-) \text {, female (vs male), children (vs no } \\
\text { children), income }(+) \text {, Assertiveness }(+)\end{array}$ & Yes \\
\hline
\end{tabular}

Note: Inc. Val. = whether personality offered incremental validity over demographics.

\section{Study III}

The results of Study III test the psychometric viability of the Preferences for Performance Based Incentives Scale (PPBIS) and provide some evidence toward construct validity. Since the initial part of Study IV proceeds in the same manner as Study III and includes the same variables, the results of the internal scale analysis for Study III includes the results from Study IV as a second sample. The relationships examined for the purpose of construct validation in Study III can also be found in the ensuing sections containing the results for Study IV. 
Internal scale analysis. An internal analysis of the PPBIS provided evidence of adequate psychometric properties (Table 13). Cronbach's $\alpha$ for the scale was .92 (.93 in Study IV), which was not affected by dropping items. The average corrected item-total correlation was .65 , ranging from .33 to $.76\left(M_{\mathrm{CITC}}=.66\right.$, ranging from .34 to $.81 \mathrm{in}$ Study IV). There is some variation in the means across items, which indicates certain incentives may be accepted as more merit-based naturally (e.g., Status and Recognition, Monetary incentives) whereas other incentives are generally desired to be independent of performance in order to allow individuals to maintain a consistent schedule and work environment (e.g., Daily Life Conveniences, Family Life Facilitation, Organizational Culture, and Physical Work Conditions). All items are within acceptable limits for skewness and kurtosis (Field, 2009).

Exploratory factor analysis (EFA) was conducted using Principal Components Analysis extraction. Parallel analysis (Horn, 1965) was used to determine the appropriate number of factors to retain; it suggests that the first two factors have a significantly higher Eigenvalue than what would be obtained from random data. Examination of the scree plot (Figure 3) confirmed the suitability of a two-factor model; the primary and secondary factors account for $50 \%$ and $11 \%$ of the item variance, respectively (Table 14).

The unrotated factor solution (see Table 15) revealed that all but one item (Status/Recognition) loaded very highly on the first factor, and many items had substantial cross-loadings on the second factor. Because simple structure (Thurstone, 1947) was not achieved for the unrotated factors, orthogonal rotation (Varimax) was applied to the model. The resulting two factors identified in the rotated solution (see Table 15 for loadings) are strongly related to the item means: the item loadings on the 
first factor have a correlation of -.92 with their corresponding item means, whereas the loadings on the second factor have a correlation of .70 with the item means. As noted previously, there are clear differences in the item means, hence the items with lower average ratings (items 7-13) load onto the first factor and items with higher average ratings (items 1-6 and 14) load onto the second factor. Accordingly, tentative labels for these two factors might be "Accepted Performance Incentives" and "Unconventional Performance Incentives." Six of the items still had sizable cross-loadings, indicating that simple structure was still not obtained. An oblique rotated factor solution (using Oblimin) was examined next, which produced the same general pattern in factors and item loadings (i.e., ) halved the number of items with cross-loadings and reduced the magnitude of the cross-loadings (compared to the factors with orthogonal rotation).

The factors produced in the oblique rotated solution were strongly correlated (.49); because the factors share nearly $25 \%$ of their variance, it is likely that a higherorder factor exists to explain that shared variance between the items in each factor. An exploratory analysis of such a model was examined using the Schmid-Leiman solution (Schmid \& Leiman, 1957) based on the results from the Oblimin rotation (Table 14). The general factor and primary factors in this solution explain $53 \%$ and $47 \%$ of the extracted item variance, respectively, providing compelling evidence in favor of the existence of such a general factor in addition to the two primary factors.

Confirmatory factor analysis (CFA) was used to compare several possible models for the PPBIS factor structure; these analyses were conducted using the data from Study IV. A unidimensional PPBI model was investigated first, with the 14 items as indicators of a single latent PPBI construct. This model produced a pattern of loadings that was 
highly similar to the first unrotated factor from the EFA on the Study III data (see Figure 4). Model fit was inspected through a number of indices, which generally indicated poor fit (using Hu and Bentler's [1999] suggestions) for the initial model. The $\chi^{2}$ test of model fit was significant: $\chi^{2}(77)=290.64, p<.001$. The Root Mean Square Error of Approximation (RMSEA) of the model was .14; the $p$-value for the test of close fit (PCLOSE) was <.001. The Comparative Fit Index (CFI) was .81. The Standardized Root Mean Square Residual (SRMR) was .08. Upon inspection of the residual covariance matrix, several items had a fairly large residual covariance with each other, indicating that the general PPBI construct was not accounting for a significant portion of the relationships observed between items.

A second model with items loading on two correlated factors was examined next (see Figure 5). Compared to the unidimensional model, the correlated factors model had improved but still poor fit: $\chi^{2}(76)=223.01, p<.001$; RMSEA = .11, PCLOSE < .001; $\mathrm{CFI}=.87 ; \mathrm{SRMR}=.07$. Once again, there were several sizeable residual covariances between items, suggesting that the two factors were still not adequately explaining the item covariances. It is also important to note that the estimated correlation between the two factors in this model was .80 , indicating that they likely stem from a common superordinate factor. Accordingly, the third model investigated a model with two primary factors subsumed under a general PPBI factor (see Figure 6). However, because the upper part of this model is just-identified, there was very little change in model fit: $\chi^{2}$ $(77)=224.09, p<.001 ; \mathrm{RMSEA}=.11, \mathrm{PCLOSE}<.001 ; \mathrm{CFI}=.87 ; \mathrm{SRMR}=.08$.

The fourth and final CFA tested a bifactor model (Figure 7), with each item loading on a general PPBI factor and on one of the two primary factors (API or UPI). 
Although the bifactor model had improved fit compared to previous models, fit was still only mediocre: $\chi^{2}(63)=143.39, p<.001 ;$ RMSEA $=.09$, PCLOSE $<.01 ;$ CFI $=.93$; SRMR $=.05$. Regardless, a bifactor model appears to explain the data the best. Altogether, the results of the EFA and CFA modeling support the existence of a general PPBI factor and two primary factors (API and UPI) related to the item means. 
Table 13

Study III and Study IV-PPBIS Item and Scale Properties

\begin{tabular}{|c|c|c|c|c|c|c|c|c|c|c|c|c|}
\hline \multirow[t]{2}{*}{ Item } & \multicolumn{2}{|c|}{$\underline{\text { Item } M}$} & \multicolumn{2}{|c|}{$\underline{\text { Item } S D}$} & \multicolumn{2}{|c|}{$\begin{array}{c}\text { Item } \\
\text { skewness } \\
\underline{\underline{y}}\end{array}$} & \multicolumn{2}{|c|}{$\begin{array}{c}\text { Item } \\
\text { kurtosis } \\
\end{array}$} & \multicolumn{2}{|c|}{$\underline{\text { CITC }}$} & \multicolumn{2}{|c|}{$\begin{array}{c}\alpha \text { if item } \\
\text { deleted }\end{array}$} \\
\hline & SIII & SIV & SIII & SIV & SIII & SIV & SIII & SIV & SIII & SIV & SIII & SIV \\
\hline 1. Monetary rewards & 3.60 & 3.16 & 1.13 & 1.30 & -0.56 & -0.09 & -0.59 & -1.17 & .56 & .62 & .92 & .92 \\
\hline 2. Retirement benefits & 3.24 & 2.61 & 1.34 & 1.47 & -0.33 & 0.28 & -1.13 & -1.37 & .62 & .70 & .92 & .92 \\
\hline 3. Time off & 3.12 & 2.83 & 1.45 & 1.50 & -0.17 & 0.06 & -1.34 & -1.45 & .69 & .70 & .92 & .92 \\
\hline 4. Job design & 3.33 & 3.01 & 1.24 & 1.42 & -0.43 & -0.06 & -0.80 & -1.30 & .63 & .64 & .92 & .92 \\
\hline 5. Personal resources & 3.09 & 2.83 & 1.35 & 1.48 & -0.19 & 0.08 & -1.16 & -1.38 & .69 & .63 & .92 & .92 \\
\hline 6. Gifts and discounts & 3.35 & 3.18 & 1.29 & 1.45 & -0.36 & -0.21 & -1.04 & -1.32 & .67 & .53 & .92 & .92 \\
\hline 7. Personal services & 2.90 & 2.47 & 1.40 & 1.50 & 0.00 & 0.41 & -1.34 & -1.29 & .73 & .81 & .91 & .92 \\
\hline 8. Daily conveniences & 2.76 & 2.13 & 1.45 & 1.41 & 0.11 & 0.75 & -1.40 & -0.91 & .76 & .68 & .91 & .92 \\
\hline 9. Health \& well-being & 2.82 & 2.27 & 1.51 & 1.48 & 0.06 & 0.57 & -1.49 & -1.24 & .70 & .75 & .92 & .92 \\
\hline 10. Family services & 2.71 & 2.29 & 1.45 & 1.47 & 0.16 & 0.57 & -1.41 & -1.20 & .74 & .79 & .91 & .92 \\
\hline 11. Professional growth & 3.41 & 3.29 & 1.32 & 1.40 & -0.44 & -0.37 & -0.99 & -1.13 & .59 & .59 & .92 & .92 \\
\hline 12. Org. culture & 2.85 & 2.65 & 1.35 & 1.44 & 0.05 & 0.25 & -1.25 & -1.31 & .67 & .69 & .92 & .92 \\
\hline 13. Work conditions & 2.83 & 2.67 & 1.47 & 1.49 & 0.01 & 0.17 & -1.45 & -1.39 & .69 & .71 & .92 & .92 \\
\hline 14. Status/recognition & 3.95 & 3.96 & 1.16 & 1.33 & -0.89 & -1.10 & -0.19 & 0.03 & .33 & .34 & .93 & .93 \\
\hline Overall Scale & 3.14 & 2.85 & 0.96 & 1.02 & 0.04 & 0.36 & -0.62 & -0.63 & .65 & .66 & .92 & .93 \\
\hline
\end{tabular}

Note: $n_{\mathrm{S} 3}=287 ; n_{\mathrm{S} 4}=250$. CITC = corrected item-total correlation; SIII = Study III; SIV = Study IV. 
Figure 3

Study III - Scree Plot

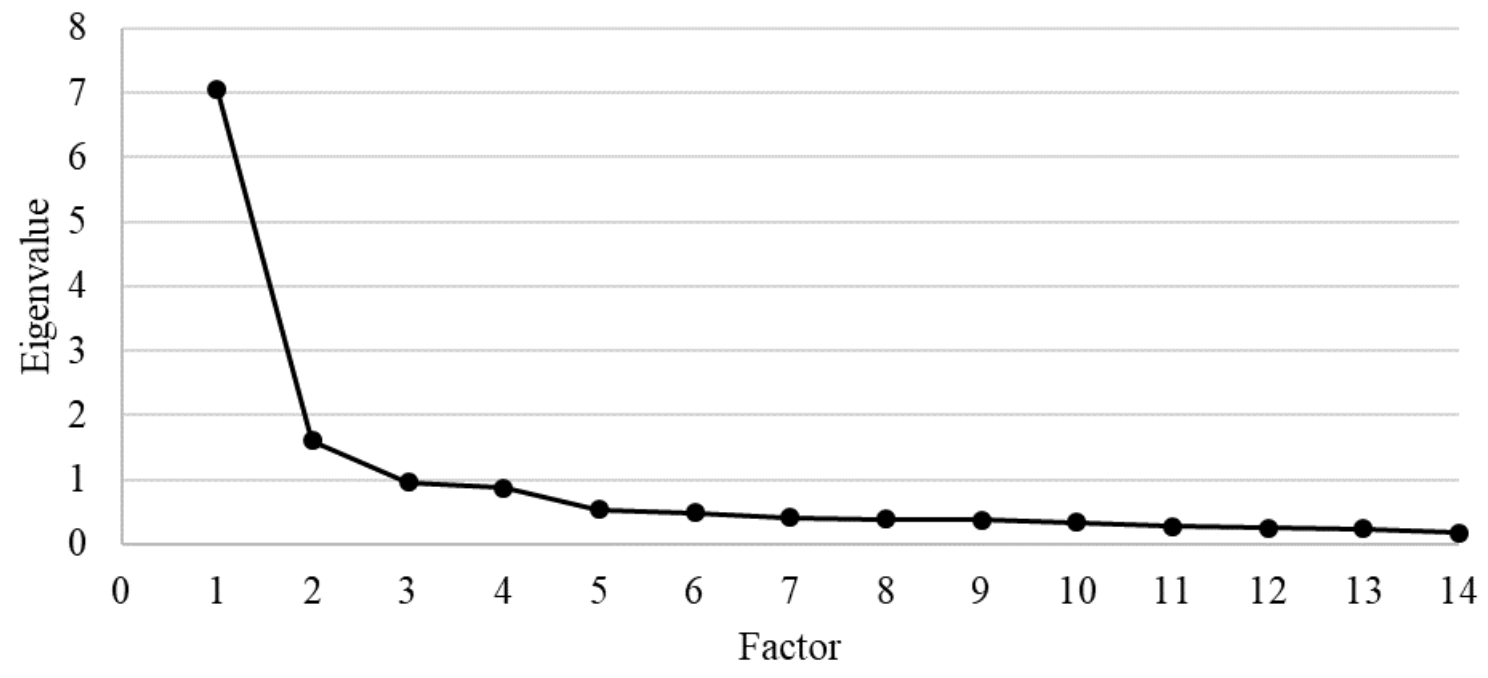

Table 14

Study III - EFA Factors

\begin{tabular}{lcccc}
\hline & \multicolumn{2}{c}{ EFA } & \multicolumn{2}{c}{ Parallel Analysis } \\
\hline Factor & Initial Eigenvalues & \% Variance & Mean & $95 \%$ UB \\
\hline 1 & 7.05 & 50.33 & 1.38 & 1.45 \\
2 & 1.60 & 11.39 & 1.29 & 1.34 \\
3 & 0.96 & 6.85 & 1.22 & 1.27 \\
4 & 0.88 & 6.25 & 1.17 & 1.20 \\
5 & 0.54 & 3.83 & 1.12 & 1.16 \\
6 & 0.49 & 3.52 & 1.06 & 1.10 \\
7 & 0.42 & 3.02 & 1.01 & 1.05 \\
8 & 0.39 & 2.80 & 0.96 & 1.00 \\
9 & 0.38 & 2.72 & 0.92 & 0.95 \\
10 & 0.34 & 2.43 & 0.86 & 0.92 \\
11 & 0.28 & 2.02 & 0.83 & 0.87 \\
12 & 0.26 & 1.87 & 0.78 & 0.82 \\
13 & 0.24 & 1.69 & 0.72 & 0.77 \\
14 & 0.18 & 1.29 & 0.66 & 0.72 \\
\hline
\end{tabular}

Note: Principal Components Analysis extraction used. \% Variance = percent of variance explained by Eigenvalues; $95 \% \mathrm{UB}=95^{\text {th }}$ percentile Eigenvalue from random datasets. 
Table 15

Study III-EFA Item Loadings

\begin{tabular}{|c|c|c|c|c|c|c|c|c|c|c|}
\hline \multirow{3}{*}{ Item } & \multicolumn{10}{|c|}{ EFA (Study III) } \\
\hline & \multirow{2}{*}{ Extraction } & \multicolumn{2}{|c|}{ Unrotated } & \multicolumn{2}{|c|}{ Varimax } & \multicolumn{2}{|c|}{ Oblimin } & \multicolumn{3}{|c|}{ S-L } \\
\hline & & F1 & $\mathrm{F} 2$ & $\mathrm{~F} 1$ & $\mathrm{~F} 2$ & F1 & $\mathrm{F} 2$ & Gen. & $\mathrm{F} 1$ & F2 \\
\hline 1. Monetary rewards & .60 & .62 & .47 & .18 & .76 & -.01 & .78 & .54 & -.01 & .56 \\
\hline 2. Retirement benefits & .56 & .68 & .37 & .29 & .71 & .13 & .70 & .58 & .09 & .50 \\
\hline 3. Time off & .66 & .74 & .34 & .35 & .73 & .19 & .70 & .62 & .14 & .51 \\
\hline 4. Job design & .57 & .68 & .32 & .33 & .68 & .17 & .66 & .58 & .12 & .47 \\
\hline 5. Personal resources & .60 & .75 & .21 & .44 & .63 & .32 & .57 & .62 & .23 & .41 \\
\hline 6. Gifts and discounts & .55 & .72 & .16 & .46 & .58 & .35 & .50 & .60 & .25 & .36 \\
\hline 7. Personal services & .62 & .79 & -.03 & .63 & .47 & .57 & .33 & .63 & .41 & .24 \\
\hline 8. Daily conveniences & .76 & .81 & -.33 & .83 & .26 & .86 & .04 & .62 & .61 & .03 \\
\hline 9. Health \& well-being & .72 & .76 & -.38 & .83 & .19 & .87 & -.04 & .58 & .62 & -.03 \\
\hline 10. Family services & .79 & .79 & -.40 & .87 & .19 & .91 & -.05 & .60 & .65 & -.04 \\
\hline 11. Professional growth & .42 & .64 & -.10 & .56 & .33 & .54 & .19 & .51 & .38 & .14 \\
\hline 12. Org. culture & .62 & .72 & -.31 & .76 & .21 & .79 & .01 & .56 & .56 & .01 \\
\hline 13. Work conditions & .71 & .75 & -.38 & .82 & .18 & .87 & -.05 & .57 & .62 & -.04 \\
\hline 14. Status/recognition & .41 & .37 & .52 & -.04 & .64 & -.22 & .72 & .35 & -.16 & .52 \\
\hline
\end{tabular}

Note: Exploratory Factor Analysis (EFA) used Principal Components Analysis extraction; Confirmatory Factor Analysis (CFA) used Maximum Likelihood estimation with a two-factor solution specified. S-L = Schmid-Leiman solution; F1 = Factor 1; F2 = Factor 2. The correlation between factors in the Oblimin solution was .49. 
Figure 4

Study III - Unidimensional PPBI Model

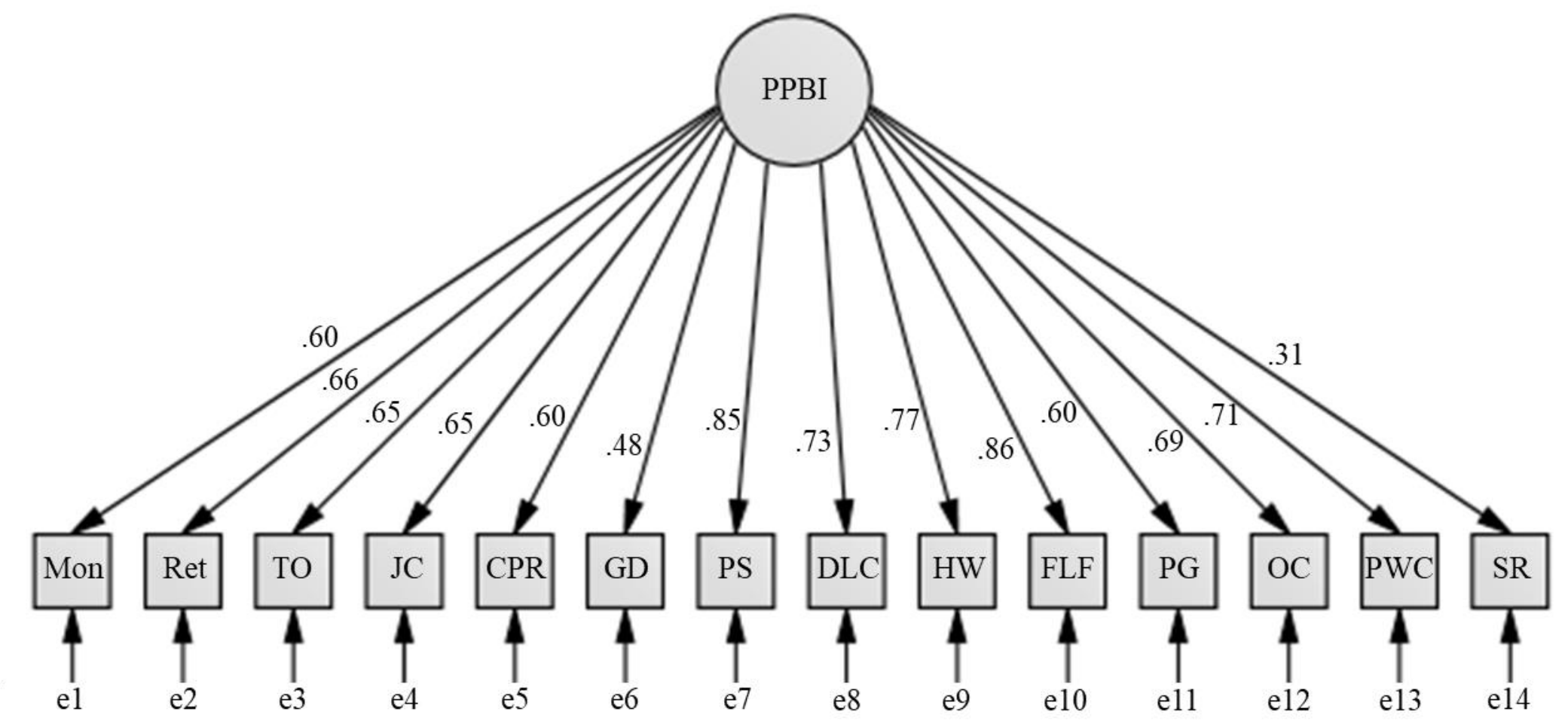

Note: CFA was conducted using data from Study IV. 
Figure 5

Study III - Correlated API and UPI Factors Model

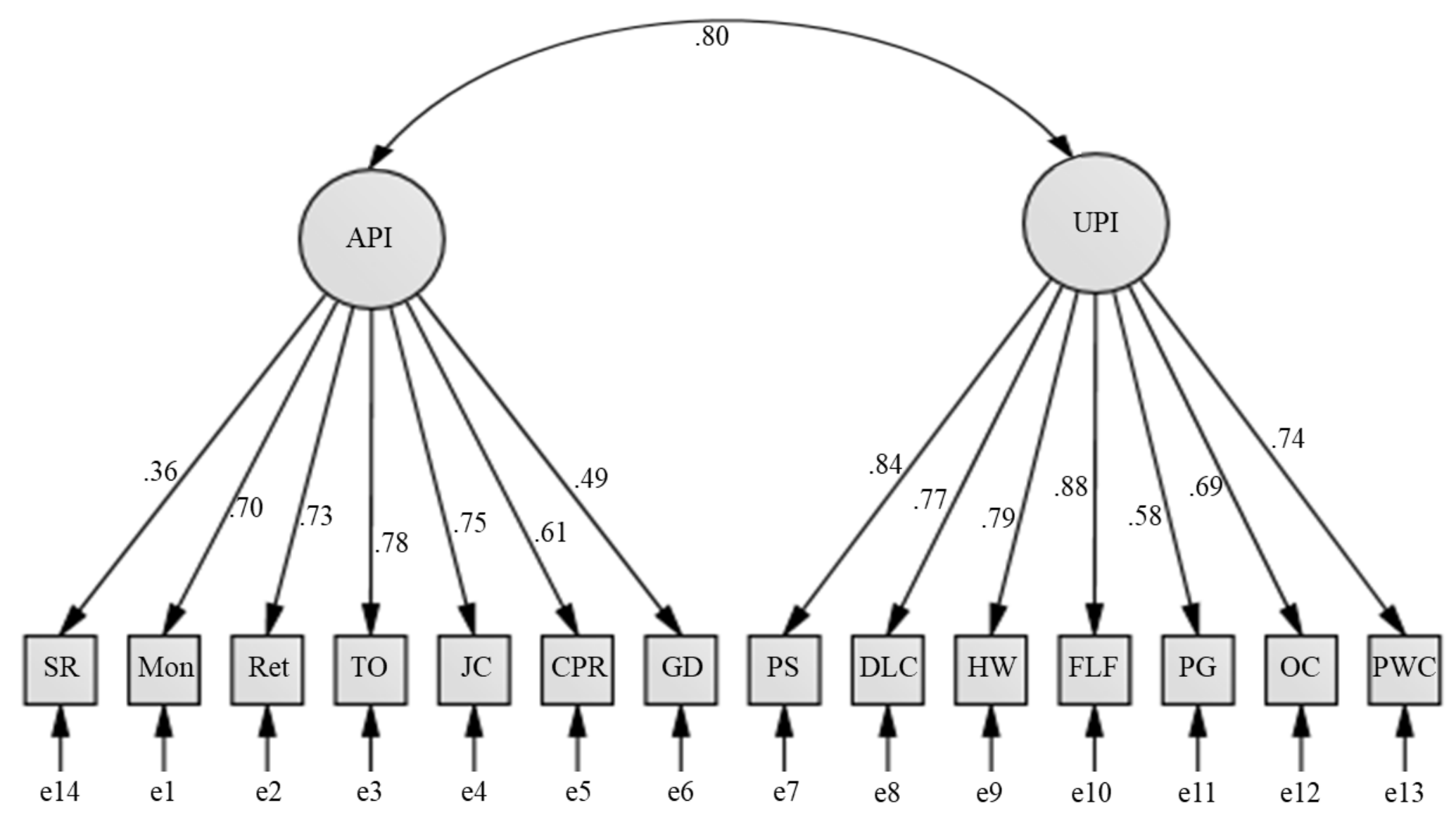

Note: CFA was conducted using data from Study IV. 
Figure 6

Study III - Superordinate PPBI Factor Model

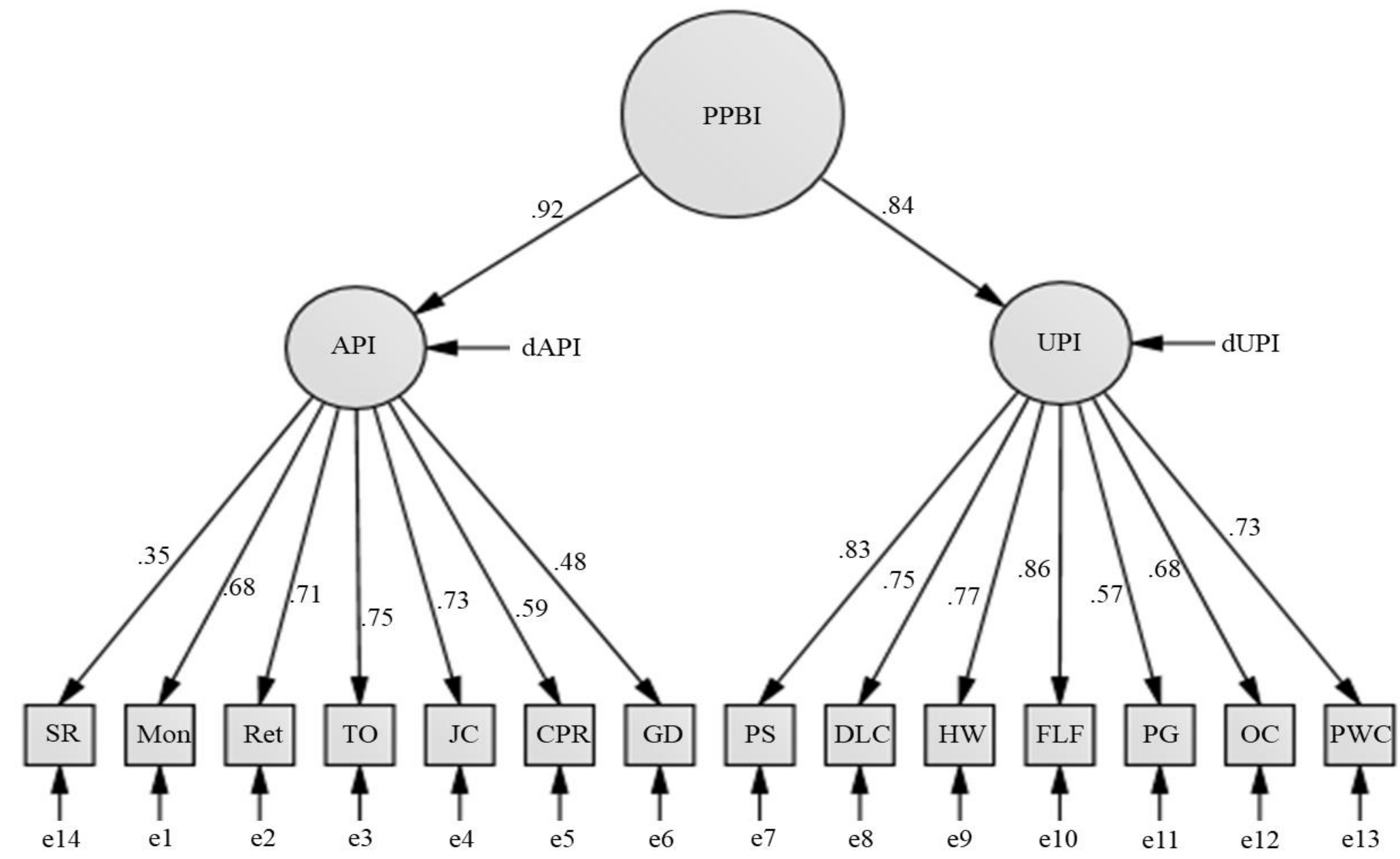

Note: CFA was conducted using data from Study IV. 
Figure 7

Study III - Bifactor PPBI Model

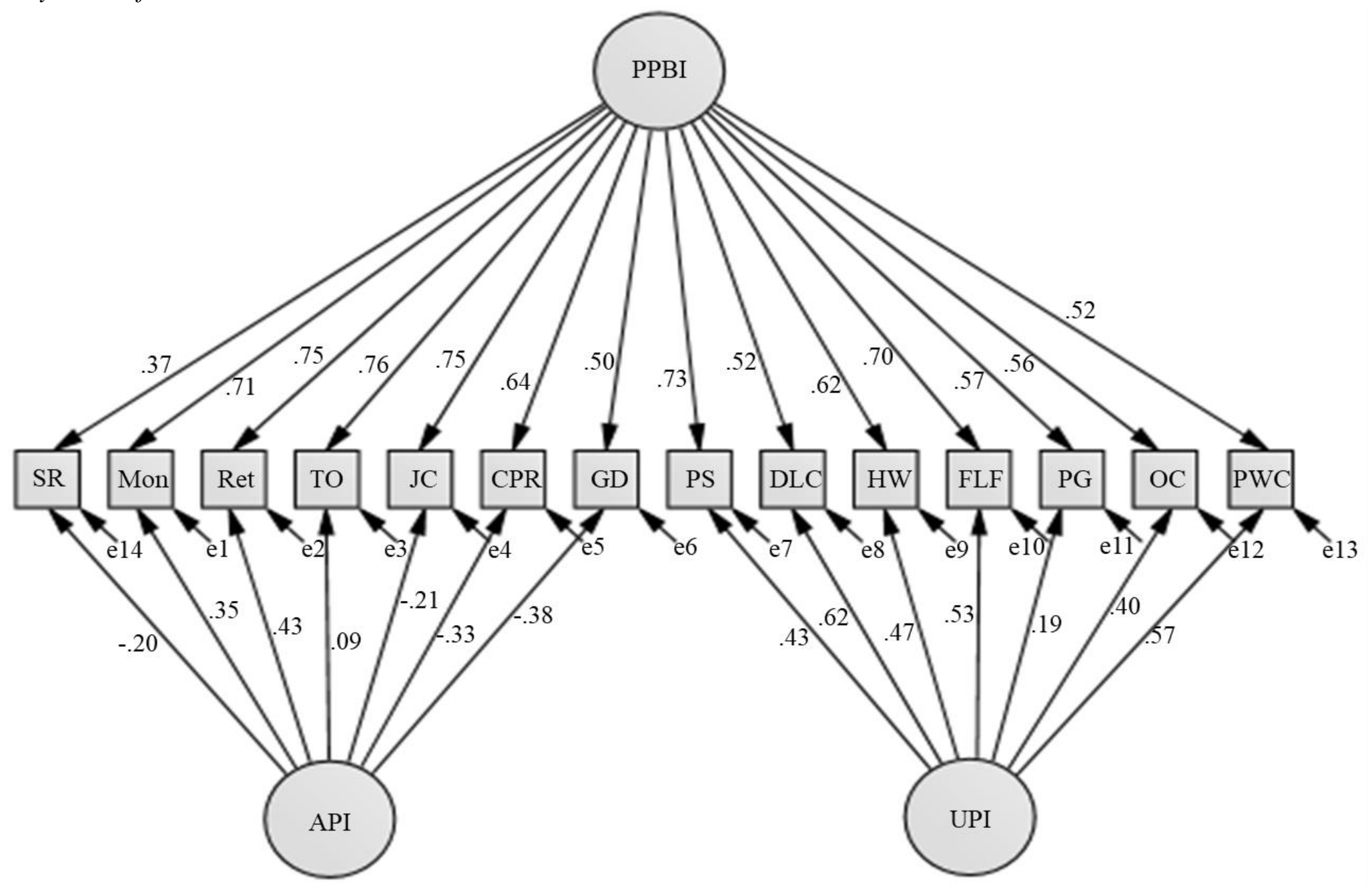

Note: CFA was conducted using data from Study IV. 
Construct validation. Initial evidence towards the construct validity of the PPBIS was obtained by examining the correlations between the PPBIS and the four proposed personality scales, which included self-efficacy (measured via the Generalized Self-Efficacy Scale [GSES]), achievement motivation (measured via the Achievement Motives Scale [AMS]), locus of control (measured via the Locus of Control Scale [LOCS]), and risk-taking (measured via the Financial subscale of the Risk-Taking Scale [RT-S]), in addition to 10 personality facets within the Big Five (see Table 16). In general the personality measures had adequate reliability; the only exceptions were Locus of Control $(\alpha=.63)$ and the Openness $(\alpha=.67)$ and Politeness $(\alpha=.68)$ facets. The PPBIS had small but significant correlations with all four of the proposed scales. These correlations provide support for Hypotheses 1-4 proposed in Chapter II, which predicted a positive relationship between PPBI and self-efficacy, financial risk-taking, an internal locus of control, and need or achievement (note that correlation between the PPBIS and LOCS displayed in Table 16 is negative since the scale is essentially reversed, with a higher score indicating a more external locus of control).

There were also correlations of similar magnitude with 4 of the 10 Big Five facets: Withdrawal, Industriousness, Enthusiasm, and Assertiveness. This pattern of results is in line with the relationships between the four proposed scales and the Big Five identified in past research outlined in Chapter II, which held that these scales in general have some overlap mainly with neuroticism/emotional stability, conscientiousness, and extraversion. Indeed, Table 16 also shows many significant correlations between the Big Five's facets and the four proposed alternate personality constructs, demonstrating that they are to some degree represented within the Big Five. 
Table 16

Study III - Correlations of Study Variables

\begin{tabular}{|c|c|c|c|c|c|c|c|c|c|c|c|c|c|c|c|c|c|}
\hline & $M$ & $S D$ & $\alpha$ & 1 & 2 & 3 & 4 & 5 & 6 & 7 & 8 & 9 & 10 & 11 & 12 & 13 & 14 \\
\hline 1 PPBIS & 3.14 & 0.96 & .92 & & & & & & & & & & & & & & \\
\hline 2 GSES & 3.82 & 0.70 & .77 & $* .13$ & & & & & & & & & & & & & \\
\hline 3 AMS & 3.48 & 0.60 & .76 & $* .15$ & $* .18$ & & & & & & & & & & & & \\
\hline 4 LOCS & 10.97 & 3.46 & .63 & $*-.20$ & $*_{-} .29$ & $*_{-} .16$ & & & & & & & & & & & \\
\hline 5 RT-F & 2.77 & 1.25 & .79 & $* .20$ & -.10 & -.11 & $*_{-.13}$ & & & & & & & & & & \\
\hline $6 \mathrm{NVol}$ & 2.67 & 0.82 & .87 & -.10 & $*-.28$ & $*_{-} .19$ & $* .16$ & .00 & & & & & & & & & \\
\hline 7 NWth & 2.89 & 0.67 & .77 & $*_{-.} 13$ & $*_{-} .35$ & $*_{-} .16$ & $* .20$ & $*_{-.} .15$ & $* .58$ & & & & & & & & \\
\hline $8 \mathrm{ACom}$ & 4.02 & 0.63 & .84 & -.02 & $* .20$ & $* .20$ & .01 & $*_{-} .29$ & $*_{-.13}$ & .09 & & & & & & & \\
\hline 9 APol & 3.89 & 0.55 & .68 & -.06 & .10 & .09 & .02 & $*_{-} .36$ & $*_{-} .30$ & .01 & $* .48$ & & & & & & \\
\hline 10 CInd & 3.54 & 0.69 & .81 & $* .14$ & $* .47$ & $* .23$ & $*_{-.26}$ & -.11 & $*_{-.42}$ & $*_{-} .55$ & .09 & $* .23$ & & & & & \\
\hline $11 \mathrm{COrd}$ & 3.78 & 0.57 & .73 & .03 & $* .20$ & $* .16$ & -.08 & -.11 & -.06 & -.05 & $* .19$ & $* .21$ & $* .46$ & & & & \\
\hline 12 EEnt & 3.65 & 0.62 & .77 & $* .15$ & $* .23$ & $* .16$ & $*_{-.18}$ & -.06 & $*_{-} .23$ & $*_{-} .33$ & $* .43$ & $* .17$ & *.34 & .05 & & & \\
\hline 13 EAst & 3.59 & 0.63 & .80 & $* .12$ & $* .47$ & .06 & $*_{-} .27$ & .06 & $*_{-.15}$ & $*_{-.47}$ & .07 & $*_{-} .14$ & *.47 & *.17 & $* .35$ & & \\
\hline 14 OInt & 3.72 & 0.59 & .78 & .05 & $* .51$ & $* .26$ & $*_{-} .27$ & -.05 & $*_{-} .23$ & $*_{-} .35$ & $* .27$ & $* .12$ & *.48 & $* .35$ & *.30 & $* .51$ & \\
\hline 15 OOpn & 3.73 & 0.54 & .67 & -.09 & $* .18$ & $* .14$ & $*_{-.16}$ & $*_{-.} .18$ & -.06 & $* .15$ & $* .42$ & $* .24$ & -.06 & .08 & .11 & .02 & *.34 \\
\hline
\end{tabular}

Note: $N=300 . *$ for correlations over $.11, p<.05$; for correlations over $.15, p<.01$; for correlations over $.20, p<.001 . \mathrm{PPBI}=$

Preference for Performance-Based Incentives Scale; GSE = Generalized Self-Efficacy Scale; AMS = Achievement Motives Scale; LOCS = Locus of Control Scale; RT-F = Risk-Taking: Financial subscale of Domain Specific Risk-Taking scale; NVol = Volatility; NWth = Withdrawal; ACom = Compassion; APol = Politeness; CInd = Industriousness; COrd = Orderliness; EEnt = Enthusiasm; EAst $=$ Assertiveness; OInt $=$ Intellect; OOpn $=$ Openness. 
A second line of evidence toward the construct validity of the PPBIS was obtained via hierarchical regression. The GSES, AMS, LOCS, and RT-F combined explained a small but significant amount $(10 \%)$ of the variance in the PPBIS. Including the 10 personality facets in the model provided an increase in variance explained of only $3 \%$, which was a non-significant change. A similar pattern of results (not presented) was found when this analysis was replicated on the sample from Study IV: the four initial scales explained $15 \%$ of the variance in the PPBIS and adding personality facets offered an additional $6 \%$ variance explained (21\% variance explained overall).

\section{Study IV}

Descriptive statistics and correlations among study variables are presented in Table 17. These are also displayed disaggregated by study condition (Non-PerformanceBased Incentives [NPBI] and Only Performance-Based Incentives [OPBI]) in Table 18. There was a difference observed between these groups for locus of control (participants in the OPBI group had a more external locus of control on average) and performance on the task (participants in the OPBI group scored higher on the task).

The goal of Study IV was to determine if the scale could be used to predict applicant or employee motivation - specifically, motivation to begin working for a company or to perform well for a company_-based on the alignment of an individual's incentive administration preferences with an organization's incentive structure. Statistically, this can be determined by (1) examining the effect of the interaction between PPBI and study condition on organizational attractiveness (OA) and performance or (2) conduct a multigroup path analysis in SEM to test for differences in the relationship between PPBI and OA/performance between study conditions. 
Table 17

Study IV-Descriptive Statistics and Correlations between Study Variables (Whole Sample)

\begin{tabular}{|c|c|c|c|c|c|c|c|c|c|c|c|}
\hline & $n$ & $M$ & $S D$ & $\alpha$ & 1 & 2 & 3 & 4 & 5 & 6 & 7 \\
\hline 1 PPBIS & 270 & 2.85 & 1.02 & .93 & & & & & & & \\
\hline 2 GSES & 266 & 3.86 & 0.61 & .86 & .06 & & & & & & \\
\hline 3 AMS & 266 & 3.36 & 0.54 & .72 & $* * .15$ & $* * * .60$ & & & & & \\
\hline 4 LOCS & 243 & 11.48 & 3.34 & .56 & -.03 & $* * *-.22$ & $* * *-.27$ & & & & \\
\hline 5 RT-F & 266 & 2.64 & 1.20 & .77 & $* * * .28$ & -.08 & .02 & -.08 & & & \\
\hline $6 \mathrm{OA}$ & 165 & 3.25 & 0.92 & .95 & *.16 & -.07 & .00 & .06 & .09 & & \\
\hline 7 Score & 165 & 8.62 & 3.09 & -- & .04 & $* .17$ & $* * .22$ & .03 & -.15 & -.03 & \\
\hline 8 NVol & 269 & 2.54 & 0.83 & .88 & .09 & $* * *-.36$ & $* * *-.39$ & $* * * .21$ & .05 & -.02 & -.12 \\
\hline $9 \mathrm{NW}$ th & 269 & 2.77 & 0.66 & .77 & -.02 & $* * *-.43$ & $* * *-.52$ & $* * * .31$ & .00 & .00 & -.06 \\
\hline 10 ACom & 269 & 3.97 & 0.66 & .85 & -.09 & $* * * .36$ & $* * * .27$ & -.11 & $* * *-.30$ & -.11 & .13 \\
\hline 11 APol & 269 & 3.85 & 0.57 & .67 & -.10 & $* * .16$ & .09 & -.01 & $* * *-.28$ & -.08 & $* .18$ \\
\hline 12 CInd & 269 & 3.76 & 0.66 & .81 & .02 & $* * * .67$ & $* * * .48$ & $* * *-.21$ & -.1 & -.02 & $* .16$ \\
\hline 13 COrd & 269 & 3.79 & 0.58 & .73 & .02 & $* * * .46$ & $* * * .27$ & $*_{-.12}$ & $* * *-.29$ & -.02 & $* .18$ \\
\hline 14 EEnt & 269 & 3.69 & 0.61 & .77 & .11 & $* * * .32$ & $* * * .37$ & $* * *-.21$ & $*_{-.12}$ & .00 & $* * .24$ \\
\hline 15 EAst & 269 & 3.67 & 0.63 & .80 & .02 & $* * * .53$ & $* * * .45$ & $* * *-.25$ & -.03 & -.10 & $* .19$ \\
\hline 16 OInt & 269 & 3.80 & 0.62 & .80 & -.02 & $* * * .51$ & $* * * .48$ & -.11 & -.07 & -.09 & $* * .25$ \\
\hline 17 OOpn & 269 & 3.73 & 0.56 & .69 & $* *-.16$ & $* * * .25$ & $* * .18$ & -.11 & $* *_{-} .16$ & -.09 & $* .16$ \\
\hline
\end{tabular}

Note: $* p<.05 ; * * p<.01 ; * * * p<.001$. PPBI = Preference for Performance-Based Incentives Scale; GSE = Generalized Self-

Efficacy Scale; AMS = Achievement Motives Scale; LOCS = Locus of Control Scale; RT-F = Risk-Taking: Financial subscale of Domain Specific Risk-Taking scale; OA = Organizational Attraction; Score = score on performance task; NVol = Volatility;

NWth = Withdrawal; ACom = Compassion; APol = Politeness $;$ CInd = Industriousness COrd = Orderliness EEnt = Enthisiasm;

EAst $=$ Assertiveness $;$ OInt $=$ Intellect $;$ OOpn $=$ Openness. 
Table 18

Study IV - Correlations between Study Variables (Disaggregated by Study Condition)

\begin{tabular}{|c|c|c|c|c|c|c|c|c|c|c|c|c|c|c|c|c|c|}
\hline & 1 & 2 & 3 & 4 & 5 & 6 & 7 & 8 & 9 & 10 & 11 & 12 & 13 & 14 & 15 & 16 & 17 \\
\hline 1 PPBIS & & .19 & .15 & .04 & $* .31$ & $* .25$ & .10 & .10 & .00 & -.15 & $*_{-.22}$ & .03 & .09 & .06 & .12 & .15 & -.09 \\
\hline 2 GSES & .04 & & $* .53$ & -.09 & .17 & .05 & .09 & $*_{-} .38$ & $*-.47$ & $* .23$ & .20 & $* .60$ & $* .27$ & $* .30$ & $* .50$ & $* .49$ & $* .22$ \\
\hline 3 AMS & .19 & $* .58$ & & -.21 & .08 & $* .23$ & .15 & $*-.42$ & $*-.47$ & $* .24$ & .07 & $* .41$ & $* .25$ & $* .29$ & $* .42$ & $* .47$ & .15 \\
\hline 4 LOCS & -.14 & $*-.22$ & $*_{-} .29$ & & -.15 & -.04 & .13 & $* .22$ & $* .27$ & .03 & -.08 & -.08 & .16 & -.15 & -.13 & -.06 & -.19 \\
\hline $5 \mathrm{RT}-\mathrm{F}$ & $* .35$ & -.07 & .14 & .03 & & .19 & -.07 & .02 & -.02 & -.20 & -.20 & -.02 & $*-.30$ & -.02 & .13 & .02 & -.08 \\
\hline $6 \mathrm{OA}$ & .07 & -.19 & -.18 & .11 & -.02 & & .09 & -.06 & -.07 & -.12 & -.18 & .02 & -.01 & -.01 & -.06 & -.06 & -.08 \\
\hline 7 Score & -.05 & $* .25$ & $* .27$ & -.12 & $*-.24$ & -.20 & & -.02 & .01 & .14 & .17 & .05 & $* .28$ & $* .28$ & .05 & .13 & .02 \\
\hline $8 \mathrm{NVol}$ & .00 & $*_{-} .37$ & $*-.38$ & $* .25$ & .03 & .04 & -.20 & & $* .56$ & $*_{-.25}$ & $*_{-.} .35$ & $*-.53$ & -.04 & $*_{-.} .24$ & -.20 & $*_{-} .25$ & -.19 \\
\hline 9 NWth & -.13 & $*-.38$ & $*-.52$ & *.36 & -.08 & .06 & -.15 & $* .69$ & & -.04 & $*_{-} .29$ & $*_{-.} .63$ & -.21 & -.15 & $*-.33$ & -.20 & .00 \\
\hline 10 ACom & -.04 & $* .38$ & $* .28$ & -.17 & $*_{-} .29$ & -.10 & .13 & -.05 & .03 & & $* .58$ & .15 & $* .29$ & $* .30$ & $* .25$ & $* .35$ & $* .49$ \\
\hline 11 APol & -.05 & .15 & .07 & -.04 & $*_{-} .40$ & .01 & .15 & $*-.39$ & -.16 & $* .32$ & & $* .30$ & $* .22$ & $* .34$ & .09 & .16 & $* .28$ \\
\hline 12 CInd & .07 & $* .61$ & $* .46$ & $*_{-.} .26$ & -.11 & -.04 & $* .32$ & $*-.55$ & $*-.58$ & $* .31$ & $* .28$ & & $* .33$ & .14 & $* .45$ & $* .33$ & .01 \\
\hline 13 COrd & .06 & $* .42$ & .18 & -.22 & -.15 & -.04 & .07 & $*_{-} .28$ & $*-.25$ & $* .32$ & $* .23$ & $* .60$ & & $* .26$ & $* .27$ & $* .35$ & $* .22$ \\
\hline 14 EEnt & .20 & $* .24$ & $* .42$ & $*-.26$ & -.09 & -.01 & .18 & -.17 & $*_{-.38}$ & $* .37$ & $* .24$ & $* .31$ & .20 & & $* .42$ & $* .51$ & $* .45$ \\
\hline 15 EAst & .05 & $* .39$ & $* .39$ & -.20 & -.08 & -.12 & $* .40$ & -.05 & $*_{-} .27$ & $* .45$ & .01 & *.39 & $* .27$ & $* .54$ & & $* .61$ & $* .32$ \\
\hline 16 OInt & -.05 & $* .47$ & $* .49$ & -.08 & .02 & -.11 & $* .40$ & $*_{-} .28$ & $*_{-.41}$ & $* .38$ & .09 & $* .52$ & $* .26$ & $* .31$ & $* .53$ & & $* .51$ \\
\hline 17 OOpn & -.04 & $* .36$ & $* .23$ & -.21 & -.17 & -.13 & $* .31$ & -.09 & .02 & $* .43$ & .20 & $* .26$ & $* .27$ & $* .23$ & $* .48$ & $* .42$ & \\
\hline$M_{\mathrm{NPBI}}$ & & 3.92 & 3.36 & 0.58 & 2.66 & 3.16 & 8.09 & 2.57 & 2.72 & 4.00 & 3.81 & 3.82 & 3.79 & 3.65 & 3.78 & 3.87 & 3.69 \\
\hline$M_{\mathrm{OPBI}}$ & & 3.89 & 3.42 & 11.76 & 2.61 & 3.34 & 14 & 2.46 & 2.80 & 3.9 & 3.94 & 3.74 & 3.76 & 3.75 & 3.65 & 3.80 & 3.78 \\
\hline$S D_{\mathrm{NPBI}}$ & & 0.59 & 0.66 & 3.65 & 1.17 & 0.92 & 2.9 & 0.88 & 0.68 & 0.63 & 0.55 & 0.60 & 0.55 & 0.60 & 0.58 & 0.60 & 0.50 \\
\hline$S D_{\text {OРВі }}$ & & .57 & 0.46 & 3.00 & 1.26 & 0.93 & 3.14 & 0.83 & 0.60 & 0.66 & 0.58 & 0.64 & 0.59 & 0.59 & 0.62 & 0.60 & 0.59 \\
\hline$t(162)$ & 0.48 & 0.32 & 0.63 & $* 2.26$ & 0.29 & 1.21 & $* 2.21$ & 0.84 & 0.74 & 0.22 & 1.46 & 0.91 & 0.34 & 0.97 & 1.41 & 0.75 & 1.08 \\
\hline
\end{tabular}

Note: Correlations for participants in the NPBI (Non-Performance-Based Incentives) condition are below the diagonal;

correlations for participants in the OPBI (Only Performance-Based Incentives) condition are above the diagonal. $N_{\mathrm{NPBI}}=80 ; n_{\mathrm{OPBI}}$ $=84{ }^{*}$ Correlations over .22 (and $t$-values over 1.97) are significant at $p<.05$; correlations over .28 are significant at $p<.01$; correlations over .37 are significant at $p<.001$. PPBI $=$ Preference for Performance-Based Incentives Scale; GSE $=$ Generalized Self-Efficacy Scale; AMS = Achievement Motives Scale; LOCS = Locus of Control Scale; RT-F = Risk-Taking: Financial subscale of Domain Specific Risk-Taking scale; OA = Organizational Attraction; Score = score on performance task. 
The first option (examining the effect of the interaction between PPBI and study condition on $\mathrm{OA}$ and performance) was tested using two hierarchical regressions with PPBIS, condition, and their interaction predicting the two outcome variables (see Tables 19A and 19B). There was a significant main effect of condition (but not PPBI) on OA, such that participants in the OPBI condition had significantly higher OA. However, the interaction between PPBIS and condition was not significant and produced a nonsignificant change in the $F$ for the model. A significant main effect was also observed for PPBIS (but not condition) on performance, though the interaction between PPBIS and condition was still not significant and produced a non-significant change in the $F$ for this model as well. Moreover, these variables predicted a small, non-significant amount of the variance (4\%) in both OA and performance. Therefore, Hypotheses 5 and 6 (which propose that incentive type offered [PBI vs NPBI, or condition in this study] moderates the PPBIS-OA and PPBIS-performance relationships) are unsupported.

Table 19A

Study IV - Hierarchical Regression of Organizational Attractiveness on PPBIS, Condition, and Interaction

\begin{tabular}{lcrrrrrrr}
\hline & $B$ & $S E$ & $\beta$ & \multicolumn{1}{c}{$t$} & \multicolumn{1}{c}{$B$} & $S E$ & $\beta$ & \multicolumn{1}{c}{$t$} \\
\hline Constant & 3.02 & 0.23 & & $* * * 13.35$ & 3.01 & 0.23 & & $* * 13.28$ \\
PPBIS & 0.16 & 0.14 & .09 & 1.10 & 0.16 & 0.14 & .09 & 1.15 \\
Condition & 0.15 & 0.07 & .16 & $* 2.09$ & -0.09 & 0.24 & -.10 & -0.40 \\
PPBISxCondition & & & & & 0.16 & 0.15 & .27 & 1.09 \\
\hline$\Delta F$ & & 2.88 & & & & 1.20 & \\
$d f$ & & 2,162 & & & 1,161 & \\
$p$ & & .06 & & & .28 & \\
$R$ & & .19 & & & .20 & \\
$R^{2}$ & & .03 & & & & .04 & \\
Adjusted $R^{2}$ & & .02 & & & & .02 & \\
$\Delta R^{2}$ & & .03 & & & & .01 & \\
\hline
\end{tabular}

Note: * indicates $p<.05$; ** indicates $p<.001$. "Condition" variable is coded as $1=$ NPBI condition, 2 = PBI condition. 
Table 19B

Study IV - Regression of Performance on PPBIS, Condition, and Interaction

\begin{tabular}{|c|c|c|c|c|c|c|c|c|}
\hline & $B$ & $S E$ & $\beta$ & $t$ & $B$ & $S E$ & $\beta$ & $t$ \\
\hline Constant & 7.05 & 0.76 & & $* * 9.29$ & 7.01 & 0.76 & & $* * 9.23$ \\
\hline PPBIS & 1.05 & 0.48 & .17 & $* 2.20$ & 1.07 & 0.48 & .17 & $* 2.24$ \\
\hline Condition & 0.11 & 0.24 & .03 & 0.44 & -0.61 & 0.79 & -.20 & -0.78 \\
\hline PPBISxCondition & & & & & 0.47 & 0.49 & .24 & 0.96 \\
\hline$\Delta F$ & \multicolumn{4}{|c|}{2.56} & \multicolumn{4}{|c|}{0.92} \\
\hline$d f$ & \multicolumn{4}{|c|}{2,162} & \multicolumn{4}{|c|}{1,161} \\
\hline$p$ & \multicolumn{4}{|c|}{.08} & \multicolumn{4}{|c|}{.34} \\
\hline$R$ & \multicolumn{4}{|c|}{.18} & \multicolumn{4}{|c|}{.19} \\
\hline$R^{2}$ & \multicolumn{4}{|c|}{.03} & \multicolumn{4}{|c|}{.04} \\
\hline Adjusted $R^{2}$ & \multicolumn{4}{|c|}{.02} & \multicolumn{4}{|c|}{.02} \\
\hline$\Delta R^{2}$ & \multicolumn{4}{|c|}{.03} & \multicolumn{4}{|c|}{.01} \\
\hline
\end{tabular}

Note: * indicates $p<.05 ; * *$ indicates $p<.001$. "Condition" variable is coded as $1=$ NPBI condition, 2 = PBI condition.

Structural equation modeling (SEM) was used to test the second option. In multigroup path analysis, a set of nested models are compared using a $\chi^{2}$ difference test to determine if the two models are invariant. The base model includes self-efficacy, achievement motivation, locus of control, and risk-taking as predictors of PPBI, and PPBI as predictors of OA and performance. Single indicators were used for the latent constructs (the personality variables and PPBI) with scale means as predictors, error variance imputed as scale variance*(1- $\alpha)$, and the loading fixed as the scale reliability $(\alpha)$. This model had acceptable fit to the data: $\chi^{2}(18)=29.75, p=.04$; RMSEA $=.06$, PCLOSE $=.26 ; \mathrm{CFI}=.89 ; \mathrm{SRMR}=.11 ;$ Akaike's Information Criteria $(\mathrm{AIC})=105.75$. See Figure 5 for the model estimates. 
Figure 8

Study IV-Standardized Estimates for Base Model in Multigroup Path Analysis

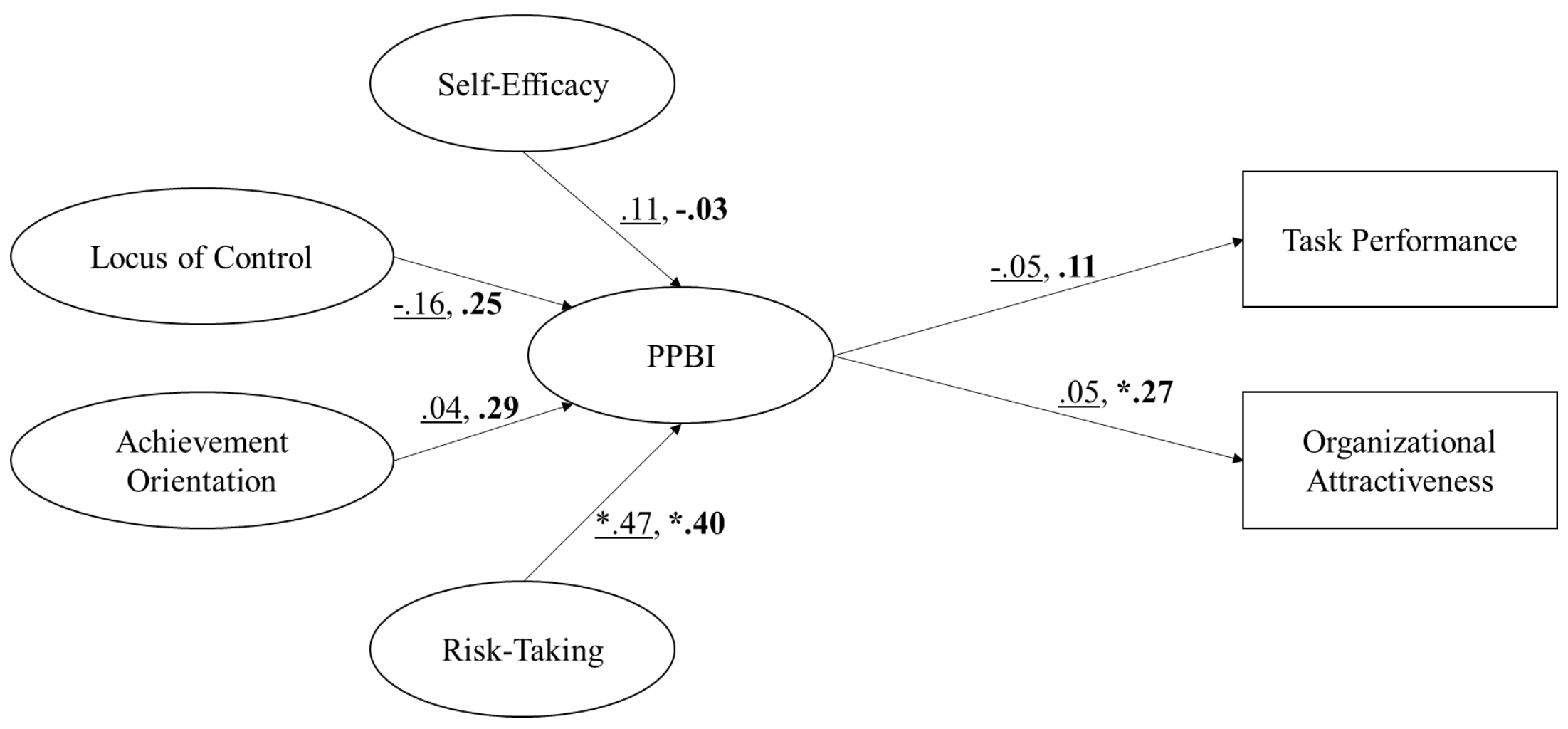

Note: underlined estimates represent those from the NPBI condition; estimates in bold represent those from the OPBI condition.

$*$ indicates $p<.05$ 
Figure 9

Study IV-Standardized Estimates for Constrained Model

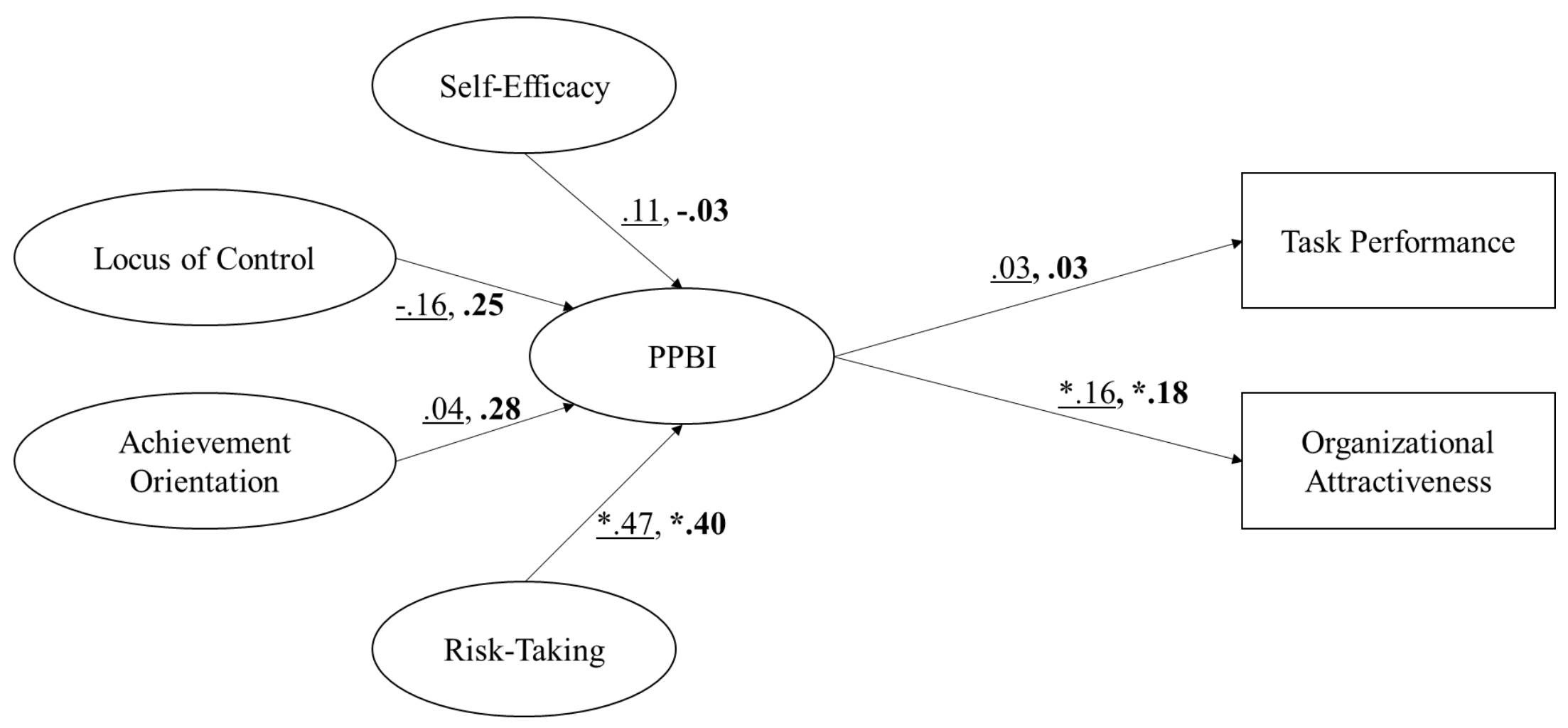

Note: Underlined estimates represent those from the NPBI condition; estimates in bold represent those from the OPBI condition.

$*$ indicates $p<.05$ 
The base SEM model was then compared to an alternate model that fixed the unstandardized PPBI-OA and PPBI-performance paths across conditions (see Figure 6 for the resulting standardized model estimates; note that although the unstandardized paths were fixed to be equal the standardized paths may still vary slightly). This model fit the data slightly worse than the base model: $\chi^{2}(20)=32.20, p=.04$; RMSEA $=.06$, $\mathrm{PCLOSE}=.29 ; \mathrm{CFI}=.88 ; \mathrm{SRMR}=.12 ; \mathrm{AIC}=104.20 . \mathrm{A} \chi^{2}$ difference test between the base model and equal-paths model showed that the two models were invariant: $\Delta \chi^{2}(2)=$ 1.52, $p=.47$. In fact, comparison of the models' AIC indicates that the equal-paths model is marginally preferable even. As such, the simpler constrained model is the preferable model.

Although both the regression and SEM results failed to confirm an interaction between PPBI and condition, examination of the effects reveals a more complex potential interpretation. In the multiple regression analysis, the standardized regression weights of the interaction term were .30 and .23 for OA and performance, respectively, which appear to be substantial (though the semi-partial correlations of the interaction term with OA and performance are .07 and .05 , respectively, indicating a weak effect). In the multigroup path analysis, there was a noticeable difference across conditions in the standardized regression weights between PPBI and OA or performance: $\beta_{\text {PPBI-OA }}=.05$ $(\mathrm{NPBI})$ vs $.27(\mathrm{OPBI})$ and $\beta_{\mathrm{PPBI}}$-performance $=-.05(\mathrm{NPBI})$ vs $.11(\mathrm{OPBI})$. Moreover, the PPBI-OA relationship was significant for the OPBI group but not for the NPBI group. The pattern becomes even more apparent when grouping participants into high vs low PPBI and comparing OA and performance between these two groups within each study condition (see Table 20). A cursory examination of the means of four groups 
reveals that high PPBI individuals in the OPBI condition (i.e., strong alignment between incentive preferences and organization incentive administration) appeared to be more attracted to their organization than any other group; there was a significant difference in OA between high and low PPBI individuals in the OPBI condition $(t[71]=2.04, p<.05)$. These individuals (high PPBI in the OPBI condition) also had the best task performance out of the four groups; though the within-condition differences were not significant, the between-condition differences were significant (refer to Table 18).

Table 20

Study IV - Effect of PBI Offered by PPBI on OA and Task Performance

\begin{tabular}{|c|c|c|c|c|c|c|c|c|}
\hline \multirow{8}{*}{ Organizational Attractiveness } & \multirow{5}{*}{$\underline{\mathrm{PPBI}}$} & & \multicolumn{6}{|c|}{ PBI offered } \\
\hline & & & \multicolumn{3}{|c|}{ Yes } & \multicolumn{3}{|c|}{ No } \\
\hline & & & $M$ & $S D$ & $n$ & $M$ & $S D$ & $n$ \\
\hline & & High & 3.61 & 0.94 & 27 & 3.17 & 1.10 & 27 \\
\hline & & Low & 3.15 & 0.92 & 46 & 3.12 & 0.84 & 45 \\
\hline & & $t$ & \multicolumn{3}{|c|}{2.04} & \multicolumn{2}{|c|}{0.19} & \\
\hline & & $d f$ & \multicolumn{3}{|c|}{71} & \multicolumn{2}{|c|}{70} & \\
\hline & & $p$ & \multicolumn{3}{|c|}{.04} & \multicolumn{2}{|c|}{.85} & \\
\hline \multirow{8}{*}{ Task Performance } & \multirow{8}{*}{$\underline{\mathrm{PPBI}}$} & & \multicolumn{6}{|c|}{ PBI offered } \\
\hline & & & \multicolumn{3}{|c|}{ Yes } & \multicolumn{3}{|c|}{ No } \\
\hline & & & $M$ & $S D$ & $n$ & $M$ & $S D$ & $n$ \\
\hline & & High & 9.41 & 3.25 & 27 & 7.93 & 3.44 & 27 \\
\hline & & Low & 8.70 & 3.18 & 46 & 8.31 & 2.58 & 45 \\
\hline & & $t$ & \multicolumn{3}{|c|}{0.99} & \multicolumn{2}{|c|}{0.23} & \\
\hline & & $d f$ & \multicolumn{3}{|c|}{71} & \multicolumn{3}{|c|}{70} \\
\hline & & $p$ & \multicolumn{3}{|c|}{.36} & \multicolumn{2}{|c|}{.59} & \\
\hline
\end{tabular}

Altogether, it remains unclear as to whether there was an interaction between PPBI and study condition. The results of the significance tests from both the regression and SEM suggest that there is not, but it is important to note that these two analyses were underpowered: it was estimated that a sample size of at least 250 would be required to 
detect a moderate effect size but the final sample for Study IV included just over 150 participants. Less complex sets of analyses (i.e., $t$-tests) provided some indication that there may indeed be a significant interaction.

\section{CHAPTER V. DISCUSSION}

Although previous sections have been split into separate segments for each study, this section will proceed as one and provide a bridge between the four studies. Study I confirmed a framework for incentive categorization that could then be used to organize the analysis in Study II and aid in the creation of the PPBIS in Study III. The scale analysis conducted in Study III then provided support for the use of the PPBIS in Study IV. Altogether, this research stream helped to shed light on the questions proposed at the outset of the project.

The results of Study I provided support for the proposed incentive categorization. However, several issues lead to the conclusion that further refinement of the categorization may be warranted. Ideally, the incentive categories would be entirely distinct such that a given incentive (or an incentive awarded for a specific purpose) could be cleanly sorted into a single category. However, the 14 suggested incentive categories are not necessarily orthogonal in that there are several incentives that can certainly fit into more than one category depending on its usage or interpretation. For example, a "spacious office" incentive was found to fit within the Physical Work Conditions category, but office size may also be an indicator of an employee's level in an organization and therefore fall within the Status and Recognition category.

As noted previously, the incentives in the list vary widely in terms of how often they tend to be used by employers. Some are practically ubiquitous (e.g., salary or a 
retirement plan) whereas some are quite rare (e.g., company-provided housing or laundry service). Unfamiliarity with items has been shown to lead content validity judges to produce alternative or incorrect ratings (Clauser, Hambleton, \& Baldwin, 2017), thus it is possible that the lack of agreement on an incentive's placement in the taxonomy is influenced by respondents' likely lack of exposure to them.

Studies I and II together also inform previous attempts by various researchers to categorize incentives. As noted in the literature review, prior research (e.g., Furnham, 2003) sought to create an incentive taxonomy by factor analyzing ratings of incentive attractiveness—similar to the ratings provided in Study II—rather than logical grouping of themes. Study II revealed that there was considerable variation within each incentive category. Notably, this variation was also fairly equal across the incentive categories, indicating that each category had incentives with a range of valences. An imbalance in the valence of various incentives within a category make it less probable that they would cluster in a factor analysis.

At the same time, the incentive categories themselves are all strongly intercorrelated. This can add further confusion to a factor analysis as individuals seem to vary in their attraction to incentives more generally, leading to a unitary "desire for incentives" factor. Based on these observations, the use of factor analysis on incentive attractiveness ratings to develop a framework of incentives will likely lead to incoherent categorization.

The results of Study II can offer a wealth of information for organizations seeking to recruit or retain employees. Two basic applications of the results of this study would be (1) to help organizations offer customized incentive packages to improve recruitment 
efforts or (2) create company-wide incentive policies based on the known characteristics of their workforce. Although most of the relationships found in Study II are rather intuitive (e.g., interest in retirement incentives increases with age; employees with a spouse or children desire incentives that facilitate family life), a more complex assessment can be made by examining the relationships in tandem. For example, while married employees (compared to unmarried) desire incentives that facilitate family life, those with children (compared to those without children) are also concerned with incentives that allow flexibility in their schedule, such as more time off, jobs with more flexible hours and greater autonomy, and personal services that help employees tackle large issues in their lives.

Organizations can also use the results from Study II to tailor their incentives to applicants for recruitment purposes. This can also be used in situations where organizations are attempting to attract or retain a certain type of employee. For example, if an organization would like their workforce to be high in conscientiousness, then they might consider offering (and actively promoting during recruitment) incentives geared toward providing employees with more professional growth opportunities, a strong and positive organizational culture, and recognition for hard work.

A second way incentives can be used in recruitment is by determining which incentives are most likely to be desired by an applicant based on their characteristics and assembling a job offer with those incentives included. This could give organizations a competitive edge in attracting top candidates, though caution must be taken that fair employment practices are maintained. For example, although men have a stronger desire for monetary incentives, they cannot and should not be offered more money than women. 
Incidentally, it appears that the actual monetary value (or cost, from an employer perspective) of an incentive has almost no practical bearing on its attractiveness:

- Of the top 20 most attractive incentives, 5 are free or intangible ("positive organizational image," "growth opportunities," "job security," “interesting/meaningful work," and "friendly coworkers/boss")

- The second most attractive incentive was "friendly coworkers/boss" (tied with "salary")

- A "company-provided tablet or laptop" was rated as more desirable than a "company car" or even "housing"

Study III provided strong evidence in favor of the existence of a PPBI construct and the psychometric soundness of the PPBIS to measure this construct. However, the construct validation conducted in Study III indicated that the proposed related constructs of self-efficacy, achievement motivation, locus of control, and risk-taking were only weakly related to PPBI. Given that PPBI was conceptualized as a personality construct, it is even more concerning that adding the Big Five facets to the aforementioned constructs as predictors still leaves more than three quarters of the variance in PPBI unexplained. Given the weak associations seen between PPBI and the demographic variables included in this dissertation (see Appendices G1 and G2), it is unlikely that demographic factors would add much explained variance (confirmed by supplemental analyses; an additional 3\% of the variance in PPBI was explained by all of the demographic variables included in the study).

Of the traits examined, PPBI had the strongest relationship with risk-taking (consistent across both Studies III and IV). It is therefore likely that individual's PPBI is 
tempered by their assessment of the risk involved in such a reward structure on a case-bycase basis. This could explain the lack of relationship between PPBI and generalized self-efficacy; the riskiness of such a transaction outweighs a general confidence in one's abilities. Given that the instructions for the scale involve respondents imagining themselves in a new position (the nature of which is unspecified) at an unfamiliar company, respondents would recognize their inability to predict their own performance in such a role and (perhaps correctly) interpret their decision to accept PBI as a risk.

Altogether, the research conducted shed some light on the place of the PPBI construct in the personality nomological network. While risk-taking does certainly play a role in PPBI, it is clear that there are several other identifiable aspects of personality that contribute to these preferences. In order to better understand how these other personality factors relate to PPBI, future research should reinvestigate these relationships in conditions where the inherent risk involved (i.e., whether a person is likely to achieve the performance necessary to obtain the incentives) is better understood by participants or in high- vs low-stakes situations.

An examination of differences in PPBI across different demographic groups revealed no discernable differences (see Appendices G1 and G2). As such, it can be tentatively concluded that utilizing a PBI vs NPBI structure should not affect the diversity of an organization and have no bearing on potential adverse impact. However, there were a limited number of demographic variables included in the studies, so it is possible that differences in PPBI may arise in different sets of subgroups (or combinations of demographics) not investigated. These differences may occur based on other employment or career preferences. It would therefore be important to explore how 
PPBI differs across occupational interest groups - i.e., students with other majors in a student sample or different sectors in organizational samples.

Although a significant interaction between PPBI and study condition was not established, there were some indications that this null result was due to inadequate power rather than a lack of effect. If the trend were to be found in a larger sample, this research would have several implications. First, the results would confirm the widely accepted notion that pay-for-performance systems do have affect performance (e.g., Campbell, 1984; Lawler, 1990; Park, 2018) and expands that concept to incentives other than pay. While these incentive schemes have an influence on performance in general, they appear to be even more effective for individuals who desire them.

Second, the alignment of an individual's incentive administration preferences with the reward system offered by an organization (e.g., a person with high PPBI working for an organization that offers PBI) seems to have a complex effect on the attractiveness of an organization to the individual. Although individuals who desire PBI are more attracted to organizations that offer them, it appears that individuals who desire NPBI are not more attracted to organizations that offer only NPBI. This may be due to the fact that a company that offers only pure NPBI is seen as automatically lacking in opportunities for personal growth or recognition of good performance, both of which were strongly desired in the study population. In practical terms, this indicates that there does not appear to be a "penalty" for offering PBI, in that those who do not prefer PBI are still attracted to organizations that offer them and may still improve their performance nevertheless. 
There were several limitations and shortcomings in the set of studies conducted, many of them dealing with the sample used in each. For Study I, the sample was comprised almost entirely of individuals in the field of industrial-organizational psychology. While this is an appropriate population for use as SMEs, experts in other strongly related fields (such as human resources or business administration more generally) may have provided different responses. More generally, a larger group of SMEs would have been preferable in order to allow for more confidence in the reliability of the results or conversely more opportunity for potential disagreeing opinions to emerge.

The most glaring problem regarding sample concerns Study II. Because this study (1) confirmed the influence of various demographic factors on incentive preferences and (2) utilized a sample that was somewhat demographically homogenous, the findings from this research may very well only apply to relatively young college students (in particular, psychology majors in the Southeast region of the United States). It is imperative that a more diverse sample be obtained in future research in order to be able to understand how other groups not represented (e.g., Asians, Baby Boomers, etc.) would rate the incentives.

Similarly, the PPBIS used in Studies III and IV has only been tested in the same homogenous population as Study II. Given the impact that certain characteristics have on incentive preferences, it is very possible that incentive administration preferences are likewise influenced by certain demographic or personality factors, which was not examined in these studies. As noted previously, Study IV also suffered from a low sample size due to attrition between the two parts of the study. 
Any future research involving large number of incentives should adopt the taxonomy developed in Study I. Confirmation of the taxonomy among a larger set of SMEs and in other countries would be an ideal first step. Further refinements to the taxonomy are likely to be necessary (e.g., reworking the category descriptions for clarity), but the use of such a framework should be very beneficial in organizing, advancing, and expanding incentive research in this domain.

Finally, the relationships investigated in these studies (particularly Study IV) should be investigated using a working sample. While the use of a student sample is not a problem per se, it does limit any inferences that can be made about the results generalizing to a wider population. Study IV examined a hypothetical organization and used a simple and short performance task. It is vital that future research test PPBI as a moderator of the effect of the type of incentive administration an organization utilizes (PBI, NPBI, or a combination) on various outcomes.

In conclusion, compensation is a major consideration in recruiting top talent and effectively managing employee performance. Understanding the various types of incentives and their valences for employees is important. Through the series of studies in this dissertation, which sampled over 800 participants, used multiple research designs, and employed various analytic strategies, several contributions were made to the body of literature in compensation.

First, a comprehensive and coherent taxonomy of employment incentives was produced — with sufficient clarity and distinctiveness to demonstrate differential relationships with other variables in subsequent studies. This taxonomy can be employed in future research to allow for more efficient examinations of the effects of various 
incentives. Second, a large amount of evidence was gathered and presented that demonstrated significant demographic differences in attraction to various incentives. Organizations can use this information to offer their employees or recruits incentive packages that are highly desirable (and therefore motivating) to them. Third, the new individual difference construct of PPBI was defined, and a measure of this construct was created and validated. This measure can be used to assess the extent to which current or incoming employees prefer "pay-for-performance" incentive administration across different incentive types. Finally, the interaction between individuals' PPBI and the incentive structure an organization offers was examined regarding the individual's attraction to the organization and their task performance. Understanding these relationships is vital to crafting incentive systems that encourage acceptance of job offers, promote retention, and help improve employees' performance on the job. 


\section{REFERENCES}

Adams, J. S. (1963). Toward an understanding of inequity. Journal of Abnormal Psychology, 67(5), 422-436. doi:10.1037/h0040968

Allport, G. W., \& Odbert, H. S. (1936). Trait-names: A psycho-lexical study. Albany, NY: Psychological Review Company.

Anderson, J. C., \& Gerbing, D. W. (1991). Predicting the performance of measures in a confirmatory factor analysis with a pretest assessment of their substantive validity. Journal of Applied Psychology, 76(5), 732-740. doi:10.1037/00219010.76.5.732

Antoni, C. H., Baeten, X., Perkins, S. J., Shaw, J. D., Vartiainen, M. (2017). Reward management: Linking employee motivation and organizational performance. Journal of Personnel Psychology, 16(2), 57-60. doi:10.1027/1866-5888/a000187.

*Bailey, C. D., \& Fessler, N. J. (2011). The moderating effects of task complexity and task attractiveness on the impact of monetary incentives in repeated tasks. Journal of Management Accounting Research, 23, 189-210. doi:10.2308/jmar-10104

Balkin, D. B., \& Groeneman, S. (1985). The effect of incentive compensation on recruitment: The case of the military. Personnel Administrator, 30(1), 29-34.

Bandura, A. (1982). Self-efficacy mechanism in human agency. American Psychologist, 37(2), 122-147. doi:10.1037/0003-066X.37.2.122.

Bandura, A. (1997). Self-efficacy: The exercise of control. New York: W. H. Freeman and Company.

Bendig, A. W., \& Stillman, E. L. (1958). Dimensions of job incentives among college students. Journal of Applied Psychology, 42(6), 367-371.

Benefitfocus. (2016, March 9). 3 reasons personalization matters in employee benefits [Blog post]. Retrieved from https://www.benefitfocus.com/blogs/benefitfocus/3reasons-personalization-matters-in-employee-benefits

Benson, J., \& Brown, M. (2011). Generations at work: Are there differences and do they matter? The International Journal of Human Resource Management, 22(9), 18431865. doi: 10.1080/09585192.2011.573966

Biro, M. M. (2014, March 23). Recognize, reward and engage your multi-generational workforce [Blog post]. Forbes. Retrieved from https://www.forbes.com/sites/meghanbiro/2014/03/23/recognize-reward-andengage-your-multi-generational-workforce/ 
Blais, A.-R., \& Weber, E. U. (2006). A Domain-Specific Risk-Taking (DOSPERT) scale for adult populations. Judgment and Decision Making, 1(1), 33-47.

Bonner, S. E., \& Sprinkle, G. B. (2002). The effects of monetary incentives on effort and task performance: Theories, evidence, and a framework for research. Accounting, Organizations and Society, 27(4-5), 303-345. doi: 10.1016/S03613682(01)00052-6

Bono, J. E., \& Judge, T. A. (2003). Core self-evaluations: A review of the trait and its role in job satisfaction and job performance. European Journal of Personality, 17, S5-S18. doi: 10.1002/per.481

Brown, W. A. and Yoshioka, C. F. (2003), Mission attachment and satisfaction as factors in employee retention. Nonprofit Management and Leadership, 14(1), 5-18. doi:10.1002/nml.18

Bureau of Labor Statistics. (2016). Benefits. Retrieved from https://www.bls.gov/bls/glossary.htm

Bureau of Labor Statistics. (2017, December 15). Employer costs for employee compensation - September 2017 (USDL Publication No. USDL-17-1646). Retrieved from https://www.bls.gov/news.release/archives/ecec_12152017.pdf

Cable, D. M., \& Turban, D. B. (2003). The value of organizational reputation in the recruitment context: A brand-equity perspective. Journal of Applied Social Psychology, 33(11), 2244-2266. doi:10.1111/j.1559-1816.2003.tb01883.x

Campbell, D. J. (1984). The effects of goal-contingent payment on the performance of a complex task. Personnel Psychology, 37(1), 23-40. doi:10.1111/j.17446570.1984.tb02245.x

Casper, W. J., \& Buffardi, L. C. (2004). Work-life benefits and job pursuit intentions: The role of anticipated organizational support. Journal of Vocational Behavior, 65(3), 391-410. doi:10.1016/j.jvb.2003.09.003

Cerasoli, C. P., Nicklin, J. M., \& Ford, M. T. (2014). Intrinsic motivation and extrinsic incentives jointly predict performance: A 40-year meta-analysis. Psychological Bulletin, 140(4), 980-1008. doi:10.1037/a0035661

Choi, J. (2011). When are signing bonuses more than just "pay to play"? An experimental investigation (Doctoral dissertation). Retrieved from ProQuest. (3461950)

*Cialdini, R. B., Eisenberg, N., Green, B. L., Rhoads, K., \& Bator, R. (1998). Undermining the undermining effect of reward on sustained interest. Journal of Applied Social Psychology, 28(3), 249-263. doi:10.1111/j.15591816.1998.tb01705.x 
*Clark, H. M., \& Schroth, C. A. (2010). Examining relationships between academic motivation and personality among college students. Learning and Individual Differences, 20(1), 19-24. doi:10.1016/j.lindif.2009.10.002

Costa, P. T., \& McCrae, R. R. (1995). Domains and facets: Hierarchical personality assessment using the Revised NEO Personality Inventory. Journal of Personality Assessment, 64(1), 21-50. doi:10.1207/s15327752jpa6401_2

Costa, P. T., Terracciano, A., \& McCrae, R. R. (2001). Gender differences in personality traits across cultures: Robust and surprising findings. Journal of Personality and Social Psychology, 81(2), 322-331. doi:10.1037/0022-3514.81.2.322

Davis, K., Giles, W., \& Field, H. (1985). Compensation and fringe benefits: How recruiters view new college graduate preferences. Personnel Administrator, 30, 43-50. doi:10.1177/088636878501700105

Dencker, J. C., Joshi, A. \& Martocchio, J. J. (2008). Towards a theoretical framework linking generational memories to workplace attitudes and behaviors. Human Resource Management Review, 18(3), 180-187. doi:10.1016/j.hrmr.2008.07.007

Depue, R. A., \& Collins, P. F. (1999). Neurobiology of the structure of personality: Dopamine, facilitation of incentive motivation, and extraversion. Behavioral and Brain Sciences, 22(3), 491-517; discussion 518-69. doi:10.1017/S0140525X99002046

De Vos, A., \& Meganck, A. (2008). What HR managers do versus what employees value: Exploring both parties' views on retention management from a psychological contract perspective. Personnel Review, 38(1), 4560. doi:10.1108/00483480910920705

DeYoung, C. G., Quilty, L. C., \& Peterson, J. B. (2007). Between facets and domains: 10 aspects of the Big Five. Journal of Personality and Social Psychology, 93, 880896. doi:10.1037/0022-3514.93.5.880

Fahey, C., Walker, J., \& Sleigh, A. (2002). Training can be a recruitment and retention tool for emergency service volunteers. Australian Journal of Emergency Management, 17(3), 3-7.

Farr, J. L. (1976). Task characteristics, reward contingency, and intrinsic motivation. Organizational Behavior \& Human Performance, 16(2), 294-307. doi:10.1016/0030-5073(76)90018-0

*Farr, J. L., Vance, R. J., \& McIntyre, R. M. (1977). Further examinations of the relationship between reward contingency and intrinsic motivation. Organizational Behavior \& Human Performance, 20(1), 31-53. doi:10.1016/00305073(77)90042-3 
Fehr, E., \& Falk, A. (2002). Psychological foundations of incentives. European Economic Review, 46(4-5), 687-724.

Field, A. (2009). Discovering statistics using SPSS. London: SAGE.

Foldes, H. J., Duehr, E. E., \& Ones, D. S. (2008). Group differences in personality: Metaanalyses comparing five U.S. racial groups. Personnel Psychology, 61(3), 579616. doi:10.1111/j.1744-6570.2008.00123.x

Fong, E. A., \& Tosi, H. L. (2007). Effort, performance, and conscientiousness: An agency theory perspective. Journal of Management, 33(2), 161-179. doi: $10.1177 / 0149206306298658$

*Frey, B. S., \& Jegen, R. (2001). Motivation crowding theory. Journal of Economic Surveys, 15(5), 589-611. doi:10.1111/1467-6419.00150

Furnham, A. (2003). Personality, individual differences and incentive schemes. North American Journal of Psychology, 5(3), 325-334.

García, M. F., Posthuma, R. A., \& Quiñones, M. (2010). How benefit information and demographics influence employee recruiting in 104exico. Journal of Business and Psychology, 25(3), 523-531. doi:10.1007/s10869-010-9175-4

Gerhart, B., \& Milkovich, G. T. (1992). Employee compensation: Research and practice. In M. D. Dunnette \& L. M. Hough (Eds.), Handbook of industrial and organizational psychology ( $2^{\text {nd }}$ ed., Vol. 3, pp. 481-569). Palo Alto, CA: Consulting Psychologists Press.

Gerhart, B., \& Rynes, S. L. (2003). Compensation: Theory, evidence, and strategic implications. Thousand Oaks, CA: Sage.

Gneezy, U., Meier, S., \& Rey-Biel, P. (2011). When and why incentives (don't) work to modify behavior. Journal of Economic Perspectives, 25(4), 191-210. doi:10.1257/jep.25.4.191

Goldberg, L. R. (1992). The development of markers for the Big-Five factor structure. Psychological Assessment, 4(1), 26-42. doi:10.1037/1040-3590.4.1.26

Gough, O., \& Hick, R. (2009). Employee evaluations of occupational pensions. Employee Relations, 31(2), 158-167. doi:10.1108/01425450910925300

Gupta, N., \& Shaw, J. D. (2014). Employee compensation: The neglected area of HRM research. Human Resource Management Review, 24(1), 1-4. doi:10.1016/j.hrmr.2013.08.007

Gurchiek, K. (2016, May 13). Employee recognition should consider personal, generational preferences [Blog post]. Society for Human Resource Management. 
Retrieved from https://www.shrm.org/resourcesandtools/hr-topics/behavioralcompetencies/global-and-cultural-effectiveness/pages/personal-touchgenerational-preferences-recognition-program.aspx

Halpert, R., \& Hill, R. (2011). 28 measures of locus of control. Beach Haven, NJ: Will to Power Press.

Hamner, W. C., \& Foster, L. W. (1975). Are intrinsic and extrinsic rewards additive: A test of Deci's cognitive evaluation theory of task motivation. Organizational Behavior \& Human Performance, 14(3), 398-415. doi:10.1016/00305073(75)90038-0

Hart, J. W., Stasson, M. F., Mahoney, J. M., \& Story, P. (2007). The Big Five and achievement motivation: Exploring the relationship between personality and a two-factor model of motivation. Individual Differences Research, 5(4), 267-274.

Hartman, R. O., \& Betz, N. E. (2007). The five-factor model and career efficacy: General and domain-specific relationships. Journal of Career Assessment, 15(2), 145-161. doi:10.1177/1069072706298011

Hewlett, S. A. (Interviewee). (2009). Use the right incentives for Gen Y, Gen X, and Boomers [Audio podcast]. Retrieved from https://hbr.org/2009/07/use-the-rightincentives-for-g

Hogan, J., \& Holland, B. (2003). Using theory to evaluate personality and jobperformance relations: A socioanalytic perspective. Journal of Applied Psychology, 88(1), 100-112. doi:10.1037/0021-9010.88.1.100

Hong, J.-C., Yang, S.-D., Wang, L.-J., Chiou, E.-F., \& Huang, S.-L. (1995). Impact of employee benefits on work motivation and productivity. International Journal of Career Management, 7(6), 10-14. doi:10.1108/09556219510098064

Horn, J. L. (1965). A rationale and test for the number of factors in factor analysis. Psychometrika, 30(2), 179-185. doi:10.1007/bf02289447

Hsieh, Y. H. (2011). Empirical study on personality traits, job satisfaction, and reward system preferences. African Journal of Business Management, 5(12), 4983-4992. doi:10.5897/AJBM11.113

Hu, L.-t., \& Bentler, P. M. (1999). Cutoff criteria for fit indexes in covariance structure analysis: Conventional criteria versus new alternatives. Structural Equation Modeling, 6(1), 1-55. doi:10.1080/10705519909540118

Human Resources inc. (n.d.). Catering benefits packages to your employees [Blog post]. Retrieved from https://www.hri-online.com/blog/catering-benefits-packages-toyour-employees 
Incentive. (2017). In BusinessDictionary.com. Retrieved from http://www.businessdictionary.com/definition/incentive.htm

Jenkins, G. D., Jr., Mitra, A., Gupta, N., \& Shaw, J. D. (1998). Are financial incentives related to performance? A meta-analytic review of empirical research. Journal of Applied Psychology, 83(5), 777-787. doi:10.1037/0021-9010.83.5.777

Jessup, P. A., \& Stahelski, A. J. (1999). The effects of a combined goal setting, feedback and incentive intervention on job performance in a manufacturing environment. Journal of Organizational Behavior Management, 19(3), 5-26. doi:10.1300/J075v19n03_02

Jex, S., \& Britt, T. (2014). Organizational psychology: A Scientist-Practitioner Approach $\left(3^{\text {rd }}\right.$ ed.). New Jersey: John Wiley and Sons, Inc.

Jurgensen, C. E. (1947). Selected factors which influence job preferences. Journal of Applied Psychology, 31(6), 553-564. doi:10.1037/h0054971

Komarraju, M., Karau, S. J., \& Schmeck, R. R. (2009). Role of the big five personality traits in predicting college students' academic motivation and achievement. Learning and Individual Differences, 19(1), 47-52.

Kowalewski, S. J., \& Phillips, S. L. (2012). Preferences for performance based employee rewards: Evidence from small business environments. International Journal of Management and Marketing Research, 5(2), 65-76.

Kristof, A. L. (1996). Person-organization fit: An integrative review of its conceptualization, measurement, and implications. Personnel Psychology, 49(1), 1-50. doi:10.1111/j.1744-6570.1996.tb01790.x

Kuhn, K. M. (2009). Compensation as a signal of organizational culture: The effects of advertising individual or collective incentives. The International Journal of Human Resource Management, 20(7), 1634-1648. doi:10.1080/09585190902985293

Kuhn, K. M., \& Yockey, M. D. (2003). Variable pay as a risky choice: Determinants of the relative attractiveness of incentive plans. Organizational Behavior and Human Decision Processes, 90(2), 323-341. doi:10.1016/S0749-5978(02)00526-5

Laffont, J.-J., \& Martimort, D. (2002). The theory of incentives: The principal-agent model. Princeton, NJ: Princeton University Press.

LaMere, J. M., Dickinson, A. M., Henry, M., Henry, G., \& Poling, A. (1996). Effects of a multicomponent monetary incentive program on the performance of truck drivers: A longitudinal study. Behavior Modification, 20(4), 385-405. doi:10.1177/01454455960204002 
Landry, A. T., Gagné, M., Forest, J., Guerrero, S., Séguin, M., \& Papachristopoulos, K. (2017). The relation between financial incentives, motivation, and performance: An integrative SDT-based investigation. Journal of Personnel Psychology, 16(2), 61-76. doi:10.1027/1866-5888/a000182.

Lawler, E. E. III. (1990). Strategic pay: Aligning organizational strategies and pay systems. San Francisco: Jossey-Bass

Lester, S. W., \& Kickul, J. (2001). Psychological contracts in the $21^{\text {st }}$ century: What employees value most and how well organizations are responding to these expectations. HR.Human Resource Planning, 24(1), 10-21.

Lievens, F., \& Slaughter, J. E. (2016). Employer image and employer branding: What we know and what we need to know. Annual Review of Organizational Psychology and Organizational Behavior, 3, 407-440. doi:10.1146/annurev-orgpsych041015-062501

Lips, H. M., \& Keener, E. (2007). Effects of gender and dominance on leadership emergence: Incentives make a difference. Sex Roles, 56(9-10), 563-571. doi:10.1007/s11199-007-9210-8

London, M. and Oldham, G. (1976). Effects of varying goal types and incentive systems on performance and satisfaction. Academy of Management Journal, 19, 537-546.

Lori, F. T., \& Aspinwall, K. R. (2009). The recruitment value of work/life benefits. Personnel Review, 38(2), 195-210. doi:10.1108/00483480910931343

*Lozano, J. H. (2016). Personality and behavior in social dilemmas: Testing the situational strength hypothesis and the role of hypothetical versus real incentives. Journal of Personality, 84(1), 71-78. doi:10.1111/jopy.12139

Mahoney, T.A (1964). Compensation preferences of managers. Industrial Relations, 3(3), 135-144. doi:10.1111/j.1468-232X.1964.tb00831.x

Mattson, M., Torbiörn, I., \& Hellgren, J. (2014). Effects of staff bonus systems on safety behaviors. Human Resource Management Review, 24(1), 17-30. doi:10.1016/j.hrmr.2013.08.012

McDonald, P. (2008). Succession planning as a retention tool. Financial Executive, 24(6), 18-21.

Milkovich, G. T., Newman, J. M., \& Gerhart, B. (1999). Compensation (12 ${ }^{\text {th }}$ ed.). New York, NY: McGraw-Hill Education.

Miller, T. I. (1984). The effects of employer-sponsored child care on employee absenteeism, turnover, productivity, recruitment or job satisfaction: What is 
claimed and what is known. Personnel Psychology, 37(2), 277-289.

doi:10.1111/j.1744-6570.1984.tb01450.x

Mir, P., Trender-Gerhard, I., Edwards, M. J., Schneider, S. A., Bhatia, K. P., \& Jahanshahi, M. (2011). Motivation and movement: The effect of monetary incentive on performance speed. Experimental Brain Research, 209(4), 551-559. doi:10.1007/s00221-011-2583-5

Moore, A., \& Bussin, M. (2012). Reward preferences for generations in selected Information and Communication Technology companies. SA Journal of Human Resource Management,10(1), 1-9. doi:10.4102/sajhrm.v10i1.325

Nagle, A., Riener, R. \& Wolf, P. (2016). How would you like to be rewarded? Relating the Big Five personality traits with reward contingency in a cognitive training puzzle game. Paper presented at 2016 IEEE International Conference on Serious Games and Applications for Health (SeGAH). doi:10.1109/SeGAH.2016.7586281

Nealey, S. T. \& Goodale, J. (1967). Worker preferences among time of benefits and pay. Journal of Applied Psychology, 51(4), 357-361. doi:10.1037/h0024869

Nealey, S. T. (1963). Pay and benefits preferences. Industrial Relations, 3(1), 17-28. doi:10.1111/j.1468-232X.1963.tb00806.x

Nelson, B. (1999). Incentives for all generations. Retrieved from https://www.inc.com/articles/1999/02/16431.html

Nicholson, N., Soane, E., Fenton-O’Creevy, M., \& Willman, P. (2005). Personality and domain-specific risk taking. Journal of Risk Research, 8(2), 157-176. doi:10.1080/1366987032000123856

Nienaber, R., Bussin, M. H. R., \& Henn, C. (2011). The relationship between personality types and reward preferences. Acta Commercii, 11(2), a153. doi:10.4102/ac.v11i2.153

Pappas, J. M., \& Flaherty, K. E. (2006). The moderating role of individual-difference variables in compensation research. Journal of Managerial Psychology, 21(1), $19-35$.

Park, S. (2018). Pay for performance in modern compensation practices. Compensation and Benefits Review, 50(1), 21-35. doi:10.1177/0886368718821006

Paunonen, S. V., \& Ashton, M. C. (2001). Big five factors and facets and the prediction of behavior. Journal of Personality and Social Psychology, 81(3), 524-539.

Pyle, G. M. (2011). The effects of tuition reimbursement on retention and recruitment: A cross case analysis (Doctoral dissertation). Retrieved from Proquest. (3458497) 
Rotter, J. B. (1966). Generalized expectancies for internal versus external control of reinforcement. Psychological Monographs: General \& Applied, 80(1), 1-28. doi:10.1037/h0092976.

Rotter, J. B. (1975). Some problems and misconceptions related to the construct of internal versus external control of reinforcement. Journal of Consulting and Clinical Psychology, 43(1), 56-67. doi:10.1037/h0076301

Saks, A. M., Wiesner, W. H., \& Summers, R. J. (1996). Effects of job previews and compensation policy on applicant attraction and job choice. Journal of Vocational Behavior, 49(1), 68-85. doi:10.1006/jvbe.1996.0034

Schaubroeck, J., Shaw, J. D., Duffy, M. K., \& Mitra, A. (2008). An under-met and overmet expectations model of employee reactions to merit raises. Journal of Applied Psychology, 93(2), 424-434. doi:10.1037/0021-9010.93.2.424

Schmid, J., \& Leiman, J. M. (1957). The development of hierarchical factor solutions. Psychometrika, 22, 53-61. doi:10.1007/BF02289209

Schwarzer, R., \& Jerusalem, M. (1995). Generalized Self-Efficacy scale. In J. Weinman, S. Wright, \& M. Johnston, Measures in health psychology: A user's portfolio. Causal and control beliefs (pp. 35-37). Windsor, UK: NFER-NELSON.

Shaw, J. D., \& Gupta, N. (2007). Pay system characteristics and quit patterns of good, average, and poor performers. Personnel Psychology, 60(4), 903-928. doi:10.1111/j.1744-6570.2007.00095.

Shaw, J. D. and Gupta, N. (2015), Let the evidence speak again! Financial incentives are more effective than we thought. Human Resource Management Journal, 25, 281293. doi:10.1111/1748-8583.12080

*Shinew, K. J. (1993). The attractiveness and effectiveness of incentive reward options: A case study. Retrieved from http://theirf.org/amsite/themes/IRF/download.php?file=http $\% 3 \mathrm{~A} \% 2 \mathrm{~F} \% 2 \mathrm{Ftheirf.org} \% 2 \mathrm{Fam}-$ site $\% 2$ Fmedia $\% 2$ Fattractiveness-and-effectiveness-of-non-cash-rewardoption.pdf

Society for Human Resource Management. (2017). 2017 Employee benefits: Remaining competitive in a challenging talent marketplace (Report No. 17-0428). Retrieved from https://www.shrm.org/hr-today/trends-and-forecasting/research-andsurveys/Documents/2017\%20Employee\%20Benefits\%20Report.pdf

Spetz, J., \& Adams, S. (2006). How can employment-based benefits help the nurse shortage? Making nursing more attractive involves more than just wage levels. Health Affairs, 25(1), 212-218. 
Tetrick, L. E., Weathington, B. L., Da Silva, N., \& Hutcheson, J. M. (2010). Individual differences in attractiveness of jobs based on compensation package components. Employee Responsibilities and Rights Journal, 22(3), 195-211. doi:10.1007/s10672-009-9141-3

Thompson, L. F., \& Aspinwall, K. R. (2009). The recruitment value of work/life benefits. Personnel Review, 38(2), 195-210. doi:10.1108/00483480910931343

Thurstone, L. L. (1947). Multiple factor analysis: A development and expansion of vectors of the mind. Chicago, IL: University of Chicago Press.

Twenge, J. M., \& Campbell, S. M. (2008). Generational differences in psychological traits and their impact on the workplace. Journal of Managerial Psychology, 23(8), 862-877. doi: 10.1108/02683940810904367

Viswesvaran, C., Ones, D. S., \& Schmidt, F. L. (1996). Comparative analysis of reliability of job performance ratings. Journal of Applied Psychology, 81(5), 557574. doi: $10.1037 / 0021-9010.81 .5 .557$

Viswesvaran, C., Schmidt., F. L., \& Ones, D. S. (2005). Is there a general factor in ratings of job performance? A meta-analytic framework for disentangling substantive and error influences. Journal of Applied Psychology, 90(1), 108-131. doi:10.1037/0021-9010.90.1.108

Vroom, V. H. (1964). Work and motivation. Oxford, England: Wiley.

Wilson, M., Northcraft, G. B., \& Neale, M. A. (1985). The perceived value of fringe benefits. Personnel Psychology, 38(2), 309-320. doi:10.1111/j.17446570.1985.tb00549.x

Wong, M., Gardiner, E., Lang, W., \& Coulon, L. (2008). Generational differences in personality and motivation: Do they exist and what are the implications for the workplace? Journal of Managerial Psychology, 23(8), 878-890. doi:10.1108/02683940810904376

*Zajac, E. J., \& Westphal, J. D. (1994). The costs and benefits of managerial incentives and monitoring in large U.S. corporations: When is more not better? Strategic Management Journal, 15(S1), 121-142. doi:10.1002/smj.4250150909 


\section{APPENDICES}

Appendix A

Incentives

Monetary

Salary

Monetary bonus

Employee stock

Profit-sharing

Gainsharing

Commuter checks

Description

Employee receives pay for employment

An extra monetary sum is received (e.g., at hiring, after project completion, annually)

Company stock is received or may be purchased at a discounted rate

A percentage of the company profits above a certain threshold are received, divided amongst employees

A monetary sum is received for improvements such as increased productivity, higher sales, or reduced expenses

Employee receives reimbursement for public transportation costs (going to or from work)

$\underline{\text { Retirement }}$

Pension plan

A fixed sum of money is received regularly after retirement

Defined contribution

plan

Employee contributions to a retirement account are matched by employer up to a certain percentage of your salary

Retiree insurance employee health care premium after employee retires

\section{$\underline{\text { Time Off }}$}

Sick days

Regular pay is received throughout days taken off for medical reasons (e.g., illness)

Paid holidays

Regular pay is received throughout days taken off for holidays

Paid jury duty

Regular pay is received throughout days taken off for jury duty

Extra paid time off

Regular pay is received throughout days taken off for miscellaneous reasons (e.g., vacation), more than required by employment law

Paid volunteer time

off Regular pay is received throughout days taken off for volunteer activities

Paid sabbatical

Regular pay is received for an extended period, typically used for study or personal accomplishment

Unpaid extended leave Employee may take a large amount of (unpaid) time off without losing his or her position

Parental leave Employee may take extended leave when caring for a new child

Military leave Employee may take extended leave when his or her spouse is away on military assignment

Bereavement leave Employee may take extended leave to grieve for a recently deceased loved one

Job Characteristics

Flextime

The start/end time of an employee's working hours may be adjusted to better fit his or her schedule 
Telecommuting/remot

e working

High autonomy

Interesting/meaningful

work

Job swapping

Job security
Work may be completed from home or other locations

Employee is given control over how his or her job is done

Job duties are intrinsically enjoyable/fulfilling

Employees regularly rotate between tasks to break monotony and prevent fatigue

Employer provides formal or informal reassurances of continued employment

\section{Company-Provided}

$\underline{\text { Resources }}$

Company phone

Company car

Employer provides a phone that may be used for personal use

Company computer or

tablet

Employer provides a vehicle that may be used for personal use

Housing

Employer provides a computer or tablet that may be used for personal use

Gifts and Discounts

Personalized items

Employer provides a personal residence

Employee receives items that are personalized (i.e., with the organization's logo)

Employee discounts Employee receives the goods or services produced by the employer at a discounted rate

Phone discounts

Employee receives a personal phone at a discounted rate

Tickets/coupons

Employee receives tickets (e.g., movie, theater, sporting event) or coupons

Gift cards

Employee receives gift cards

Free travel

Vacation travel expenses are paid by employer

Personal Services

Financial advising

Legal counsel

Employee receives free/discounted financial advising

Loan assistance

Employee receives free/discounted legal counsel

Relocation costs

Employee receives assistance obtaining a bank loan

Life coaching

Employer pays for costs associated with home relocation

Employee assistance

programs

Employee receives free/discounted life coaching

Employee may receive assistance in a variety of ways to help with personal or professional problems (e.g., short-term counseling or referrals)

Travel concierge Employee receives assistance with travel planning

\section{$\underline{\text { Daily Life }}$}

Conveniences

On-site dining options

Food is available on the organization's property

On-site hair/nail salon

A salon is located on the organization's property

Laundry service

Employer provides laundromat services for employees 
On-site car services Car services (e.g., car wash, oil change) are available on the organization's property.

\section{Health and Well-being}

Health insurance

Dental insurance

Vision insurance

Life insurance

Disability/accident insurance

Staff psychologist

Gym membership

Standing desks

On-site gym

On-site health

clinic/pharmacy

Massages

Diet/exercise plans/classes

Family Life

Facilitation

On-site daycare

Lactation/mother's room

Fertility assistance

Adoption assistance

Dependent care

Family medical leave

Professional Growth

Tuition/student loan reimbursement

Conference funding

Growth opportunities
Employer provides health insurance or pays for a portion of employee health care premium

Employer provides dental insurance or pays for a portion of employee dental care premium

Employer provides vision insurance or pays for a portion of employee vision care premium

Employer provides life insurance or pays for a portion of employee life insurance premium

Employer provides disability insurance or pays for a portion of employee disability/accident insurance premium

Employer retains a psychologist to provide mental health services to employees

Employer pays for a portion of gym memberships for employees

Employer provides the option for employees to have standing desks

A gym is available on the organization's property

A health clinic and/or pharmacy is available on the organization's property

Employer arranges for employees to have massages in their work areas to reduce stress

Employer pays for a portion of diet and/or exercise plans or classes
A daycare center is available on the organization's property

Employer provides a private location designated for mothers to pump breast milk

Employer provides financial assistance in fertilization treatment costs Employer provides legal and/or financial assistance in the adoption process

Employer provides financial assistance in caring for young or elderly family members

Employee may take extended leave when a family member requires extended medical care

Employer pays for costs related to past or present education

Employer pays for costs related to a conference (e.g., travel, lodging, registration)

Employer provides a formal or informal structure or plan for promoting employees into higher level positions 
Mentoring

Employer has a formal or informal system for pairing less experienced employees with more experienced employees to foster a mentoring relationship

Training opportunities

Employer provides employee training opportunities for various skills

Organizational Culture

Employee

outings/retreats/social

events

Employer holds regular gatherings for employees across the

organization to bond socially

Team bonding events

Employer holds regular gatherings for employees in each

organizational unit to build stronger working relationships

Positive organizational Employer is recognized as having positive qualities (e.g.,

image

environmentally friendly or charitable)

Diversity program

Employer has initiatives designed to create a more diverse workforce and promote a greater respect for diversity

Charitable gift

Employer matches donations from employees to certain charities

matching

Friendly work

Employer promotes positive interactions between employees and a

environment friendly work atmosphere

Physical Working

Conditions

Free food, snacks, beverages

Employer provides free food or drinks within employees' work areas

Game rooms, nap

rooms

Pet friendly workplace

Casual dress

Employer has designated areas for relaxation or enjoyment

Comfortable working

conditions

Employer allows employees to bring their pets to the workplace

Employer allows employees to wear more casual attire

Employer allows employees to change aspects of their environment to their comfort (e.g., temperature or lighting)

$\underline{\text { Status and }}$

Recognition

Employee of month

Employer provides special recognition a specific employee each month

Birthday celebration Employer provides special recognition to employees on their birthday (e.g., gifts or cake)

Premium parking spot Employer awards certain employees with a more convenient parking spot

Office size/location Employer provides certain employees with a superior office (e.g., more room, better view, better location)

Private bathroom Employer provides certain employees with a more exclusive bathroom

Praise

Employer provides formal or informal commendation to employees for their contribution to the organization

Work anniversary gifts Employee receives a gift after remaining employed for a certain length of time 
Work anniversary awards
Employer provides special recognition to employees at certain points in their tenure (e.g., gifts or certificates) 


\section{Appendix B}

\section{Preference for Performance-Based Incentives Scale (PPBIS)}

Imagine you are being recruited for a position at a new company. Before you begin this job, your employer allows you to pick whether you would like your various employment incentives (pay, benefits, etc.) completely tied to your performance (performance-based) OR not tied to your performance at all (traditional) OR something in between. For each item that follows, indicate the extent to which you would like to have the compensation, rewards, or opportunities you receive from this employer tied to your own performance (performance-based) versus being given independently of your performance (traditional). For example, you may put that you would prefer "some" of your salary to be linked with your performance, in which case a larger portion of your salary would be administered regardless of your performance. As you consider the items, assume that:

(1) The organization already offers a moderate amount or quality of each incentive type.

(2) If you respond that you would like none of the incentive tied to your performance, the incentive will remain the same moderate amount or quality regardless of your performance.

(3) If you respond that you would like at least "some" of the incentive tied to your performance, you will earn more/better incentives for good performance OR less/worse incentives for poor performance.

(4) The more an incentive is tied to your performance, the greater the opportunity to earn more or better incentives with good performance BUT the greater the risk of having less or worse incentives if you have poor performance.

(5) The measure being used to determine your performance in the organization will be an accurate assessment of your performance over a month.

Think carefully about the incentives represented in each item and whether or not you would like them tied to your performance!

\begin{tabular}{ccccc}
\hline 1 & 2 & 3 & 4 & 5 \\
\hline None & Some & Half & Most & All \\
\hline
\end{tabular}




\begin{tabular}{|c|c|}
\hline Item & Incentive \\
\hline 1 & $\begin{array}{l}\text { I would prefer _ of my monetary reward (e.g., salary, yearly bonus) be } \\
\text { linked to my performance. }\end{array}$ \\
\hline 2 & 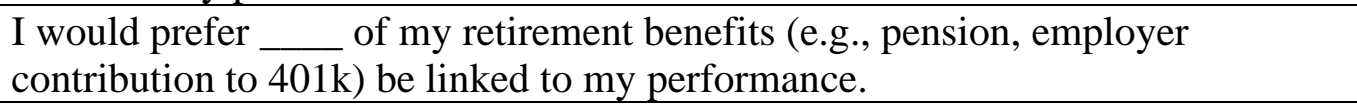 \\
\hline 3 & $\begin{array}{l}\text { I would prefer } \ldots \text { of my time off (e.g., number of paid holidays or unpaid } \\
\text { extended leave) be linked to my performance. }\end{array}$ \\
\hline 4 & $\begin{array}{l}\text { I would prefer } \\
\text { remotely or your level of autonomy) be linked to my performance. }\end{array}$ \\
\hline 5 & $\begin{array}{l}\text { I would prefer } \_ \text {of the personal resources provided to me by my employer } \\
\text { (e.g., the quality of a car or cell phone provided by your employer) be linked to } \\
\text { my performance. }\end{array}$ \\
\hline 6 & $\begin{array}{l}\text { I would prefer } \_ \text {of the gifts and discounts provided by my employer (e.g., } \\
\text { gift card amount or size of the discount for movie tickets) be linked to my } \\
\text { performance. }\end{array}$ \\
\hline 7 & $\begin{array}{l}\text { I would prefer } \ldots \text { of the personal services offered by my employer (e.g., hours } \\
\text { of financial advising or legal counsel) be linked to my performance. }\end{array}$ \\
\hline 8 & $\begin{array}{l}\text { I would prefer } \ldots \text { of the conveniences offered by my employer (e.g., quality } \\
\text { of food served in the workplace cafeteria) be linked to my performance. }\end{array}$ \\
\hline 9 & $\begin{array}{l}\text { I would prefer } \quad \text { of the health and well-being benefits offered by my } \\
\text { employer (e.g., quality of health care plan or dental insurance plan) be linked to } \\
\text { my performance. }\end{array}$ \\
\hline 10 & $\begin{array}{l}\text { I would prefer } \_ \text {of the family life facilitation offered by my employer (e.g., } \\
\text { contributions to dependent care or access to on-site daycare) be linked to my } \\
\text { performance. }\end{array}$ \\
\hline 11 & $\begin{array}{l}\text { I would prefer } \ldots \text { of the professional growth offered by my employer (e.g., } \\
\text { training opportunities or conference funding) be linked to my performance. }\end{array}$ \\
\hline 12 & $\begin{array}{l}\text { I would prefer } \_ \text {of the organizational culture programs offered by my } \\
\text { employer (e.g., number of team bonding events or organization retreats) be } \\
\text { linked to my performance. }\end{array}$ \\
\hline 13 & $\begin{array}{l}\text { I would prefer } \_ \text {of the work condition enhancements provided by my } \\
\text { employer (e.g., quality of free snacks in the office or access to nap rooms) be } \\
\text { linked to my performance. }\end{array}$ \\
\hline 14 & $\begin{array}{l}\text { I would prefer } \ldots \text { of the status/recognition rewards offered by my employer } \\
\text { (e.g., likelihood of winning employee of the month or quality of work } \\
\text { anniversary awards) be linked to my performance. }\end{array}$ \\
\hline
\end{tabular}


Appendix C

\begin{tabular}{|c|c|c|c|c|c|c|c|c|c|c|c|c|c|c|c|c|}
\hline Incentives & PSA & Rep. & 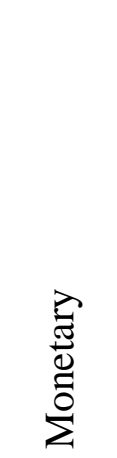 & 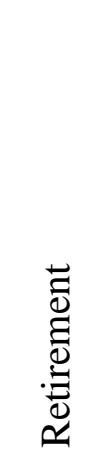 & $\begin{array}{l}\bigcup^{ \pm} \\
\Xi \\
\Xi \\
\Xi\end{array}$ & 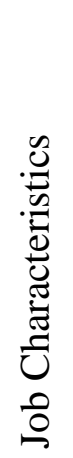 & 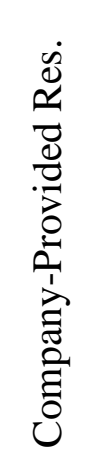 & 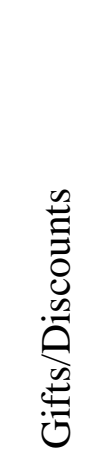 & 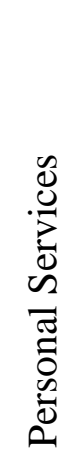 & 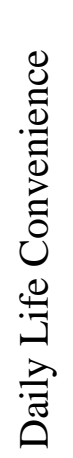 & 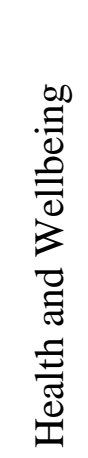 & 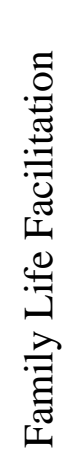 & 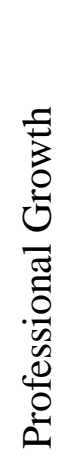 & 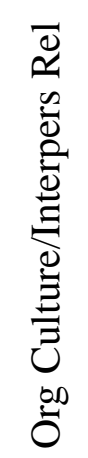 & 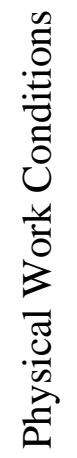 & 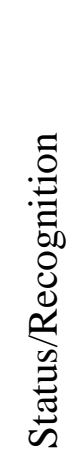 \\
\hline Salary & 1.00 & 2.80 & 14 & & & & & & & & & & & & & (1) \\
\hline Monetary bonus & 1.00 & 3.00 & 14 & & & & & (1) & & & & & & & & (1) \\
\hline Employee stock & 1.00 & 2.73 & $13(1)$ & (1) & & & (1) & $1(1)$ & & & & & & & & \\
\hline Profit-sharing & 1.00 & 2.93 & 14 & & & & (1) & & & & & & & & & (1) \\
\hline Gainsharing & 1.00 & 2.87 & 14 & & & & & & & & & & & & & (4) \\
\hline Commuter checks & .71 & 2.30 & 10 & & & & (1) & $3(2)$ & & 1 & & & & (1) & & \\
\hline Relocation costs & .57 & 2.44 & 8 & & & & 5 & 1 & & & & $(1)$ & & & & \\
\hline Pension plan & .86 & 3.00 & $4(1)$ & $10(2)$ & & & & & & & & & & & & \\
\hline Defined contribution plan & .86 & 2.93 & $4(3)$ & $10(2)$ & & & & & & & & & & & & \\
\hline Retiree insurance & .50 & 2.75 & $2(2)$ & 7 & & & 1 & & & & $4(1)$ & & & & & \\
\hline Sick days & .86 & 2.69 & $1(1)$ & & $10(2)$ & & & & & & $3(4)$ & & & & & \\
\hline Paid holidays & .93 & 2.86 & $3(1)$ & & $11(2)$ & & & & & & & & & & & \\
\hline Paid jury duty & .57 & 2.22 & 4 & & $7(1)$ & & 1 & & & 1 & & & & 1 & & \\
\hline Extra paid time off & .93 & 2.94 & $1(1)$ & & 13 & & & & (1) & & & (1) & & & & \\
\hline Paid volunteer time off & .79 & 2.73 & 1 & & 11 & & & & & & & & 1 & $1(1)$ & & \\
\hline
\end{tabular}




\begin{tabular}{|c|c|c|c|c|c|c|c|c|c|c|c|c|c|c|c|c|}
\hline Incentives & PSA & Rep. & 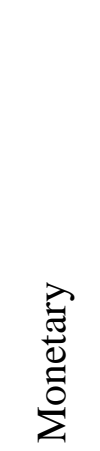 & 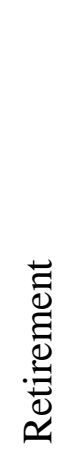 & 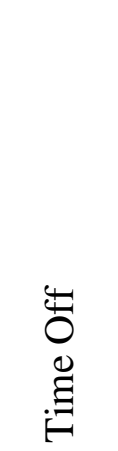 & 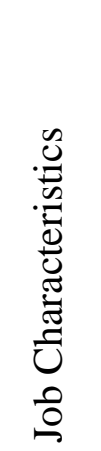 & 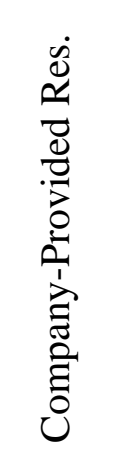 & 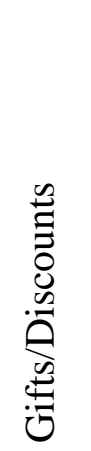 & 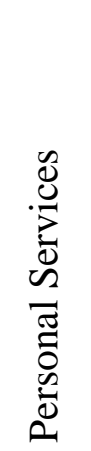 & 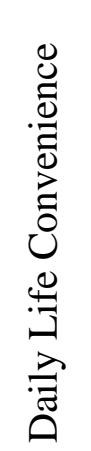 & 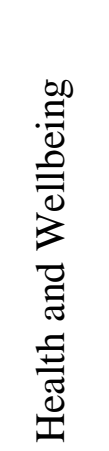 & 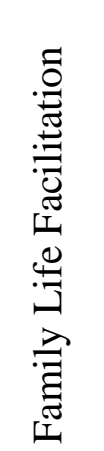 & 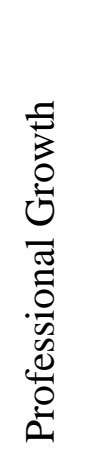 & 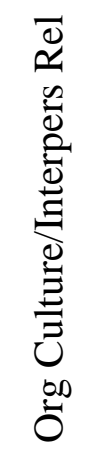 & 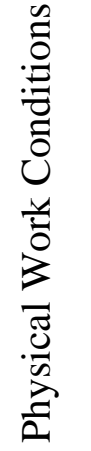 & 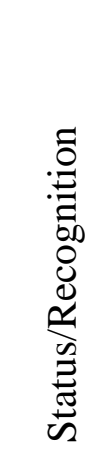 \\
\hline Paid sabbatical & .71 & 2.82 & $3(1)$ & & $9(1)$ & & & & & & & & $2(2)$ & & & \\
\hline Unpaid extended leave & .86 & 2.83 & & & $11(1)$ & & 1 & & 1 & & (1) & 1(2) & & & & \\
\hline Parental leave & .86 & 3.00 & 1 & & $11(1)$ & & & & (2) & & (1) & (2) & 1 & 1 & & \\
\hline Military leave & .79 & 2.62 & & & $10(1)$ & & 1 & & 1(1) & & & 2 & & (1) & & \\
\hline Bereavement leave & .86 & 2.42 & & & 12 & & 1 & & & & (2) & $1(2)$ & & & & \\
\hline Flextime & .64 & 2.44 & & & & 9 & & & & 1 & & $3(4)$ & & (1) & 1 & \\
\hline Telecommuting/remote work & .57 & 2.38 & & & (1) & 8 & & & & 3 & (1) & $3(1)$ & & & (2) & \\
\hline High autonomy & .79 & 3.00 & & & & 11 & & & (1) & & & & & 3 & & (1) \\
\hline Interesting/meaningful work & .79 & 2.58 & & & & 11 & & & & & 1 & & 1 & 1 & & \\
\hline Job swapping & .71 & 2.27 & & & & $9(1)$ & & & & 1 & & (1) & 3 & 1(1) & & \\
\hline Job security & .64 & 1.90 & & & & 9 & & & & & 2(1) & & (1) & 2 & & 1 \\
\hline Company phone & .86 & 2.92 & 1(1) & & & 1(1) & 11(1) & & & & & & & & 1 & \\
\hline Company car & .86 & 2.85 & 1(1) & & & 3 & $10(2)$ & & & (1) & & & & & & (1) \\
\hline Company computer or tablet & .71 & 2.67 & & & & 3 & 10 & 1 & & & & & & & & \\
\hline Housing & .57 & 2.50 & $3(1)$ & & & & $6(2)$ & & 3 & 1(3) & & 1 & & & & \\
\hline Personalized items & .57 & 1.89 & & & & & 4 & $7(1)$ & & & & & & 1(1) & & 2(1) \\
\hline
\end{tabular}




\begin{tabular}{|c|c|c|c|c|c|c|c|c|c|c|c|c|c|c|c|c|}
\hline Incentives & PSA & Rep. & 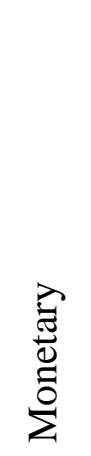 & 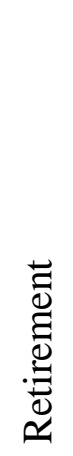 & 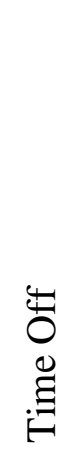 & 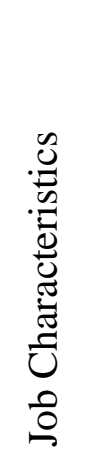 & 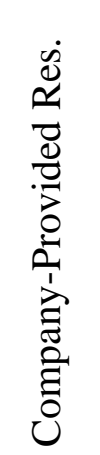 & 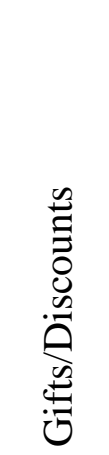 & 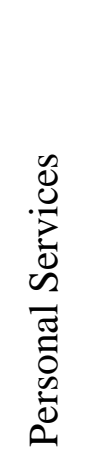 & 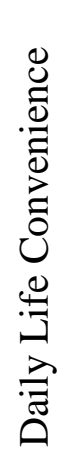 & 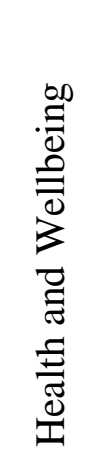 & 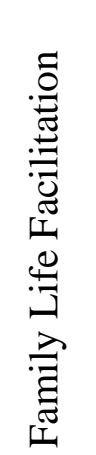 & 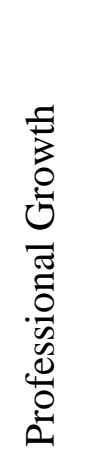 & 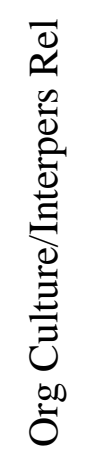 & 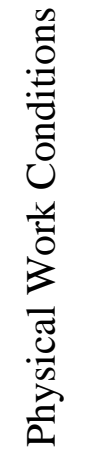 & 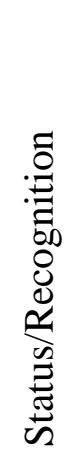 \\
\hline Phone discounts & .79 & 2.81 & 3 & & & 1 & & $10(1)$ & & & & & & & & \\
\hline Employee discounts & .86 & 2.58 & 1(1) & & & & 1(1) & 12 & & & & & & & & \\
\hline Tickets/coupons & .93 & 2.77 & 1(1) & & & & 2 & $11(2)$ & & & & & & & & \\
\hline Gift cards & .93 & 2.71 & 2(3) & & & & & $12(1)$ & & & & & & & & (2) \\
\hline Free travel & .36 & 2.80 & $5(1)$ & & (2) & (1) & 4 & $4(1)$ & 1 & & (1) & & & & & \\
\hline Financial advising & .71 & 2.70 & & 1 & & & 2 & (1) & $9(1)$ & & & 1(1) & 1 & & & \\
\hline Legal counsel & .71 & 2.36 & 1 & & & & $2(1)$ & $1(1)$ & 10 & & & & & & & \\
\hline Loan assistance & .71 & 2.55 & 3 & & & & 1 & & $9(1)$ & & & (3) & 1 & & & \\
\hline Life coaching & .64 & 2.50 & (1) & & & & & & $6(3)$ & & $3(1)$ & & $5(3)$ & & & \\
\hline Assistance programs (EAP) & .50 & 2.29 & & & & & 2 & & 4(3) & & 7 & & 1(3) & & & \\
\hline Travel concierge & .29 & 2.50 & & & & 1 & 1(1) & & 8 & 4 & & & & & & \\
\hline On-site dining options & .79 & 2.50 & & & & & 2 & & 1 & 11 & & (1) & & (1) & & \\
\hline On-site hair/nail salon & .93 & 2.50 & & & & & 1 & & (1) & 13 & & & & & (1) & \\
\hline Laundry service & .79 & 2.58 & 1 & & & & (1) & & 2(1) & 11 & & & & & & \\
\hline On-site car services & .79 & 2.64 & & & & & 2 & & 1 & 11 & & & & & & \\
\hline Health insurance & .93 & 2.73 & 1(3) & & & & & (1) & (1) & & 13 & (1) & & & & \\
\hline
\end{tabular}




\begin{tabular}{|c|c|c|c|c|c|c|c|c|c|c|c|c|c|c|c|c|}
\hline Incentives & PSA & Rep. & 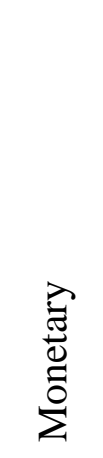 & 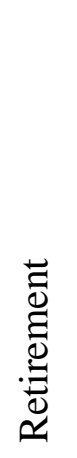 & 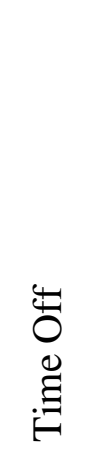 & 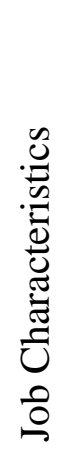 & 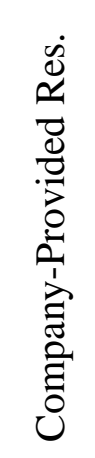 & 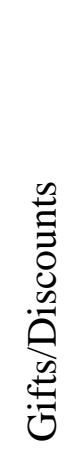 & 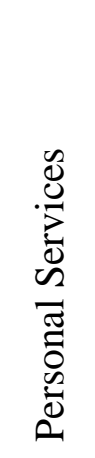 & 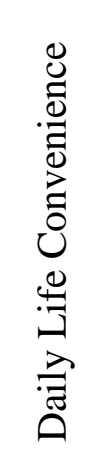 & 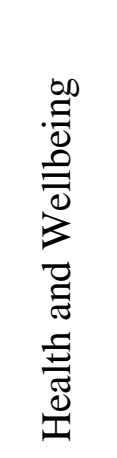 & 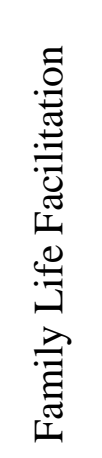 & 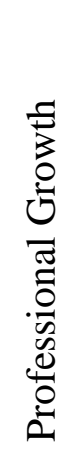 & 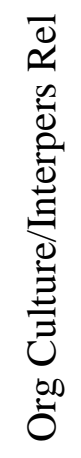 & 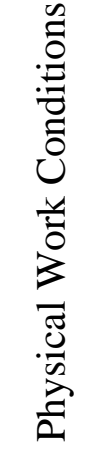 & 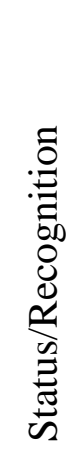 \\
\hline Dental insurance & .93 & 2.79 & $3(1)$ & & & & & & (2) & & $11(2)$ & & & & & \\
\hline Vision insurance & .86 & 2.62 & 2 & & & & & (1) & & & 12 & & & & & \\
\hline Life insurance & .50 & 2.71 & $4(2)$ & 1 & & & 2 & & & & $6(1)$ & $1(1)$ & & & & \\
\hline Disability/accident insurance & .64 & 2.44 & $3(1)$ & & 1 & & 1 & & $1(1)$ & & $8(1)$ & & & & & \\
\hline Staff psychologist & .86 & 2.69 & & & & & $2(1)$ & & $2(3)$ & & $10(2)$ & & (1) & (1) & & \\
\hline Gym membership & .71 & 2.73 & 2 & & & & $1(1)$ & 4 & $1(2)$ & & $6(4)$ & & & & & \\
\hline On-site gym & .86 & 2.67 & & & & & & & 1 & $1(5)$ & 11(1) & & & & $1(1)$ & \\
\hline On-site clinic/pharmacy & .79 & 2.71 & & & & & $2(1)$ & & (1) & $3(6)$ & $9(2)$ & & & & & \\
\hline Diet/exercise plans/classes & .79 & 2.67 & $1(1)$ & & & & $1(1)$ & & $2(2)$ & & $10(1)$ & & & & & \\
\hline Massages & .64 & 2.60 & & & & & & & & $3(1)$ & 9 & & & 1 & 1 & \\
\hline On-site daycare & .86 & 2.86 & & & & & & & $(2)$ & $5(3)$ & 1 & $8(4)$ & & & & \\
\hline Lactation/mother's room & .50 & 2.50 & & & & & & & $2(2)$ & $2(1)$ & 2 & $5(2)$ & & 1 & $2(2)$ & \\
\hline Fertility assistance & .50 & 2.71 & 2 & & & & & & $4(1)$ & & $4(3)$ & $4(3)$ & & & & \\
\hline Adoption assistance & .71 & 2.55 & $1(1)$ & & & & & & 7 & & & $6(4)$ & & & & \\
\hline Dependent care & .71 & 2.82 & $2(1)$ & & & & 1 & & (1) & 1 & $1(1)$ & $9(1)$ & & & & \\
\hline Family medical leave & .57 & 2.75 & & & $3(2)$ & & & & (1) & & 5 & $6(2)$ & & & & \\
\hline
\end{tabular}




\begin{tabular}{|c|c|c|c|c|c|c|c|c|c|c|c|c|c|c|c|c|}
\hline Incentives & PSA & Rep. & $\begin{array}{l}\vec{E} \\
\stackrel{0}{0} \\
\stackrel{0}{\Sigma}\end{array}$ & 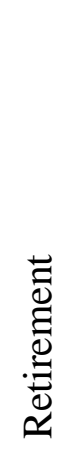 & 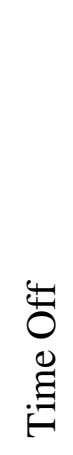 & 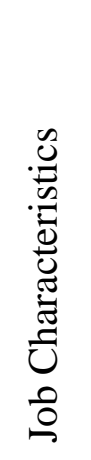 & 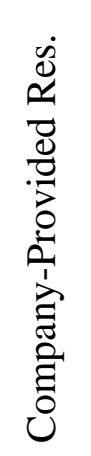 & 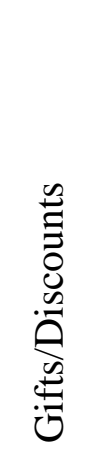 & 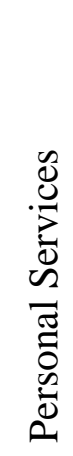 & 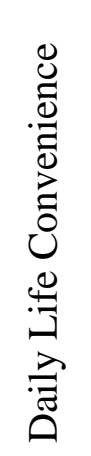 & 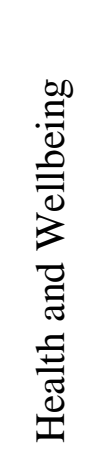 & 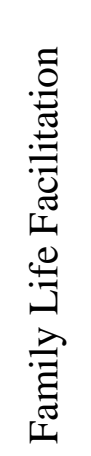 & 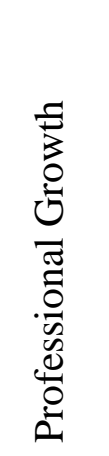 & 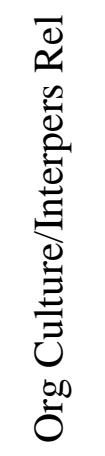 & 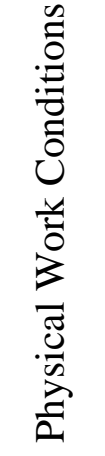 & 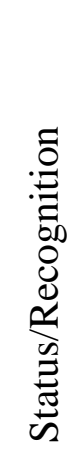 \\
\hline Tuition/loan reimbursement & .50 & 2.57 & $10(1)$ & & & & (1) & 1 & & & & & $3(4)$ & & & \\
\hline Growth opportunities & 1.00 & 2.62 & & & & & & & & & & & 14 & & & (2) \\
\hline Conference funding & .93 & 2.78 & $3(1)$ & & & & 1 & & & & & & 10(3) & (1) & & \\
\hline Mentoring & .86 & 2.85 & & & & 1 & & & & & 1 & & 12 & (1) & & \\
\hline Training opportunities & 1.00 & 2.93 & & & & (1) & & & & & & & 14 & (1) & & \\
\hline Employee outings/retreats & 1.00 & 2.67 & & & & & (1) & & & & & & & 14 & & \\
\hline Team bonding events & 1.00 & 2.67 & & & & (1) & & & (1) & & & & & 14 & & \\
\hline Positive organizational image & .79 & 2.64 & & & & & & & & & & & & 11 & & 3 \\
\hline Diversity program & .79 & 2.50 & & & & & (1) & & & & $1(1)$ & & 1 & 11 & & \\
\hline Charitable gift matching & .43 & 2.00 & (1) & & & & 2 & $6(1)$ & & & 1 & & & $4(2)$ & (1) & \\
\hline Friendly coworkers/boss & .93 & 2.64 & & & & 1 & & & & & & & & 13 & & \\
\hline Birthday celebration & .57 & 2.56 & & & & & & 1 & & & & & & $7(1)$ & & 6 \\
\hline Free food, snacks, beverages & .07 & 2.00 & 1 & & & & 3 & 6 & & $3(2)$ & & & & 1(1) & (1) & \\
\hline Game rooms, nap rooms & .79 & 2.45 & & & & 1 & 1 & & & 1 & $2(3)$ & & & $2(1)$ & $7(4)$ & \\
\hline Pet friendly workplace & .29 & 2.00 & & & & 1 & 1 & & 2 & (1) & (1) & 1(1) & & $6(1)$ & $3(1)$ & \\
\hline Casual dress & .50 & 1.88 & & & & $2(1)$ & & 1 & & $2(1)$ & (1) & & & $3(1)$ & $6(1)$ & \\
\hline
\end{tabular}




\begin{tabular}{|c|c|c|c|c|c|c|c|c|c|c|c|c|c|c|c|c|}
\hline Incentives & PSA & Rep. & 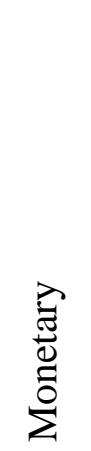 & 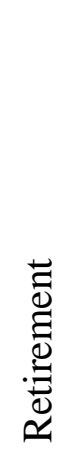 & $\begin{array}{l}\stackrel{\varpi}{0} \\
\Xi \\
\Xi \\
\Xi\end{array}$ & 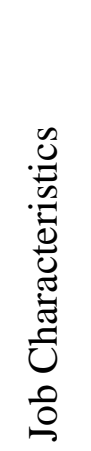 & 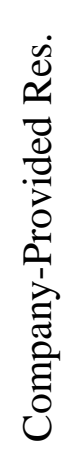 & 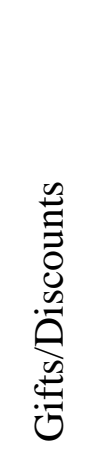 & 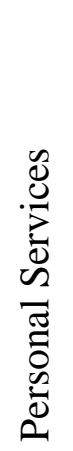 & 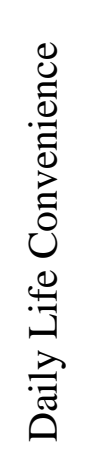 & 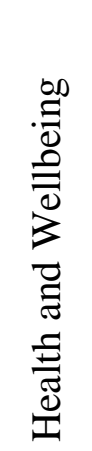 & 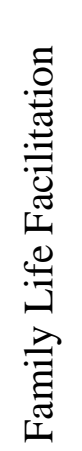 & 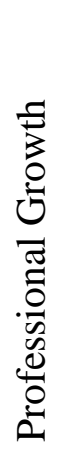 & 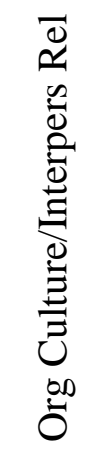 & 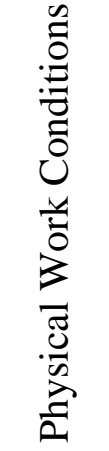 & 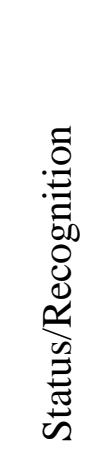 \\
\hline Office size/location & .64 & 2.86 & & & & 2(1) & & & & & & & & & $8(1)$ & $4(1)$ \\
\hline Comfortable work conditions & 1.00 & 2.50 & & & & 1(2) & & & & & (1) & & & (1) & $13(1)$ & \\
\hline Standing desks & .57 & 2.30 & & & & 3 & 2 & & & & $4(2)$ & & & & $5(3)$ & \\
\hline Employee of month & 1.00 & 2.88 & & & & & & & & & & & & (2) & & 14 \\
\hline Premium parking spot & .57 & 2.50 & & & & 1 & & & & $5(2)$ & & & & & 1(3) & $7(1)$ \\
\hline Private bathroom & .50 & 2.43 & & & & 1 & 1 & & & 1(2) & & & & & $5(1)$ & $6(1)$ \\
\hline Praise & .64 & 3.00 & & & & 1 & & & & & & & 2 & $3(2)$ & & $8(1)$ \\
\hline Work anniversary awards & .79 & 2.83 & (1) & 1 & & & & $1(2)$ & & & & & & 2 & & $10(1)$ \\
\hline Work anniversary gifts & .57 & 2.56 & (2) & 1 & & & 1 & 4(3) & & & & & & 2(1) & & $6(2)$ \\
\hline
\end{tabular}

Note: PSA = Proportion of Substantive Agreement, calculated as number of SMEs that placed the item as belonging to the highlighted category divided by the total sample size; Rep. $=$ Average rating of representativeness rating from respondents that placed the item in the highlighted category, using a scale where $1=$ Slightly Representative, $2=$ Moderately Representative, $3=$ Very Representative. Numbers in parentheses represent secondary category ratings. 
Appendix D1

Study II - Correlations between Incentive Categories

\begin{tabular}{|c|c|c|c|c|c|c|c|c|c|c|c|c|c|c|c|}
\hline Incentive & $M$ & $S D$ & Mon. & Ret. & TO & $\mathrm{JC}$ & CPR & GD & PS & DLC & HW & FLF & PG & $\mathrm{OC}$ & PWC \\
\hline Mon. & 3.85 & 0.77 & & & & & & & & & & & & & \\
\hline Ret. & 4.16 & 0.86 & .55 & & & & & & & & & & & & \\
\hline TO & 3.93 & 0.64 & .64 & .58 & & & & & & & & & & & \\
\hline $\mathrm{JC}$ & 4.08 & 0.67 & .72 & .57 & .67 & & & & & & & & & & \\
\hline CPR & 3.45 & 1.06 & .58 & .45 & .53 & .56 & & & & & & & & & \\
\hline GD & 3.98 & 0.77 & .49 & .34 & .55 & .49 & .53 & & & & & & & & \\
\hline PS & 3.46 & 0.88 & .63 & .56 & .62 & .56 & .58 & .53 & & & & & & & \\
\hline DLC & 3.19 & 1.05 & .52 & .34 & .46 & .50 & .70 & .61 & .56 & & & & & & \\
\hline HW & 3.95 & 0.71 & .60 & .63 & .64 & .59 & .66 & .62 & .68 & .64 & & & & & \\
\hline FLF & 3.20 & 0.93 & .51 & .50 & .62 & .49 & .48 & .40 & .67 & .49 & .56 & & & & \\
\hline PG & 4.23 & 0.64 & .59 & .49 & .59 & .67 & .50 & .52 & .53 & .43 & .57 & .45 & & & \\
\hline $\mathrm{OC}$ & 3.84 & 0.71 & .44 & .32 & .52 & .53 & .43 & .60 & .53 & .43 & .55 & .42 & .55 & & \\
\hline PWC & 3.64 & 0.70 & .53 & .44 & .54 & .52 & .60 & .63 & .58 & .63 & .65 & .49 & .44 & .59 & \\
\hline SR & 3.72 & 0.86 & .45 & .29 & .53 & .49 & .48 & .66 & .54 & .51 & .49 & .44 & .50 & .71 & .67 \\
\hline
\end{tabular}

Note: $N=300$. All correlations are significant at $p<.001$. Responses to incentive attractiveness were made on a 5-point scale $(1=$ Not at all desirable, $2=$ Slightly desirable, $3=$ Moderately desirable, $4=$ Highly desirable, $5=$ Extremely desirable $)$. Mon $=$ Monetary, Ret $=$ Retirement, TO $=$ Time Off, JC $=$ Job Characteristics, CPR $=$ Company-Provided Resources, GD $=$ Gifts and Discounts, PS = Personal Services, DLC = Daily Life Convenience, HW = Health and Well-being, FLF = Family Life Facilitation, $\mathrm{PG}=$ Professional Growth, $\mathrm{OC}=$ Organizational Culture, $\mathrm{PWC}=$ Physical Working Conditions, SR $=$ Status and Recognition. 
Appendix D2

Study II - Correlations between Personality Traits

\begin{tabular}{|c|c|c|c|c|c|c|c|c|c|c|c|c|c|c|c|c|}
\hline Trait & $M$ & $S D$ & 1 & 2 & 3 & 4 & 5 & 6 & 7 & 8 & 9 & 10 & 11 & 12 & 13 & 14 \\
\hline 1. Neuroticism & 2.61 & 0.66 & & & & & & & & & & & & & & \\
\hline 2. (N)Volatility & 2.49 & 0.79 & $* .92$ & & & & & & & & & & & & & \\
\hline 3. (N)Withdrawal & 2.72 & 0.66 & $* .88$ & $* .63$ & & & & & & & & & & & & \\
\hline 4. Agreeableness & 3.95 & 0.50 & $*-.24$ & $*_{-} .33$ & -.08 & & & & & & & & & & & \\
\hline 5. (A)Compassion & 4.01 & 0.63 & $*_{-} .20$ & $*_{-} .27$ & -.08 & $* .89$ & & & & & & & & & & \\
\hline 6. (A)Politeness & 3.89 & 0.53 & $*_{-} .21$ & $*_{-} .31$ & -.05 & $* .84$ & $* .50$ & & & & & & & & & \\
\hline 7. Conscientious. & 3.82 & 0.52 & $*_{-} .54$ & $*_{-.49}$ & $*_{-.48}$ & $* .40$ & $* .33$ & $* .37$ & & & & & & & & \\
\hline 8. (C)Industrious. & 3.80 & 0.65 & $*_{-} .64$ & $*_{-} .56$ & $*_{-} .60$ & $* .31$ & $* .26$ & $* .27$ & $* .88$ & & & & & & & \\
\hline 9. (C)Orderliness & 3.83 & 0.57 & $*_{-} .26$ & $*_{-} .26$ & $*_{-} .20$ & $* .39$ & $* .31$ & $* .36$ & $* .84$ & $* .48$ & & & & & & \\
\hline 10. Extraversion & 3.68 & 0.55 & $*_{-} .43$ & $*_{-} .36$ & $*_{-.} 43$ & $* .33$ & $* .44$ & .09 & $* .50$ & $* .52$ & $* .34$ & & & & & \\
\hline 11. (E)Enthusiasm & 3.67 & 0.64 & $*_{-} .37$ & $*_{-} .35$ & $*_{-} .31$ & $* .43$ & $* .48$ & $* .25$ & $* .35$ & $* .35$ & $* .25$ & $* .85$ & & & & \\
\hline 12. (E)Assertive. & 3.69 & 0.65 & $*_{-} .37$ & $*_{-} .26$ & $*_{-.42}$ & $* .12$ & $* .26$ & -.08 & $* .50$ & $* .53$ & $* .32$ & $* .85$ & $* .44$ & & & \\
\hline 13. Openness/Intel. & 3.80 & 0.45 & $*_{-} .37$ & $*_{-} .33$ & $*_{-} .34$ & $* .35$ & $* .41$ & $* .18$ & $* .42$ & $* .45$ & $* .26$ & $* .55$ & $* .40$ & $* .52$ & & \\
\hline 14. (O)Intellect & 3.85 & 0.59 & $*_{-} .48$ & $*_{-} .39$ & $*_{-.49}$ & $* .23$ & $* .29$ & .10 & $* .54$ & $* .59$ & $* .32$ & $* .56$ & $* .36$ & $* .59$ & $* .84$ & \\
\hline 15. (O)Openness & 3.74 & 0.53 & -.10 & $*_{-} .13$ & -.04 & $* .35$ & $* .39$ & $* .20$ & $* .12$ & .11 & .09 & $* .32$ & $* .30$ & $* .24$ & $* .79$ & $* .33$ \\
\hline
\end{tabular}

Note: $N=300$. ${ }^{*}$ Correlations over .11 are significant at $p<.05$; correlations over .14 are significant at $p<.01$; correlations over .18 are significant at $p<.001$. Responses to personality items were made on a 5-point scale $(1=$ Strongly disagree, $2=$ Somewhat disagree, $3=$ Neither agree nor disagree, 4=Somewhat agree, 5=Strongly agree). 


\section{Appendix D3}

Study II - Correlations between Non-Personality Individual Differences

\begin{tabular}{lrrrrrrr}
\hline Variable & $M$ & \multicolumn{1}{c}{$S D$} & Age & $\begin{array}{c}\text { Avg. } \\
\text { Work Hrs. }\end{array}$ & $\begin{array}{c}\text { Total } \\
\text { Tenure }\end{array}$ & $\begin{array}{c}\text { Total } \\
\text { Jobs Held }\end{array}$ & $\begin{array}{c}\text { Physical } \\
\text { Health }\end{array}$ \\
\hline Age & 23.92 & 6.06 & & & & & \\
Avg. Work Hrs. & 28.74 & 12.23 & $* * * .24$ & & & & \\
Total Tenure & 5.92 & 5.32 & $* * * .88$ & $* * * .30$ & & & \\
Total Jobs Held & 3.60 & 2.38 & $* * * .48$ & $* * * .26$ & $* * * .60$ & & \\
Physical Health & 6.67 & 1.54 & .07 & .08 & .11 & .04 & \\
Mental Health & 6.45 & 2.09 & .07 & $* .15$ & .09 & -.06 & $* * * .33$ \\
\hline Note: $n$ ranges from $237-300 . * p<.05 ; * * * p<.001$. & & &
\end{tabular}




\section{Appendix E1}

Study II - Incentive Preferences by Personality

\begin{tabular}{|c|c|c|}
\hline Low Neuroticism & $\underline{\text { Rank }}$ & $\underline{\text { High Neuroticism }}$ \\
\hline$\overline{\text { Paid holidays }}$ & 1 & $\overline{\text { Paid holidays }}$ \\
\hline Interesting/meaningful work & 2 & Friendly coworkers/boss \\
\hline Comfortable working conditions & 3 & Interesting/meaningful work \\
\hline Tuition/student loan reimbursement & 4 & Salary \\
\hline Friendly coworkers/boss & 5 & Comfortable working conditions \\
\hline Low Agreeableness & & High Agreeableness \\
\hline Paid holidays & 1 & Paid holidays \\
\hline Salary & 2 & Interesting/meaningful work \\
\hline Tuition/student loan reimbursement & 3 & Friendly coworkers/boss \\
\hline Extra paid time off & 4 & Comfortable working conditions \\
\hline Sick days & 5 & Tuition/student loan reimbursement \\
\hline Low Conscientiousness & & $\underline{\text { High Conscientiousness }}$ \\
\hline$\overline{\text { Paid holidays }}$ & 1 & $\overline{\text { Paid holidays }}$ \\
\hline Salary & 2 & Comfortable working conditions \\
\hline Interesting/meaningful work & 3 & Tuition/student loan reimbursement \\
\hline Friendly coworkers/boss & 4 & Friendly coworkers/boss \\
\hline Tuition/student loan reimbursement & 5 & Interesting/meaningful work \\
\hline Low Extraversion & & $\underline{\text { High Extraversion }}$ \\
\hline Paid holidays & 1 & Paid holidays \\
\hline Interesting/meaningful work & 2 & Friendly coworkers/boss \\
\hline Salary & 3 & Interesting/meaningful work \\
\hline Comfortable working conditions & 4 & Tuition/student loan reimbursement \\
\hline Friendly coworkers/boss & 5 & Health insurance \\
\hline Low Openness/Intellect & & High Openness/Intellect \\
\hline Paid holidays & 1 & Paid holidays \\
\hline Friendly coworkers/boss & 2 & Comfortable working conditions \\
\hline Salary & 3 & Interesting/meaningful work \\
\hline Tuition/student loan reimbursement & 4 & Salary \\
\hline Sick days & 5 & Tuition/student loan reimbursement \\
\hline
\end{tabular}




\section{Appendix E2}

Study II - Incentive Preferences by Demographics

\begin{tabular}{|c|c|c|}
\hline Male & $\underline{\text { Rank }}$ & Female \\
\hline$\overline{\text { Paid holidays }}$ & 1 & $\overline{\text { Paid holidays }}$ \\
\hline Salary & 2 & Interesting/meaningful work \\
\hline Health insurance & 3 & Friendly coworkers/boss \\
\hline Friendly coworkers/boss & 4 & Salary \\
\hline Tuition/student loan reimbursement & 5 & Tuition/student loan reimbursement \\
\hline Generation $\mathrm{Z}$ & & $\underline{\text { Millennials }}$ \\
\hline Paid holidays & 1 & Paid holidays \\
\hline Friendly coworkers/boss & 2 & Health insurance \\
\hline Interesting/meaningful work & 3 & Salary \\
\hline Salary & 4 & Growth opportunities \\
\hline Comfortable working conditions & 5 & Job security \\
\hline Hispanic & & Caucasian/White \\
\hline Paid holidays & 1 & $\overline{\text { Comfortable working conditions }}$ \\
\hline Salary & 2 & Friendly coworkers/boss \\
\hline Interesting/meaningful work & 3 & Paid holidays \\
\hline Friendly coworkers/boss & 4 & Interesting/meaningful work \\
\hline Job security & 5 & Tuition/student loan reimbursement \\
\hline Black/African American & & $\underline{\text { Asian }}$ \\
\hline Paid holidays & 1 & Job security \\
\hline Tuition/student loan reimbursement & 2 & Growth opportunities \\
\hline Salary & 3 & Pension plan \\
\hline Interesting/meaningful work & 4 & Free travel \\
\hline Dental insurance & 5 & Monetary bonus \\
\hline Married & & $\underline{\text { Unmarried }}$ \\
\hline Paid holidays & 1 & Paid holidays \\
\hline Job security & 2 & Friendly coworkers/boss \\
\hline Interesting/meaningful work & 3 & Salary \\
\hline Defined contribution plan & 4 & Interesting/meaningful work \\
\hline Health insurance & 5 & Tuition/student loan reimbursement \\
\hline Parent & & Non-Parent \\
\hline Paid holidays & 1 & Paid holidays \\
\hline Defined contribution plan & 2 & Friendly coworkers/boss \\
\hline Health insurance & 3 & Salary \\
\hline Job security & 4 & Interesting/meaningful work \\
\hline Growth opportunities & 5 & Tuition/student loan reimbursement \\
\hline
\end{tabular}


Appendix E2 (continued)

\begin{tabular}{lcll}
\hline Low Physical Health & Rank & & High Physical Health \\
Family medical leave & 1 & Paid holidays \\
Interesting/meaningful work & 2 & Salary \\
Tuition/student loan reimbursement & 3 & Friendly coworkers/boss \\
Paid holidays & 4 & Interesting/meaningful work \\
Comfortable working conditions & 5 & Tuition/student loan reimbursement \\
\hline Low Mental Health & & High Mental Health \\
Interesting/meaningful work & 1 & Paid holidays \\
Paid holidays & 2 & Friendly coworkers/boss \\
Salary & 3 & Salary \\
Tuition/student loan reimbursement & 4 & Interesting/meaningful work \\
Comfortable working conditions & 5 & Comfortable working conditions \\
\hline Employed Full-Time & & Employed Part-Time \\
Paid holidays & 1 & Paid holidays \\
Friendly coworkers/boss & 2 & Salary \\
Interesting/meaningful work & 3 & Friendly coworkers/boss \\
Health insurance & 4 & Interesting/meaningful work \\
Tuition/student loan reimbursement & 5 & Comfortable working conditions \\
\hline
\end{tabular}




\section{Appendix F1}

Study II - Monetary Regression

\begin{tabular}{|c|c|c|c|c|c|c|c|c|}
\hline & $B$ & $S E$ & $\beta$ & $t$ & $B$ & $S E$ & $\beta$ & $t$ \\
\hline Constant & 7.22 & 2.59 & & $* * 2.79$ & 7.78 & 2.67 & & $* * 2.91$ \\
\hline Age & -0.02 & 0.01 & -.17 & -1.76 & -0.03 & 0.01 & -.19 & -1.96 \\
\hline${ }^{1}$ Gender & -0.10 & 0.14 & -.05 & -0.72 & -0.02 & 0.15 & -.01 & -0.12 \\
\hline${ }^{2}$ White & -0.43 & 0.21 & -.15 & $*_{-} 2.10$ & -0.46 & 0.21 & -.16 & $*_{-} 2.21$ \\
\hline${ }^{2}$ Black & -0.06 & 0.16 & -.03 & -0.38 & -0.11 & 0.17 & -.05 & -0.66 \\
\hline${ }^{3}$ Married & 0.08 & 0.22 & .03 & 0.35 & 0.05 & 0.22 & .02 & 0.24 \\
\hline${ }^{4}$ Children & 0.23 & 0.20 & .10 & 1.13 & -0.29 & 0.21 & -.13 & -1.41 \\
\hline Work Hours & 0.00 & 0.01 & -.01 & -0.17 & 0.00 & 0.01 & -.02 & -0.31 \\
\hline Jobs Held & 0.07 & 0.03 & .21 & $* 2.52$ & 0.07 & 0.03 & .22 & $* 2.52$ \\
\hline Income & 0.01 & 0.02 & .02 & 0.33 & 0.00 & 0.02 & -.01 & -0.10 \\
\hline Grad Degree Wanted & -0.33 & 0.16 & -.15 & $*-2.04$ & -0.41 & 0.17 & -.19 & $*-2.43$ \\
\hline Physical Health & -0.05 & 0.04 & -.10 & -1.33 & -0.05 & 0.04 & -.11 & -1.41 \\
\hline Mental Health & 0.07 & 0.03 & .18 & $* 2.35$ & 0.07 & 0.03 & .20 & $* 2.28$ \\
\hline (N) Volatility & & & & & -0.13 & 0.11 & -.13 & -1.19 \\
\hline (N) Withdrawal & & & & & 0.12 & 0.13 & .10 & 0.87 \\
\hline (A) Compassion & & & & & 0.11 & 0.12 & .09 & 0.89 \\
\hline (A) Politeness & & & & & -0.11 & 0.14 & -.08 & -0.80 \\
\hline (C) Industriousness & & & & & -0.08 & 0.15 & -.07 & -0.58 \\
\hline (C) Orderliness & & & & & 0.06 & 0.12 & .05 & 0.53 \\
\hline (E) Enthusiasm & & & & & -0.20 & 0.11 & -.17 & -1.81 \\
\hline (E) Assertiveness & & & & & 0.22 & 0.13 & .19 & 1.71 \\
\hline (O) Intellect & & & & & 0.14 & 0.13 & .11 & 1.06 \\
\hline (O) Openness & & & & & -0.07 & 0.12 & -.05 & -0.58 \\
\hline$\Delta F$ & \multicolumn{4}{|c|}{1.91} & \multicolumn{4}{|c|}{1.26} \\
\hline$d f$ & \multicolumn{4}{|c|}{12,184} & \multicolumn{4}{|c|}{10,174} \\
\hline$p$ & \multicolumn{4}{|c|}{.04} & \multicolumn{4}{|c|}{.26} \\
\hline$R$ & \multicolumn{4}{|c|}{.33} & \multicolumn{4}{|c|}{.41} \\
\hline$\Delta R^{2}$ & \multicolumn{4}{|c|}{.11} & \multicolumn{4}{|c|}{.06} \\
\hline Adjusted $R^{2}$ & \multicolumn{4}{|c|}{.05} & \multicolumn{4}{|c|}{.07} \\
\hline
\end{tabular}

Note: $*$ indicates $p<.05 .{ }^{1}$ Male $=0$, Female $=1 ;{ }^{2}$ Hispanic $=0$, White/Black $=1$;

${ }^{3}$ Unmarried $=0$, Married $=1 ;{ }^{4}$ No Children $=0$, Children $=1$. 


\section{Appendix F2}

Study II - Retirement Regression

\begin{tabular}{|c|c|c|c|c|c|c|c|c|}
\hline & $B$ & $S E$ & $\beta$ & $t$ & $B$ & $S E$ & $\beta$ & $t$ \\
\hline Constant & 3.54 & 0.62 & & $* * 5.72$ & 3.02 & 1.18 & & $* 2.55$ \\
\hline Age & 0.01 & 0.02 & .03 & 0.34 & 0.01 & 0.02 & .03 & 0.29 \\
\hline${ }^{1}$ Gender & -0.04 & 0.17 & -.02 & -0.27 & -0.03 & 0.18 & -.02 & -0.18 \\
\hline${ }^{2}$ White & -0.22 & 0.24 & -.07 & -0.89 & -0.21 & 0.25 & -.06 & -0.85 \\
\hline${ }^{2}$ Black & 0.16 & 0.19 & .06 & 0.86 & 0.16 & 0.20 & .06 & 0.80 \\
\hline${ }^{3}$ Married & 0.22 & 0.26 & .07 & 0.87 & 0.25 & 0.26 & .08 & 0.96 \\
\hline${ }^{4}$ Children & 0.14 & 0.24 & .05 & 0.59 & 0.17 & 0.25 & .06 & 0.67 \\
\hline Work Hours & 0.01 & 0.01 & .17 & $* 2.24$ & 0.01 & 0.01 & .17 & $* 2.23$ \\
\hline Jobs Held & 0.03 & 0.03 & .07 & 0.79 & 0.03 & 0.03 & .07 & 0.81 \\
\hline Income & 0.01 & 0.02 & .04 & 0.56 & 0.01 & 0.02 & .02 & 0.26 \\
\hline Grad Degree Wanted & 0.00 & 0.19 & .00 & -0.02 & -0.09 & 0.20 & -.03 & -0.42 \\
\hline Physical Health & -0.04 & 0.04 & -.08 & -1.01 & -0.05 & 0.05 & -.09 & -1.11 \\
\hline Mental Health & 0.03 & 0.03 & .08 & 1.00 & 0.03 & 0.04 & .07 & 0.77 \\
\hline (N) Volatility & & & & & -0.03 & 0.13 & -.02 & -0.20 \\
\hline (N) Withdrawal & & & & & 0.11 & 0.16 & .08 & 0.69 \\
\hline (A) Compassion & & & & & 0.16 & 0.14 & .11 & 1.12 \\
\hline (A) Politeness & & & & & -0.28 & 0.17 & -.16 & -1.63 \\
\hline (C) Industriousness & & & & & 0.15 & 0.18 & .11 & 0.87 \\
\hline (C) Orderliness & & & & & 0.09 & 0.15 & .06 & 0.60 \\
\hline (E) Enthusiasm & & & & & 0.03 & 0.13 & .02 & 0.22 \\
\hline (E) Assertiveness & & & & & -0.01 & 0.16 & -.01 & -0.07 \\
\hline (O) Intellect & & & & & -0.04 & 0.16 & -.03 & -0.27 \\
\hline (O) Openness & & & & & 0.03 & 0.14 & .02 & 0.19 \\
\hline$\Delta F$ & \multicolumn{4}{|c|}{1.64} & \multicolumn{4}{|c|}{0.58} \\
\hline$d f$ & \multicolumn{4}{|c|}{12,184} & \multicolumn{4}{|c|}{10,174} \\
\hline$p$ & \multicolumn{4}{|c|}{.08} & \multicolumn{4}{|c|}{.83} \\
\hline$R$ & \multicolumn{4}{|c|}{.31} & \multicolumn{4}{|c|}{.35} \\
\hline$\Delta R^{2}$ & \multicolumn{4}{|c|}{.10} & \multicolumn{4}{|c|}{.03} \\
\hline Adjusted $R^{2}$ & \multicolumn{4}{|c|}{.04} & \multicolumn{4}{|c|}{.02} \\
\hline
\end{tabular}




\section{Appendix F3}

Study II - Time Off Regression

\begin{tabular}{|c|c|c|c|c|c|c|c|c|}
\hline & $B$ & $S E$ & $\beta$ & $t$ & $B$ & $S E$ & $\beta$ & $t$ \\
\hline Constant & 3.80 & 0.44 & & $* * 8.60$ & 3.12 & 0.83 & & $* * 3.78$ \\
\hline Age & -0.02 & 0.01 & -.17 & -1.69 & -0.02 & 0.01 & -.19 & -1.91 \\
\hline${ }^{1}$ Gender & 0.19 & 0.12 & .12 & 1.58 & 0.19 & 0.13 & .12 & 1.47 \\
\hline${ }^{2}$ White & -0.35 & 0.17 & -.15 & $*-2.04$ & -0.40 & 0.17 & -.17 & $*-2.33$ \\
\hline${ }^{2}$ Black & 0.08 & 0.14 & .04 & 0.58 & 0.09 & 0.14 & .05 & 0.62 \\
\hline${ }^{3}$ Married & 0.14 & 0.18 & .06 & 0.75 & 0.16 & 0.18 & .07 & 0.88 \\
\hline${ }^{4}$ Children & 0.34 & 0.17 & .19 & $* 2.00$ & 0.42 & 0.17 & .23 & $* 2.43$ \\
\hline Work Hours & 0.00 & 0.00 & .09 & 1.15 & 0.01 & 0.00 & .11 & 1.49 \\
\hline Jobs Held & 0.03 & 0.02 & .12 & 1.36 & 0.03 & 0.02 & .12 & 1.40 \\
\hline Income & 0.01 & 0.01 & .05 & 0.61 & 0.00 & 0.02 & .02 & 0.25 \\
\hline Grad Degree Wanted & -0.07 & 0.14 & -.04 & -0.48 & -0.10 & 0.14 & -.05 & -0.68 \\
\hline Physical Health & -0.02 & 0.03 & -.05 & -0.69 & -0.03 & 0.03 & -.07 & -0.90 \\
\hline Mental Health & 0.01 & 0.02 & .02 & 0.21 & 0.00 & 0.03 & .01 & 0.13 \\
\hline (N) Volatility & & & & & -0.05 & 0.09 & -.06 & -0.57 \\
\hline (N) Withdrawal & & & & & 0.13 & 0.11 & .13 & 1.14 \\
\hline (A) Compassion & & & & & 0.07 & 0.10 & .07 & 0.71 \\
\hline (A) Politeness & & & & & -0.02 & 0.12 & -.02 & -0.17 \\
\hline (C) Industriousness & & & & & -0.10 & 0.12 & -.10 & -0.84 \\
\hline (C) Orderliness & & & & & 0.21 & 0.10 & .19 & 2.10 \\
\hline (E) Enthusiasm & & & & & 0.01 & 0.09 & .01 & 0.09 \\
\hline (E) Assertiveness & & & & & 0.17 & 0.11 & .17 & 1.54 \\
\hline (O) Intellect & & & & & 0.01 & 0.11 & .01 & 0.05 \\
\hline (O) Openness & & & & & -0.18 & 0.10 & -.15 & -1.79 \\
\hline$\Delta F$ & \multicolumn{4}{|c|}{1.49} & \multicolumn{4}{|c|}{1.48} \\
\hline$d f$ & \multicolumn{4}{|c|}{12,184} & \multicolumn{4}{|c|}{10,174} \\
\hline$p$ & \multicolumn{4}{|c|}{.13} & \multicolumn{4}{|c|}{.15} \\
\hline$R$ & \multicolumn{4}{|c|}{.30} & \multicolumn{4}{|c|}{.40} \\
\hline$\Delta R^{2}$ & \multicolumn{4}{|c|}{.09} & \multicolumn{4}{|c|}{.07} \\
\hline Adjusted $R^{2}$ & \multicolumn{4}{|c|}{.03} & \multicolumn{4}{|c|}{.05} \\
\hline
\end{tabular}




\section{Appendix F4}

Study II - Job Characteristics Regression

\begin{tabular}{|c|c|c|c|c|c|c|c|c|}
\hline & $B$ & $S E$ & $\beta$ & $t$ & $B$ & $S E$ & $\beta$ & $t$ \\
\hline Constant & 3.58 & 0.44 & & $* * 8.05$ & 2.20 & 0.83 & & $* * 2.64$ \\
\hline Age & 0.00 & 0.01 & .00 & -0.04 & 0.00 & 0.01 & -.04 & -0.41 \\
\hline${ }^{1}$ Gender & 0.15 & 0.12 & .09 & 1.25 & 0.13 & 0.13 & .08 & 1.05 \\
\hline${ }^{2}$ White & -0.20 & 0.17 & -.08 & -1.13 & -0.21 & 0.18 & -.09 & -1.20 \\
\hline${ }^{2}$ Black & -0.05 & 0.14 & -.03 & -0.34 & -0.06 & 0.14 & -.03 & -0.42 \\
\hline${ }^{3}$ Married & 0.16 & 0.18 & .07 & 0.89 & 0.13 & 0.19 & .06 & 0.70 \\
\hline${ }^{4}$ Children & 0.27 & 0.17 & .14 & 1.58 & 0.35 & 0.17 & .19 & $* 2.03$ \\
\hline Work Hours & 0.01 & 0.00 & .09 & 1.25 & 0.01 & 0.00 & .10 & 1.37 \\
\hline Jobs Held & 0.03 & 0.02 & .11 & 1.34 & 0.03 & 0.02 & .10 & 1.17 \\
\hline Income & 0.02 & 0.02 & .09 & 1.25 & 0.01 & 0.02 & .06 & 0.74 \\
\hline Grad Degree Wanted & -0.14 & 0.14 & -.08 & -1.02 & -0.17 & 0.14 & -.09 & -1.17 \\
\hline Physical Health & -0.05 & 0.03 & -.11 & -1.51 & -0.05 & 0.03 & -.12 & -1.51 \\
\hline Mental Health & 0.02 & 0.02 & .08 & 1.01 & 0.02 & 0.03 & .08 & 0.89 \\
\hline (N) Volatility & & & & & -0.03 & 0.09 & -.04 & -0.35 \\
\hline (N) Withdrawal & & & & & 0.13 & 0.11 & .14 & 1.20 \\
\hline (A) Compassion & & & & & 0.00 & 0.10 & .00 & -0.01 \\
\hline (A) Politeness & & & & & 0.13 & 0.12 & .11 & 1.12 \\
\hline (C) Industriousness & & & & & -0.13 & 0.12 & -.12 & -1.03 \\
\hline (C) Orderliness & & & & & 0.04 & 0.10 & .03 & 0.37 \\
\hline (E) Enthusiasm & & & & & -0.05 & 0.09 & -.05 & -0.49 \\
\hline (E) Assertiveness & & & & & 0.22 & 0.11 & .22 & $* 2.01$ \\
\hline (O) Intellect & & & & & 0.20 & 0.11 & .18 & 1.77 \\
\hline (O) Openness & & & & & -0.07 & 0.10 & -.05 & -0.65 \\
\hline$\Delta F$ & \multicolumn{4}{|c|}{1.88} & \multicolumn{4}{|c|}{1.37} \\
\hline$d f$ & \multicolumn{4}{|c|}{12,184} & \multicolumn{4}{|c|}{10,174} \\
\hline$p$ & \multicolumn{4}{|c|}{.04} & \multicolumn{4}{|c|}{.20} \\
\hline$R$ & \multicolumn{4}{|c|}{.33} & \multicolumn{4}{|c|}{.42} \\
\hline$\Delta R^{2}$ & \multicolumn{4}{|c|}{.11} & \multicolumn{4}{|c|}{.07} \\
\hline Adjusted $R^{2}$ & \multicolumn{4}{|c|}{.05} & \multicolumn{4}{|c|}{.07} \\
\hline
\end{tabular}




\section{Appendix F5}

Study II - Company-Provided Resources Regression

\begin{tabular}{|c|c|c|c|c|c|c|c|c|}
\hline & $B$ & $S E$ & $\beta$ & $t$ & $B$ & $S E$ & $\beta$ & $t$ \\
\hline Constant & 3.00 & 0.74 & & $* * 4.07$ & 3.46 & 1.42 & & $* 2.44$ \\
\hline Age & -0.01 & 0.02 & -.05 & -0.56 & -0.01 & 0.02 & -.03 & -0.32 \\
\hline${ }^{1}$ Gender & 0.00 & 0.20 & .00 & 0.02 & 0.05 & 0.22 & .02 & 0.23 \\
\hline${ }^{2}$ White & -0.35 & 0.29 & -.09 & -1.22 & -0.42 & 0.30 & -.10 & -1.40 \\
\hline${ }^{2}$ Black & -0.11 & 0.23 & -.04 & -0.48 & -0.06 & 0.24 & -.02 & -0.23 \\
\hline${ }^{3}$ Married & -0.21 & 0.31 & -.06 & -0.67 & -0.15 & 0.32 & -.04 & -0.46 \\
\hline${ }^{4}$ Children & 0.23 & 0.29 & .07 & 0.79 & 0.22 & 0.30 & .07 & 0.76 \\
\hline Work Hours & 0.01 & 0.01 & .09 & 1.24 & 0.01 & 0.01 & .10 & 1.25 \\
\hline Jobs Held & 0.11 & 0.04 & .25 & $* 2.92$ & 0.10 & 0.04 & .22 & $* 2.53$ \\
\hline Income & 0.01 & 0.02 & .02 & 0.24 & 0.00 & 0.03 & .01 & 0.14 \\
\hline Grad Degree Wanted & -0.21 & 0.23 & -.07 & -0.93 & -0.23 & 0.24 & -.08 & -0.97 \\
\hline Physical Health & -0.06 & 0.05 & -.09 & -1.22 & -0.06 & 0.05 & -.09 & -1.16 \\
\hline Mental Health & 0.09 & 0.04 & .18 & $* 2.31$ & 0.09 & 0.05 & .18 & $* 2.06$ \\
\hline (N) Volatility & & & & & 0.01 & 0.16 & .00 & 0.03 \\
\hline (N) Withdrawal & & & & & 0.06 & 0.19 & .04 & 0.33 \\
\hline (A) Compassion & & & & & -0.05 & 0.17 & -.03 & -0.27 \\
\hline (A) Politeness & & & & & -0.15 & 0.20 & -.08 & -0.74 \\
\hline (C) Industriousness & & & & & -0.17 & 0.21 & -.10 & -0.83 \\
\hline (C) Orderliness & & & & & 0.06 & 0.18 & .03 & 0.34 \\
\hline (E) Enthusiasm & & & & & 0.09 & 0.16 & .05 & 0.55 \\
\hline (E) Assertiveness & & & & & 0.02 & 0.19 & .01 & 0.09 \\
\hline (O) Intellect & & & & & 0.16 & 0.19 & .09 & 0.84 \\
\hline (O) Openness & & & & & -0.15 & 0.17 & -.07 & -0.85 \\
\hline$\Delta F$ & \multicolumn{4}{|c|}{1.86} & \multicolumn{4}{|c|}{0.41} \\
\hline$d f$ & \multicolumn{4}{|c|}{12,184} & \multicolumn{4}{|c|}{10,174} \\
\hline$p$ & \multicolumn{4}{|c|}{.04} & \multicolumn{4}{|c|}{.94} \\
\hline$R$ & \multicolumn{4}{|c|}{.33} & \multicolumn{4}{|c|}{.36} \\
\hline$\Delta R^{2}$ & \multicolumn{4}{|c|}{.11} & \multicolumn{4}{|c|}{.02} \\
\hline Adjusted $R^{2}$ & \multicolumn{4}{|c|}{.05} & \multicolumn{4}{|c|}{.02} \\
\hline
\end{tabular}

Note: $*$ indicates $p<.05 ; * *$ indicates $p<.01 .{ }^{1}$ Male $=0$, Female $=1 ;{ }^{2}$ Hispanic $=0$, White/Black $=1 ;{ }^{3}$ Unmarried $=0$, Married $=1 ;{ }^{4}$ No Children $=0$, Children $=1$. 


\section{Appendix F6}

Study II - Gifts and Discounts Regression

\begin{tabular}{|c|c|c|c|c|c|c|c|c|}
\hline & $B$ & $S E$ & $\beta$ & $t$ & $B$ & $S E$ & $\beta$ & $t$ \\
\hline Constant & 3.60 & 0.52 & & $* * 6.97$ & 2.96 & 0.96 & & $* * 3.09$ \\
\hline Age & -0.02 & 0.01 & -.17 & -1.69 & -0.02 & 0.01 & -.18 & -1.83 \\
\hline${ }^{1}$ Gender & 0.31 & 0.14 & .17 & $* 2.25$ & 0.37 & 0.15 & .20 & $* 2.56$ \\
\hline${ }^{2}$ White & -0.20 & 0.20 & -.07 & -1.00 & -0.27 & 0.20 & -.10 & -1.32 \\
\hline${ }^{2}$ Black & 0.06 & 0.16 & .03 & 0.37 & 0.07 & 0.16 & .03 & 0.45 \\
\hline${ }^{3}$ Married & -0.02 & 0.21 & -.01 & -0.08 & 0.04 & 0.21 & .02 & 0.19 \\
\hline${ }^{4}$ Children & 0.13 & 0.20 & .06 & 0.66 & 0.21 & 0.20 & .10 & 1.04 \\
\hline Work Hours & 0.00 & 0.01 & -.03 & -0.40 & 0.00 & 0.01 & -.02 & -0.28 \\
\hline Jobs Held & 0.07 & 0.03 & .21 & $* 2.41$ & 0.07 & 0.03 & .23 & $* * 2.62$ \\
\hline Income & 0.01 & 0.02 & .02 & 0.33 & 0.01 & 0.02 & .03 & 0.34 \\
\hline Grad Degree Wanted & -0.09 & 0.16 & -.05 & -0.58 & -0.13 & 0.16 & -.06 & -0.81 \\
\hline Physical Health & -0.02 & 0.04 & -.04 & -0.50 & -0.02 & 0.04 & -.04 & -0.47 \\
\hline Mental Health & 0.04 & 0.03 & .11 & 1.44 & 0.02 & 0.03 & .06 & 0.72 \\
\hline (N) Volatility & & & & & 0.01 & 0.11 & .01 & 0.05 \\
\hline (N) Withdrawal & & & & & 0.11 & 0.13 & .10 & 0.87 \\
\hline (A) Compassion & & & & & -0.03 & 0.12 & -.03 & -0.28 \\
\hline (A) Politeness & & & & & -0.14 & 0.14 & -.10 & -1.01 \\
\hline (C) Industriousness & & & & & 0.15 & 0.14 & .13 & 1.03 \\
\hline (C) Orderliness & & & & & 0.28 & 0.12 & .22 & $* 2.39$ \\
\hline (E) Enthusiasm & & & & & 0.06 & 0.11 & .05 & 0.58 \\
\hline (E) Assertiveness & & & & & 0.03 & 0.13 & .03 & 0.22 \\
\hline (O) Intellect & & & & & -0.05 & 0.13 & -.04 & -0.38 \\
\hline (O) Openness & & & & & -0.20 & 0.12 & -.15 & -1.75 \\
\hline$\Delta F$ & \multicolumn{4}{|c|}{1.08} & \multicolumn{4}{|c|}{1.77} \\
\hline$d f$ & \multicolumn{4}{|c|}{12,184} & \multicolumn{4}{|c|}{10,174} \\
\hline$p$ & \multicolumn{4}{|c|}{.38} & \multicolumn{4}{|c|}{.07} \\
\hline$R$ & \multicolumn{4}{|c|}{.26} & \multicolumn{4}{|c|}{.39} \\
\hline$\Delta R^{2}$ & \multicolumn{4}{|c|}{.07} & \multicolumn{4}{|c|}{.09} \\
\hline Adjusted $R^{2}$ & \multicolumn{4}{|c|}{.01} & \multicolumn{4}{|c|}{.05} \\
\hline
\end{tabular}




\section{Appendix F7}

Study II - Personal Services Regression

\begin{tabular}{|c|c|c|c|c|c|c|c|c|}
\hline & $B$ & $S E$ & $\beta$ & $t$ & $B$ & $S E$ & $\beta$ & $t$ \\
\hline Constant & 3.24 & 0.58 & & $* * 5.55$ & 2.83 & 1.09 & & $* 2.59$ \\
\hline Age & -0.02 & 0.01 & -.13 & -1.35 & -0.02 & 0.01 & -.15 & -1.55 \\
\hline${ }^{1}$ Gender & 0.03 & 0.16 & .01 & 0.18 & 0.07 & 0.17 & .03 & 0.41 \\
\hline${ }^{2}$ White & -0.82 & 0.23 & -.25 & $* *-3.59$ & -0.84 & 0.23 & -.26 & $* *-3.67$ \\
\hline${ }^{2}$ Black & 0.19 & 0.18 & .07 & 1.04 & 0.20 & 0.18 & .08 & 1.11 \\
\hline${ }^{3}$ Married & -0.04 & 0.24 & -.01 & -0.18 & 0.02 & 0.24 & .01 & 0.10 \\
\hline${ }^{4}$ Children & 0.54 & 0.23 & .21 & $* 2.41$ & 0.59 & 0.23 & .23 & $* 2.58$ \\
\hline Work Hours & 0.00 & 0.01 & .06 & 0.81 & 0.01 & 0.01 & .07 & 0.97 \\
\hline Jobs Held & 0.09 & 0.03 & .24 & $* * 2.99$ & 0.09 & 0.03 & .23 & $* * 2.75$ \\
\hline Income & 0.02 & 0.02 & .06 & 0.80 & 0.00 & 0.02 & .02 & 0.22 \\
\hline Grad Degree Wanted & -0.15 & 0.18 & -.06 & -0.84 & -0.16 & 0.19 & -.07 & -0.87 \\
\hline Physical Health & -0.03 & 0.04 & -.05 & -0.70 & -0.02 & 0.04 & -.03 & -0.47 \\
\hline Mental Health & 0.03 & 0.03 & .08 & 1.01 & 0.01 & 0.04 & .01 & 0.13 \\
\hline (N) Volatility & & & & & 0.13 & 0.12 & .11 & 1.07 \\
\hline (N) Withdrawal & & & & & -0.05 & 0.15 & -.04 & -0.33 \\
\hline (A) Compassion & & & & & -0.09 & 0.13 & -.06 & -0.67 \\
\hline (A) Politeness & & & & & -0.17 & 0.16 & -.10 & -1.07 \\
\hline (C) Industriousness & & & & & 0.06 & 0.16 & .04 & 0.37 \\
\hline (C) Orderliness & & & & & 0.19 & 0.14 & .12 & 1.43 \\
\hline (E) Enthusiasm & & & & & 0.11 & 0.12 & .08 & 0.89 \\
\hline (E) Assertiveness & & & & & 0.15 & 0.14 & .11 & 1.04 \\
\hline (O) Intellect & & & & & -0.04 & 0.15 & -.03 & -0.29 \\
\hline (O) Openness & & & & & -0.07 & 0.13 & -.04 & -0.54 \\
\hline$\Delta F$ & \multicolumn{4}{|c|}{3.44} & \multicolumn{4}{|c|}{1.38} \\
\hline$d f$ & \multicolumn{4}{|c|}{12,184} & \multicolumn{4}{|c|}{10,174} \\
\hline$p$ & \multicolumn{4}{|c|}{$<.001$} & \multicolumn{4}{|c|}{.20} \\
\hline$R$ & \multicolumn{4}{|c|}{.43} & \multicolumn{4}{|c|}{.49} \\
\hline$\Delta R^{2}$ & \multicolumn{4}{|c|}{.18} & \multicolumn{4}{|c|}{.06} \\
\hline Adjusted $R^{2}$ & \multicolumn{4}{|c|}{.13} & \multicolumn{4}{|c|}{.15} \\
\hline
\end{tabular}

Note: $*$ indicates $p<.05 ; * *$ indicates $p<.01 .{ }^{1}$ Male $=0$, Female $=1 ;{ }^{2}$ Hispanic $=0$, White/Black $=1 ;{ }^{3}$ Unmarried $=0$, Married $=1 ;{ }^{4}$ No Children $=0$, Children $=1$. 


\section{Appendix F8}

Study II - Daily Life Conveniences Regression

\begin{tabular}{|c|c|c|c|c|c|c|c|c|}
\hline & $B$ & $S E$ & $\beta$ & $t$ & $B$ & $S E$ & $\beta$ & $t$ \\
\hline Constant & 2.79 & 0.72 & & $* * 3.88$ & 3.56 & 1.37 & & $* 2.60$ \\
\hline Age & -0.05 & 0.02 & -.25 & $* *-2.64$ & -0.04 & 0.02 & -.24 & $*-2.44$ \\
\hline${ }^{1}$ Gender & 0.42 & 0.19 & .16 & $* 2.16$ & 0.52 & 0.21 & .20 & $* 2.50$ \\
\hline${ }^{2}$ White & -0.18 & 0.28 & -.05 & -0.64 & -0.28 & 0.29 & -.07 & -0.96 \\
\hline${ }^{2}$ Black & -0.17 & 0.22 & -.05 & -0.75 & -0.14 & 0.23 & -.05 & -0.63 \\
\hline${ }^{3}$ Married & 0.02 & 0.30 & .01 & 0.06 & 0.04 & 0.31 & .01 & 0.14 \\
\hline${ }^{4}$ Children & 0.41 & 0.28 & .13 & 1.46 & 0.42 & 0.29 & .14 & 1.48 \\
\hline Work Hours & 0.01 & 0.01 & .08 & 1.11 & 0.01 & 0.01 & .08 & 1.03 \\
\hline Jobs Held & 0.13 & 0.04 & .29 & $* * 3.42$ & 0.12 & 0.04 & .26 & $* * 2.99$ \\
\hline Income & 0.01 & 0.02 & .03 & 0.35 & 0.01 & 0.03 & .03 & 0.33 \\
\hline Grad Degree Wanted & -0.23 & 0.22 & -.08 & -1.06 & -0.27 & 0.23 & -.09 & -1.15 \\
\hline Physical Health & -0.08 & 0.05 & -.12 & -1.55 & -0.07 & 0.05 & -.10 & -1.35 \\
\hline Mental Health & 0.10 & 0.04 & .19 & $* 2.50$ & 0.09 & 0.04 & .18 & $* 2.11$ \\
\hline (N) Volatility & & & & & 0.10 & 0.15 & .08 & 0.68 \\
\hline (N) Withdrawal & & & & & -0.14 & 0.18 & -.09 & -0.75 \\
\hline (A) Compassion & & & & & -0.04 & 0.17 & -.02 & -0.25 \\
\hline (A) Politeness & & & & & -0.10 & 0.20 & -.05 & -0.53 \\
\hline (C) Industriousness & & & & & -0.19 & 0.20 & -.12 & -0.95 \\
\hline (C) Orderliness & & & & & 0.16 & 0.17 & .08 & 0.92 \\
\hline (E) Enthusiasm & & & & & -0.11 & 0.15 & -.07 & -0.71 \\
\hline (E) Assertiveness & & & & & 0.02 & 0.18 & .01 & 0.13 \\
\hline (O) Intellect & & & & & 0.20 & 0.18 & .11 & 1.08 \\
\hline (O) Openness & & & & & -0.16 & 0.17 & -.08 & -0.95 \\
\hline$\Delta F$ & \multicolumn{4}{|c|}{2.12} & \multicolumn{4}{|c|}{0.75} \\
\hline$d f$ & \multicolumn{4}{|c|}{12,184} & \multicolumn{4}{|c|}{10,174} \\
\hline$p$ & \multicolumn{4}{|c|}{.02} & \multicolumn{4}{|c|}{.68} \\
\hline$R$ & \multicolumn{4}{|c|}{.35} & \multicolumn{4}{|c|}{.40} \\
\hline$\Delta R^{2}$ & \multicolumn{4}{|c|}{.12} & \multicolumn{4}{|c|}{.04} \\
\hline Adjusted $R^{2}$ & \multicolumn{4}{|c|}{.06} & \multicolumn{4}{|c|}{.05} \\
\hline
\end{tabular}

Note: $*$ indicates $p<.05 ; * *$ indicates $p<.01 .{ }^{1}$ Male $=0$, Female $=1 ;{ }^{2}$ Hispanic $=0$, White/Black $=1 ;{ }^{3}$ Unmarried $=0$, Married $=1 ;{ }^{4}$ No Children $=0$, Children $=1$. 


\section{Appendix F9}

Study II - Health and Well-being Regression

\begin{tabular}{|c|c|c|c|c|c|c|c|c|}
\hline & $B$ & $S E$ & $\beta$ & $t$ & $B$ & $S E$ & $\beta$ & $t$ \\
\hline Constant & 3.72 & 0.49 & & $* * 7.55$ & 2.71 & 0.94 & & $* * 2.89$ \\
\hline Age & -0.02 & 0.01 & -.14 & -1.44 & -0.02 & 0.01 & -.16 & -1.57 \\
\hline${ }^{1}$ Gender & 0.18 & 0.13 & .10 & 1.32 & 0.19 & 0.14 & .11 & 1.32 \\
\hline${ }^{2}$ White & -0.09 & 0.19 & -.04 & -0.47 & -0.11 & 0.20 & -.04 & -0.57 \\
\hline${ }^{2}$ Black & -0.02 & 0.15 & -.01 & -0.11 & -0.02 & 0.16 & -.01 & -0.13 \\
\hline${ }^{3}$ Married & 0.20 & 0.21 & .08 & 0.97 & 0.21 & 0.21 & .09 & 1.02 \\
\hline${ }^{4}$ Children & 0.35 & 0.19 & .17 & 1.81 & 0.41 & 0.20 & .20 & $* 2.11$ \\
\hline Work Hours & 0.00 & 0.00 & .06 & 0.74 & 0.00 & 0.00 & .07 & 0.90 \\
\hline Jobs Held & 0.05 & 0.03 & .16 & 1.91 & 0.05 & 0.03 & .17 & 1.95 \\
\hline Income & 0.01 & 0.02 & .04 & 0.48 & 0.00 & 0.02 & .02 & 0.25 \\
\hline Grad Degree Wanted & -0.03 & 0.15 & -.02 & -0.20 & -0.09 & 0.16 & -.05 & -0.58 \\
\hline Physical Health & -0.03 & 0.04 & -.06 & -0.84 & -0.03 & 0.04 & -.07 & -0.95 \\
\hline Mental Health & 0.02 & 0.03 & .05 & 0.66 & 0.02 & 0.03 & .04 & 0.49 \\
\hline (N) Volatility & & & & & -0.02 & 0.10 & -.02 & -0.14 \\
\hline (N) Withdrawal & & & & & 0.14 & 0.13 & .14 & 1.14 \\
\hline (A) Compassion & & & & & 0.07 & 0.11 & .06 & 0.58 \\
\hline (A) Politeness & & & & & -0.13 & 0.13 & -.10 & -1.00 \\
\hline (C) Industriousness & & & & & 0.11 & 0.14 & .10 & 0.77 \\
\hline (C) Orderliness & & & & & 0.17 & 0.12 & .14 & 1.51 \\
\hline (E) Enthusiasm & & & & & 0.00 & 0.10 & .00 & -0.04 \\
\hline (E) Assertiveness & & & & & 0.06 & 0.12 & .06 & 0.49 \\
\hline (O) Intellect & & & & & -0.02 & 0.12 & -.02 & -0.16 \\
\hline (O) Openness & & & & & -0.04 & 0.11 & -.03 & -0.32 \\
\hline$\Delta F$ & \multicolumn{4}{|c|}{1.28} & \multicolumn{4}{|c|}{0.83} \\
\hline$d f$ & \multicolumn{4}{|c|}{12,184} & \multicolumn{4}{|c|}{10,174} \\
\hline$p$ & \multicolumn{4}{|c|}{.23} & \multicolumn{4}{|c|}{.60} \\
\hline$R$ & \multicolumn{4}{|c|}{.28} & \multicolumn{4}{|c|}{.35} \\
\hline$\Delta R^{2}$ & \multicolumn{4}{|c|}{.08} & \multicolumn{4}{|c|}{.04} \\
\hline Adjusted $R^{2}$ & \multicolumn{4}{|c|}{.02} & \multicolumn{4}{|c|}{.01} \\
\hline
\end{tabular}




\section{Appendix F10}

Study II - Family Life Facilitation Regression

\begin{tabular}{|c|c|c|c|c|c|c|c|c|}
\hline & $B$ & $S E$ & $\beta$ & $t$ & $B$ & $S E$ & $\beta$ & $t$ \\
\hline Constant & 3.04 & 0.65 & & $* * 4.69$ & 2.72 & 1.23 & & $* 2.21$ \\
\hline Age & -0.02 & 0.02 & -.09 & -0.97 & -0.02 & 0.02 & -.10 & -1.00 \\
\hline${ }^{1}$ Gender & 0.27 & 0.18 & .11 & 1.53 & 0.37 & 0.19 & .15 & 1.95 \\
\hline${ }^{2}$ White & -0.24 & 0.25 & -.07 & -0.97 & -0.26 & 0.26 & -.07 & -1.01 \\
\hline${ }^{2}$ Black & 0.07 & 0.20 & .03 & 0.36 & 0.07 & 0.21 & .03 & 0.34 \\
\hline${ }^{3}$ Married & 0.21 & 0.27 & .06 & 0.77 & 0.24 & 0.27 & .07 & 0.87 \\
\hline${ }^{4}$ Children & 0.44 & 0.25 & .16 & 1.73 & 0.48 & 0.26 & .18 & 1.88 \\
\hline Work Hours & 0.00 & 0.01 & .03 & 0.41 & 0.00 & 0.01 & .03 & 0.33 \\
\hline Jobs Held & 0.07 & 0.04 & .16 & 1.92 & 0.07 & 0.04 & .18 & $* 2.01$ \\
\hline Income & 0.01 & 0.02 & .03 & 0.38 & 0.00 & 0.02 & .02 & 0.19 \\
\hline Grad Degree Wanted & 0.01 & 0.20 & .01 & 0.07 & -0.03 & 0.21 & -.01 & -0.14 \\
\hline Physical Health & -0.11 & 0.05 & -.18 & $*-2.38$ & -0.11 & 0.05 & -.18 & $*-2.36$ \\
\hline Mental Health & 0.03 & 0.04 & .07 & 0.94 & 0.04 & 0.04 & .09 & 1.01 \\
\hline (N) Volatility & & & & & -0.10 & 0.14 & -.08 & -0.72 \\
\hline (N) Withdrawal & & & & & 0.25 & 0.16 & .18 & 1.50 \\
\hline (A) Compassion & & & & & -0.11 & 0.15 & -.08 & -0.76 \\
\hline (A) Politeness & & & & & -0.19 & 0.18 & -.11 & -1.05 \\
\hline (C) Industriousness & & & & & 0.11 & 0.18 & .07 & 0.61 \\
\hline (C) Orderliness & & & & & 0.11 & 0.15 & .06 & 0.69 \\
\hline (E) Enthusiasm & & & & & -0.06 & 0.14 & -.04 & -0.43 \\
\hline (E) Assertiveness & & & & & 0.20 & 0.16 & .14 & 1.23 \\
\hline (O) Intellect & & & & & -0.05 & 0.16 & -.03 & -0.30 \\
\hline (O) Openness & & & & & -0.05 & 0.15 & -.03 & -0.35 \\
\hline$\Delta F$ & \multicolumn{4}{|c|}{1.80} & \multicolumn{4}{|c|}{0.93} \\
\hline$d f$ & \multicolumn{4}{|c|}{12,184} & \multicolumn{4}{|c|}{10,174} \\
\hline$p$ & \multirow{2}{*}{\multicolumn{4}{|c|}{.05}} & \multirow{2}{*}{\multicolumn{4}{|c|}{$\begin{array}{l}.51 \\
.39\end{array}$}} \\
\hline$R$ & & & & & & & & \\
\hline$\Delta R^{2}$ & \multicolumn{4}{|c|}{11} & \multicolumn{4}{|c|}{.05} \\
\hline Adjusted $R^{2}$ & \multicolumn{4}{|c|}{.05} & \multicolumn{4}{|c|}{.04} \\
\hline
\end{tabular}




\section{Appendix F11}

Study II - Professional Growth Regression

\begin{tabular}{|c|c|c|c|c|c|c|c|c|}
\hline & $B$ & $S E$ & $\beta$ & $t$ & $B$ & $S E$ & $\beta$ & $t$ \\
\hline Constant & 3.79 & 0.43 & & $* * 8.81$ & 2.59 & 0.79 & & $* * 3.29$ \\
\hline Age & 0.01 & 0.01 & .05 & 0.49 & 0.00 & 0.01 & .00 & 0.01 \\
\hline${ }^{1}$ Gender & 0.17 & 0.12 & .11 & 1.45 & 0.18 & 0.12 & .11 & 1.50 \\
\hline${ }^{2}$ White & -0.48 & 0.17 & -.21 & $* *-2.83$ & -0.50 & 0.17 & -.22 & $* *-3.05$ \\
\hline${ }^{2}$ Black & 0.00 & 0.13 & .00 & 0.00 & -0.02 & 0.13 & -.01 & -0.12 \\
\hline${ }^{3}$ Married & -0.05 & 0.18 & -.02 & -0.26 & -0.06 & 0.18 & -.03 & -0.32 \\
\hline${ }^{4}$ Children & 0.17 & 0.17 & .09 & 0.99 & 0.25 & 0.16 & .14 & 1.50 \\
\hline Work Hours & 0.00 & 0.00 & .06 & 0.76 & 0.00 & 0.00 & .06 & 0.77 \\
\hline Jobs Held & 0.03 & 0.02 & .10 & 1.23 & 0.03 & 0.02 & .13 & 1.48 \\
\hline Income & 0.01 & 0.01 & .04 & 0.60 & 0.01 & 0.01 & .02 & 0.32 \\
\hline Grad Degree Wanted & -0.07 & 0.13 & -.04 & -0.50 & -0.09 & 0.13 & -.05 & -0.67 \\
\hline Physical Health & -0.06 & 0.03 & -.14 & -1.82 & -0.06 & 0.03 & -.14 & -1.86 \\
\hline Mental Health & 0.03 & 0.02 & .08 & 1.06 & 0.01 & 0.03 & .05 & 0.55 \\
\hline (N) Volatility & & & & & -0.07 & 0.09 & -.09 & -0.80 \\
\hline (N) Withdrawal & & & & & 0.14 & 0.11 & .15 & 1.32 \\
\hline (A) Compassion & & & & & 0.09 & 0.10 & .09 & 0.98 \\
\hline (A) Politeness & & & & & 0.11 & 0.11 & .10 & 0.99 \\
\hline (C) Industriousness & & & & & -0.02 & 0.12 & -.02 & -0.14 \\
\hline (C) Orderliness & & & & & 0.08 & 0.10 & .07 & 0.84 \\
\hline (E) Enthusiasm & & & & & -0.06 & 0.09 & -.06 & -0.70 \\
\hline (E) Assertiveness & & & & & 0.20 & 0.10 & .22 & 1.97 \\
\hline (O) Intellect & & & & & 0.13 & 0.10 & .12 & 1.25 \\
\hline (O) Openness & & & & & -0.23 & 0.10 & -.20 & $*-2.42$ \\
\hline$\Delta F$ & \multicolumn{4}{|c|}{1.77} & \multicolumn{4}{|c|}{2.29} \\
\hline$d f$ & \multicolumn{4}{|c|}{12,184} & \multicolumn{4}{|c|}{10,174} \\
\hline$p$ & \multicolumn{4}{|c|}{.06} & \multicolumn{4}{|c|}{.02} \\
\hline$R$ & \multicolumn{4}{|c|}{.32} & \multicolumn{4}{|c|}{.46} \\
\hline$\Delta R^{2}$ & \multicolumn{4}{|c|}{.10} & \multicolumn{4}{|c|}{.10} \\
\hline Adjusted $R^{2}$ & \multicolumn{4}{|c|}{.05} & \multicolumn{4}{|c|}{.11} \\
\hline
\end{tabular}

Note: $*$ indicates $p<.05 ; * *$ indicates $p<.01 .{ }^{1}$ Male $=0$, Female $=1 ;{ }^{2}$ Hispanic $=0$, White/Black $=1 ;{ }^{3}$ Unmarried $=0$, Married $=1 ;{ }^{4}$ No Children $=0$, Children $=1$. 


\section{Appendix F12}

Study II - Organizational Culture Regression

\begin{tabular}{|c|c|c|c|c|c|c|c|c|}
\hline & $B$ & $S E$ & $\beta$ & $t$ & $B$ & $S E$ & $\beta$ & $t$ \\
\hline Constant & 3.65 & 0.48 & & $* * 7.67$ & 2.22 & 0.84 & & $* * 2.64$ \\
\hline Age & -0.02 & 0.01 & -.19 & $*-2.02$ & -0.03 & 0.01 & -.27 & $* *-2.93$ \\
\hline${ }^{1}$ Gender & 0.33 & 0.13 & .19 & $* 2.59$ & 0.32 & 0.13 & .18 & $* 2.47$ \\
\hline${ }^{2}$ White & -0.49 & 0.19 & -.19 & $* *-2.65$ & -0.49 & 0.18 & -.19 & $* *-2.79$ \\
\hline${ }^{2}$ Black & 0.05 & 0.15 & .02 & 0.31 & -0.01 & 0.14 & -.01 & -0.10 \\
\hline${ }^{3}$ Married & 0.07 & 0.20 & .03 & 0.35 & 0.07 & 0.19 & .03 & 0.39 \\
\hline${ }^{4}$ Children & 0.20 & 0.18 & .10 & 1.09 & 0.33 & 0.18 & .17 & 1.90 \\
\hline Work Hours & 0.00 & 0.00 & -.04 & -0.47 & 0.00 & 0.00 & -.01 & -0.20 \\
\hline Jobs Held & 0.03 & 0.03 & .11 & 1.34 & 0.04 & 0.02 & .14 & 1.75 \\
\hline Income & 0.02 & 0.02 & .09 & 1.26 & 0.01 & 0.02 & .03 & 0.40 \\
\hline Grad Degree Wanted & -0.17 & 0.15 & -.09 & -1.17 & -0.19 & 0.14 & -.09 & -1.29 \\
\hline Physical Health & -0.07 & 0.03 & -.15 & $*-2.00$ & -0.07 & 0.03 & -.15 & $*_{-} 2.08$ \\
\hline Mental Health & 0.07 & 0.03 & .19 & $* 2.52$ & 0.03 & 0.03 & .09 & 1.15 \\
\hline (N) Volatility & & & & & -0.11 & 0.09 & -.12 & -1.17 \\
\hline (N) Withdrawal & & & & & 0.12 & 0.11 & .12 & 1.08 \\
\hline (A) Compassion & & & & & -0.08 & 0.10 & -.07 & -0.80 \\
\hline (A) Politeness & & & & & 0.06 & 0.12 & .05 & 0.53 \\
\hline (C) Industriousness & & & & & -0.01 & 0.12 & -.01 & -0.07 \\
\hline (C) Orderliness & & & & & 0.22 & 0.10 & .18 & $* 2.12$ \\
\hline (E) Enthusiasm & & & & & 0.15 & 0.09 & .14 & 1.64 \\
\hline (E) Assertiveness & & & & & 0.26 & 0.11 & .25 & $* 2.40$ \\
\hline (O) Intellect & & & & & 0.02 & 0.11 & .01 & 0.15 \\
\hline (O) Openness & & & & & -0.10 & 0.10 & -.08 & -1.00 \\
\hline$\Delta F$ & \multicolumn{4}{|c|}{1.98} & \multicolumn{4}{|c|}{3.57} \\
\hline$d f$ & \multicolumn{4}{|c|}{12,184} & \multicolumn{4}{|c|}{10,174} \\
\hline$p$ & \multicolumn{4}{|c|}{.03} & \multicolumn{4}{|c|}{$<.001$} \\
\hline$R$ & \multicolumn{4}{|c|}{.34} & \multicolumn{4}{|c|}{.52} \\
\hline$\Delta R^{2}$ & \multicolumn{4}{|c|}{.11} & \multicolumn{4}{|c|}{.15} \\
\hline Adjusted $R^{2}$ & \multicolumn{4}{|c|}{.06} & \multicolumn{4}{|c|}{.17} \\
\hline
\end{tabular}

Note: $*$ indicates $p<.05 ; * *$ indicates $p<.01 .{ }^{1}$ Male $=0$, Female $=1 ;{ }^{2}$ Hispanic $=0$, White/Black $=1 ;{ }^{3}$ Unmarried $=0$, Married $=1 ;{ }^{4}$ No Children $=0$, Children $=1$. 


\section{Appendix F13}

Study II - Physical Work Conditions Regression

\begin{tabular}{|c|c|c|c|c|c|c|c|c|}
\hline & $B$ & $S E$ & $\beta$ & $t$ & $B$ & $S E$ & $\beta$ & $t$ \\
\hline Constant & 3.42 & 0.48 & & $* * 7.16$ & 3.21 & 0.92 & & $* * 3.49$ \\
\hline Age & -0.04 & 0.01 & -.37 & $* *-3.82$ & -0.05 & 0.01 & -.38 & $* *-3.82$ \\
\hline${ }^{1}$ Gender & 0.19 & 0.13 & .11 & 1.46 & 0.21 & 0.14 & .12 & 1.50 \\
\hline${ }^{2}$ White & -0.23 & 0.19 & -.09 & -1.24 & -0.22 & 0.19 & -.08 & -1.12 \\
\hline${ }^{2}$ Black & -0.05 & 0.15 & -.02 & -0.31 & -0.05 & 0.16 & -.03 & -0.34 \\
\hline${ }^{3}$ Married & 0.02 & 0.20 & .01 & 0.12 & 0.02 & 0.21 & .01 & 0.10 \\
\hline${ }^{4}$ Children & 0.29 & 0.19 & .14 & 1.56 & 0.31 & 0.19 & .15 & 1.59 \\
\hline Work Hours & 0.01 & 0.00 & .14 & 1.83 & 0.01 & 0.00 & .13 & 1.74 \\
\hline Jobs Held & 0.07 & 0.03 & .21 & $* 2.54$ & 0.06 & 0.03 & 21 & $* 2.35$ \\
\hline Income & 0.03 & 0.02 & .16 & $* 2.14$ & 0.03 & 0.02 & .14 & 1.78 \\
\hline Grad Degree Wanted & -0.21 & 0.15 & -.11 & -1.45 & -0.20 & 0.16 & -.10 & -1.26 \\
\hline Physical Health & -0.01 & 0.03 & -.03 & -0.40 & -0.01 & 0.04 & -.02 & -0.20 \\
\hline Mental Health & 0.03 & 0.03 & .10 & 1.31 & 0.03 & 0.03 & .09 & 1.01 \\
\hline (N) Volatility & & & & & 0.05 & 0.10 & .05 & 0.45 \\
\hline (N) Withdrawal & & & & & -0.01 & 0.12 & -.01 & -0.09 \\
\hline (A) Compassion & & & & & -0.15 & 0.11 & -.13 & -1.34 \\
\hline (A) Politeness & & & & & 0.02 & 0.13 & .02 & 0.16 \\
\hline (C) Industriousness & & & & & 0.02 & 0.14 & .02 & 0.18 \\
\hline (C) Orderliness & & & & & 0.02 & 0.11 & .01 & 0.14 \\
\hline (E) Enthusiasm & & & & & -0.01 & 0.10 & -.01 & -0.07 \\
\hline (E) Assertiveness & & & & & 0.11 & 0.12 & .10 & 0.90 \\
\hline (O) Intellect & & & & & -0.02 & 0.12 & -.02 & -0.19 \\
\hline (O) Openness & & & & & 0.07 & 0.11 & .05 & 0.58 \\
\hline$\Delta F$ & \multicolumn{4}{|c|}{2.20} & \multicolumn{4}{|c|}{0.43} \\
\hline$d f$ & \multicolumn{4}{|c|}{12,184} & \multicolumn{4}{|c|}{10,174} \\
\hline$p$ & \multicolumn{4}{|c|}{.01} & \multicolumn{4}{|c|}{.93} \\
\hline$R$ & \multicolumn{4}{|c|}{.35} & \multicolumn{4}{|c|}{.38} \\
\hline$\Delta R^{2}$ & \multicolumn{4}{|c|}{.13} & \multicolumn{4}{|c|}{.02} \\
\hline Adjusted $R^{2}$ & \multicolumn{4}{|c|}{.07} & \multicolumn{4}{|c|}{.04} \\
\hline
\end{tabular}

Note: $*$ indicates $p<.05 ; * *$ indicates $p<.01 .{ }^{1}$ Male $=0$, Female $=1 ;{ }^{2}$ Hispanic $=0$, White/Black $=1 ;{ }^{3}$ Unmarried $=0$, Married $=1 ;{ }^{4}$ No Children $=0$, Children $=1$. 


\section{Appendix F14}

Study II - Status and Recognition Regression

\begin{tabular}{|c|c|c|c|c|c|c|c|c|}
\hline & $B$ & $S E$ & $\beta$ & $t$ & $B$ & $S E$ & $\beta$ & $t$ \\
\hline Constant & 2.95 & 0.57 & & $* * 5.16$ & 2.27 & 1.05 & & $* 2.16$ \\
\hline Age & -0.03 & 0.01 & -.22 & $*-2.33$ & -0.04 & 0.01 & -.26 & $* *-2.75$ \\
\hline${ }^{1}$ Gender & 0.26 & 0.15 & .12 & 1.67 & 0.32 & 0.16 & .15 & $* 2.00$ \\
\hline${ }^{2}$ White & -0.41 & 0.22 & -.13 & -1.85 & -0.42 & 0.22 & -.13 & -1.91 \\
\hline${ }^{2}$ Black & -0.09 & 0.18 & -.04 & -0.49 & -0.09 & 0.18 & -.04 & -0.53 \\
\hline${ }^{3}$ Married & -0.18 & 0.24 & -.06 & -0.77 & -0.13 & 0.23 & -.04 & -0.54 \\
\hline${ }^{4}$ Children & 0.39 & 0.22 & .16 & 1.77 & 0.46 & 0.22 & .19 & $* 2.08$ \\
\hline Work Hours & 0.00 & 0.01 & .04 & 0.57 & 0.00 & 0.01 & .05 & 0.64 \\
\hline Jobs Held & 0.04 & 0.03 & .10 & 1.22 & 0.04 & 0.03 & .12 & 1.45 \\
\hline Income & 0.05 & 0.02 & .20 & $* * 2.82$ & 0.04 & 0.02 & .17 & $* 2.27$ \\
\hline Grad Degree Wanted & 0.08 & 0.18 & .03 & 0.45 & 0.07 & 0.18 & .03 & 0.41 \\
\hline Physical Health & -0.07 & 0.04 & -.13 & -1.80 & -0.07 & 0.04 & -.12 & -1.68 \\
\hline Mental Health & 0.08 & 0.03 & .19 & $* 2.42$ & 0.05 & 0.03 & .13 & 1.59 \\
\hline (N) Volatility & & & & & 0.03 & 0.12 & .03 & 0.23 \\
\hline (N) Withdrawal & & & & & 0.08 & 0.14 & .07 & 0.58 \\
\hline (A) Compassion & & & & & -0.07 & 0.13 & -.05 & -0.52 \\
\hline (A) Politeness & & & & & -0.12 & 0.15 & -.08 & -0.79 \\
\hline (C) Industriousness & & & & & 0.18 & 0.16 & .14 & 1.15 \\
\hline (C) Orderliness & & & & & 0.21 & 0.13 & .14 & 1.63 \\
\hline (E) Enthusiasm & & & & & 0.00 & 0.12 & .00 & 0.03 \\
\hline (E) Assertiveness & & & & & 0.27 & 0.14 & .21 & $* 1.98$ \\
\hline (O) Intellect & & & & & -0.17 & 0.14 & -.12 & -1.19 \\
\hline (O) Openness & & & & & -0.14 & 0.13 & -.09 & -1.10 \\
\hline$\Delta F$ & \multicolumn{4}{|c|}{2.25} & \multicolumn{4}{|c|}{2.08} \\
\hline$d f$ & \multicolumn{4}{|c|}{12,184} & \multicolumn{4}{|c|}{10,174} \\
\hline$p$ & \multicolumn{4}{|c|}{.01} & \multicolumn{4}{|c|}{.03} \\
\hline$R$ & & \multicolumn{4}{|c|}{.47} \\
\hline$\Delta R^{2}$ & \multicolumn{4}{|c|}{.13} & \multicolumn{4}{|c|}{.09} \\
\hline Adjusted $R^{2}$ & \multicolumn{4}{|c|}{.07} & \multicolumn{4}{|c|}{.12} \\
\hline
\end{tabular}

Note: $*$ indicates $p<.05 ; * *$ indicates $p<.01 .{ }^{1}$ Male $=0$, Female $=1 ;{ }^{2}$ Hispanic $=0$, White/Black $=1 ;{ }^{3}$ Unmarried $=0$, Married $=1 ;{ }^{4}$ No Children $=0$, Children $=1$. 


\section{Appendix G1}

Studies III and IV - Correlations between Demographics and PPBIS

\begin{tabular}{|c|c|c|c|c|c|c|c|c|}
\hline & \multicolumn{2}{|c|}{ Age } & \multicolumn{2}{|c|}{ Work Hours } & \multicolumn{2}{|c|}{ Current Tenure } & \multicolumn{2}{|c|}{ Total Jobs Held } \\
\hline & S-III & S-IV & S-III & S-IV & S-III & S-IV & S-III & S-IV \\
\hline PPBIS & .03 & .08 & .04 & -.01 & .04 & .02 & -.05 & -.02 \\
\hline
\end{tabular}

Note: S-III = Study III; S-IV = Study IV 


\section{Appendix G2}

Studies III and IV - Demographic Differences in PPBIS

\begin{tabular}{|c|c|c|c|c|c|c|}
\hline & \multicolumn{3}{|c|}{$\underline{\text { S-III }}$} & \multicolumn{3}{|c|}{$\underline{\text { S-IV }}$} \\
\hline & $n$ & $\bar{M}$ & $S D$ & $n$ & $\bar{M}$ & $S D$ \\
\hline \multicolumn{7}{|l|}{ Gender } \\
\hline Male & 41 & 3.34 & 1.01 & 27 & 2.91 & 0.75 \\
\hline Female & 257 & 3.11 & 0.96 & 236 & 2.86 & 1.05 \\
\hline$t(d f)$ & \multicolumn{3}{|c|}{$1.33(296)$} & \multicolumn{3}{|c|}{$0.35(38.66)^{1}$} \\
\hline \multicolumn{7}{|l|}{ Generation } \\
\hline$\overline{\text { Gen. Z }}$ & 205 & 3.07 & 0.89 & 131 & 2.82 & 0.99 \\
\hline Millennials & 80 & 3.28 & 1.06 & 103 & 2.81 & 0.99 \\
\hline$t(d f)$ & \multicolumn{3}{|c|}{$1.54(124.80)^{1}$} & \multicolumn{3}{|c|}{$0.04(232)$} \\
\hline \multicolumn{7}{|l|}{ Married } \\
\hline Yes & 15 & 3.18 & 1.22 & 39 & 3.02 & 1.16 \\
\hline No & 285 & 3.14 & 0.95 & 227 & 2.84 & 0.99 \\
\hline$t(d f)$ & \multicolumn{3}{|c|}{$0.15(14.91)^{1}$} & \multicolumn{3}{|c|}{$1.03(264)$} \\
\hline \multicolumn{7}{|l|}{ Children } \\
\hline$\overline{\text { Yes }}$ & 25 & 3.13 & 1.03 & 50 & 2.87 & 1.16 \\
\hline No & 275 & 3.14 & 0.96 & 215 & 2.86 & 0.98 \\
\hline$t(d f)$ & \multicolumn{3}{|c|}{$0.03(298)$} & \multicolumn{3}{|c|}{$0.02(66.10)^{1}$} \\
\hline \multicolumn{7}{|l|}{ Grad Deg. Wanted } \\
\hline Yes & 255 & 3.11 & 0.95 & 216 & 2.88 & 1.00 \\
\hline No & 45 & 3.31 & 1.05 & 50 & 2.77 & 1.07 \\
\hline$t(d f)$ & \multicolumn{3}{|c|}{$1.28(298)$} & \multicolumn{3}{|c|}{$0.69(264)$} \\
\hline \multicolumn{7}{|l|}{ Ethnicity } \\
\hline Caucasian & 19 & 3.36 & 0.92 & 16 & 2.58 & 0.83 \\
\hline Hispanic & 219 & 3.15 & 0.97 & 199 & 2.89 & 1.01 \\
\hline African American & 46 & 3.13 & 0.98 & 34 & 2.92 & 1.16 \\
\hline$F(d f)$ & \multicolumn{3}{|c|}{$0.44(2,281)$} & \multicolumn{3}{|c|}{$0.73(2,246)$} \\
\hline \multicolumn{7}{|l|}{ Income } \\
\hline$\overline{0-49 k}$ & 168 & 3.19 & 0.95 & 128 & 2.86 & 1.04 \\
\hline $50-99 k$ & 57 & 3.21 & 0.92 & 44 & 2.74 & 0.98 \\
\hline $100-150 \mathrm{k}$ & 12 & 3.16 & 1.33 & 18 & 3.33 & 0.99 \\
\hline$>150 \mathrm{k}$ & 7 & 3.55 & 0.94 & 15 & 3.07 & 1.26 \\
\hline$F(d f)$ & \multicolumn{3}{|c|}{$0.33(3,240)$} & \multicolumn{3}{|c|}{$1.57(3,201)$} \\
\hline
\end{tabular}

Note: S-III = Study III; S-IV = Study IV.${ }^{1}$ Results of $t$-test when equal variances not assumed, reported when Levene's test for equality of variances is significant. 
VITA

\section{ANDREW J. LAGINESS}

Born, Ypsilanti, Michigan

2011

B.S., Psychology

Central Michigan University

Mt. Pleasant, Michigan

2011-2016.

Teaching Assistant

Florida International University

Miami, Florida

2017

M.S., Psychology

Florida International University

Miami, Florida

2016-2020

Adjunct Professor

Florida International University

Miami, Florida

$2017-2020$

Doctoral Candidate

Florida International University

Miami, Florida

\section{PUBLICATIONS AND PRESENTATIONS}

Speer, A. B., \& Laginess, A. J. (2012). Trait and performance-based social aptitude factors and relationships with personality. Poster presented at SIOP Annual Conference; San Diego, CA.

Harari, M. B., Laginess, A. J., \& Viswesvaran, C. (2014). Dynamic validities across maintenance and transition job stages: An empirical test of theoretically grounded predictions. Poster presented at SIOP Annual Conference; Honolulu, HI.

Harari, M. B., Rudolph, C. W., \& Laginess, A. J. (2014). Does rater personality matter? A meta-analysis of rater Big Five-performance rating relationships. Poster presented at SIOP Annual Conference; Honolulu, HI.

Harari, M. B., Rudolph, C. W., \& Laginess, A. J. (2015). Does rater personality matter? A meta-analysis of rater Big Five-performance rating relationships. Journal of Occupational and Organizational Psychology, 88, 387-414. doi: 10.1111/joop.12086

Broschard, D., \& Laginess, A. J. (2017). Identifying incoming FTICs at risk of dropout: A decision tree model for finding at-risk students before school begins. Paper presented at FAIR Conference; Howey-in-the-Hills, FL. 
Harari, M. B., Laginess, A. J., Beane, D. A., \& Viswesvaran, C. (2017). A meta-analysis of personality-expatriate adjustment relationships. Poster presented at SIOP Annual Conference; Orlando, FL.

Ozgen Novelli, S.,\& Laginess, A. J. (2017). Factor structure of Implicit Person Theory Scale: A 34-nation examination. Poster presented at SIOP Annual Conference; Orlando, FL.

Ozgen Novelli, S., Laginess, A. J., \& Viswesvaran, C. (2017). The Motivation to Lead Questionnaire: A meta-analytic examination of score reliability. Paper presented at Academy of Management Annual Meeting; Atlanta, GA.

Beane, D. A., Ponnapalli, A. R., Laginess, A. J., Herrera, J., \& Viswesvaran, C. (2017). From outside looking in: How applicants view workplace religious displays. Poster presented at SIOP Annual Conference; Orlando, FL.

Harari, M. B., Reaves, A. C., Beane, D. A., Laginess, A. J. \& Viswesvaran, C. (2018). Personality and expatriate adjustment: A meta-analysis. Journal of Occupational and Organizational Psychology. doi:10.1111/joop.12215

Speer, A. B., Christiansen, N. D. \& Laginess, A. J. (2019). Social intelligence and interview accuracy: Individual differences in the ability to construct interviews and rate accurately. International Journal of Selection and Assessment. doi:10.1111/ijsa.12237

Laginess, A. J., \& Nicholas, T. (2020). Predictors of retention and successful progress: Academic outcomes one year after taking the Freshman Survey. Paper presented at FAIR Conference; Orlando, FL. 